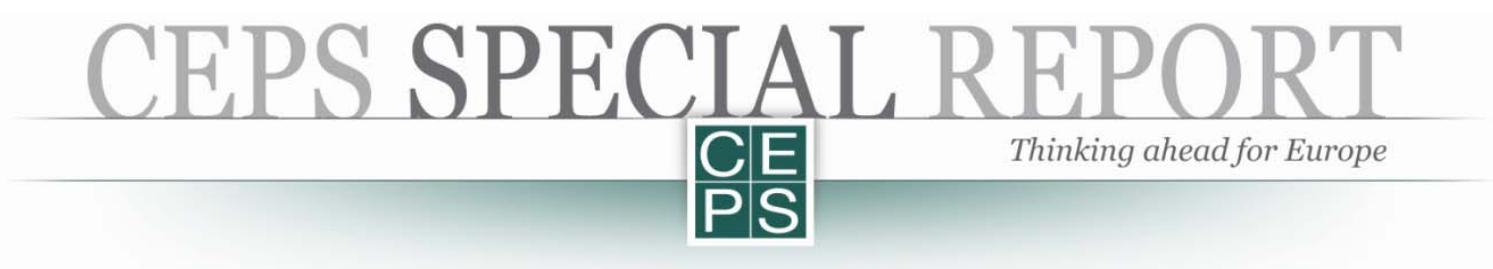

\title{
Workplace Innovation and Technological Change
}

\author{
Miroslav Beblavý \\ Ilaria Maselli \\ Elisa Martellucci
}

\author{
No. 65/September 2012
}

\begin{abstract}
This paper explores the extent to which the illusive phenomenon of workplace innovation has pervaded workplaces in Europe and whether it could be one of the answers to Europe's longterm social and economic challenges that stem from an ageing workforce and the need for more flexibility to stay competitive. Basic data drawn from European Working Conditions Survey conducted every five years by the Dublin-based European Foundation for the Improvement of Living and Working Conditions are supplemented by a series of case studies to look at the problems encountered in introducing workplace innovation and possible solutions. One set of case studies examines the following organisations: SGI/GI (Slovak Governance Institute (Slovakia), as representative of the world of small- and medium-sized enterprises; Oticon (Denmark) as representative of manufacturing companies; the Open University (UK), as representative of educational organizations; and FPS Social Security (Belgium) representing the public sector. Two final case studies focus on the country-level, one looking at of how a specific innovation can become fully mainstreamed (in the Netherlands and the 'part-time economy') and the other (Finland and TEKES) looking at how a government programme can help disseminate workplace innovation. These six case studies, together with the statistical analysis, constitute the main empirical value added of the report.
\end{abstract}

CEPS gratefully acknowledges financial support for this research from the Microsoft Corporation. The views expressed are those of the authors and do not necessarily represent CEPS, Microsoft or any other institution with which they are affiliated.

ISBN 978-94-6138-227-6

(C) Copyright 2012, Centre for European Policy Studies.

All rights reserved. No part of this publication may be reproduced, stored in a retrieval system or transmitted in any form or by any means - electronic, mechanical, photocopying, recording or otherwise - without the prior permission of CEPS. 


\section{Table of Contents}

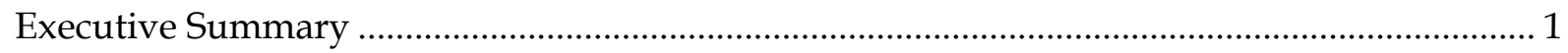

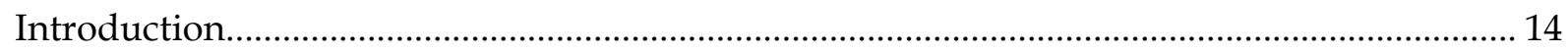

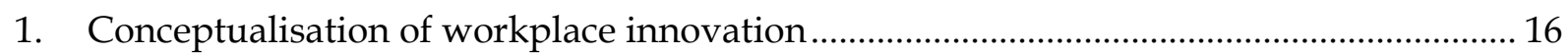

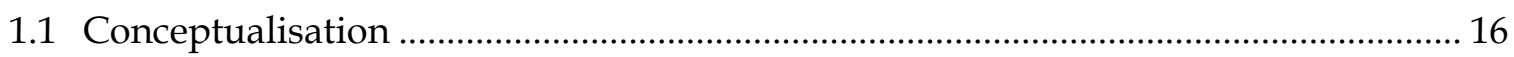

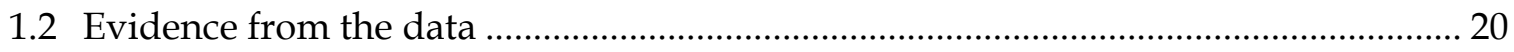

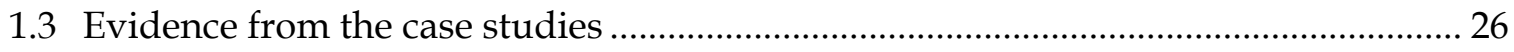

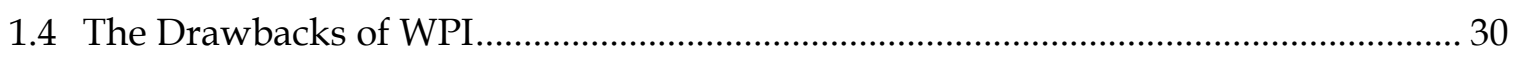

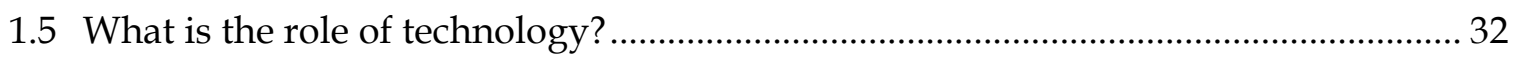

2. Recent trends in the intersection between technology and WPI.......................................... 35

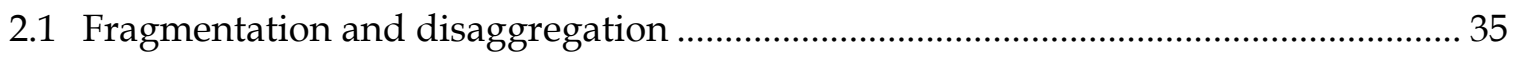

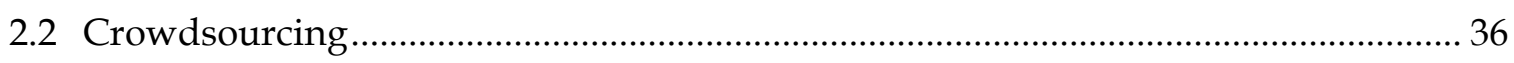

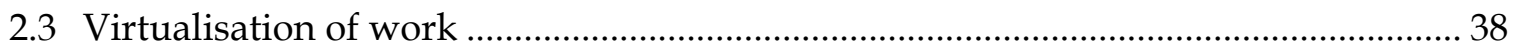

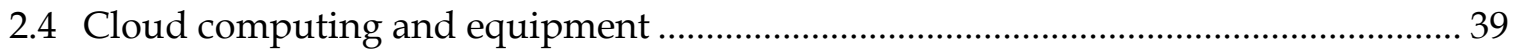

2.5 Is WPI a win-win solution and what is the role of technology? ................................. 41

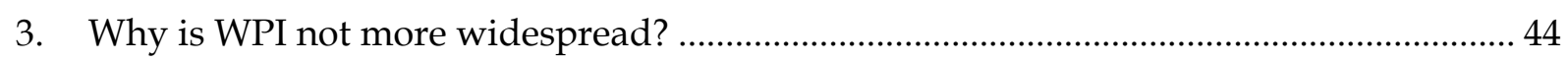

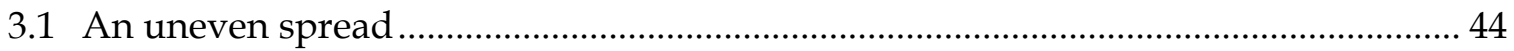

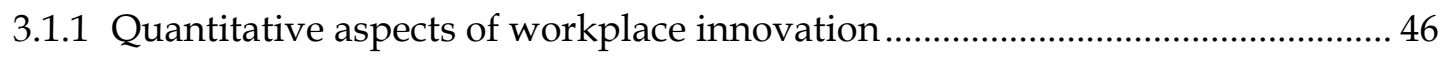

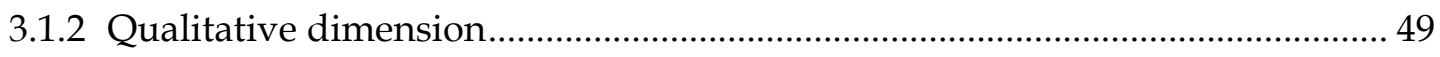

3.1.3 Complementarity between quantitative and qualitative aspects ...................... 51

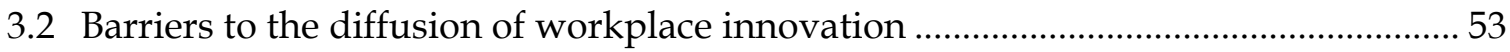

3.2.1 Risk aversion, resistance and lack of trust ......................................................... 53

3.2.2 Costs of a transition towards WPI........................................................................ 57

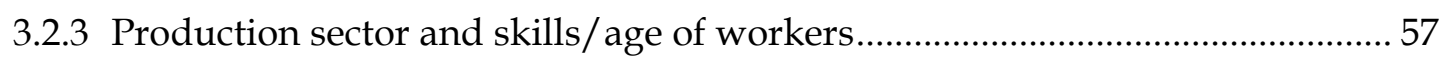

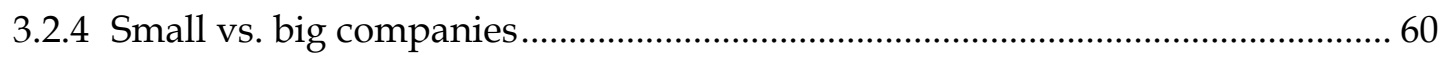

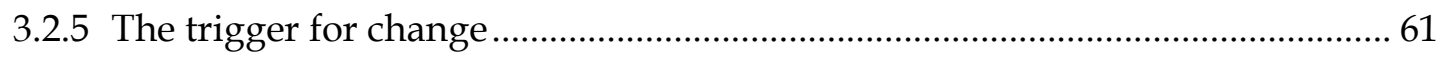

3.2.6 Workplace innovation and national policies - Case studies ……....................... 64

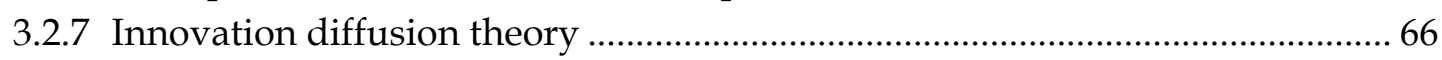

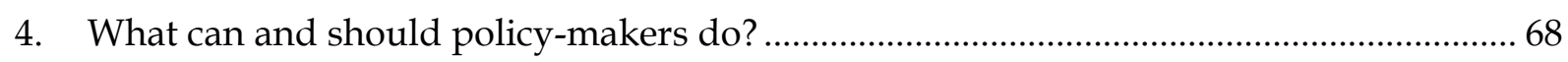

4.1 What do international organisations recommend and what can the EU do? ............ 69

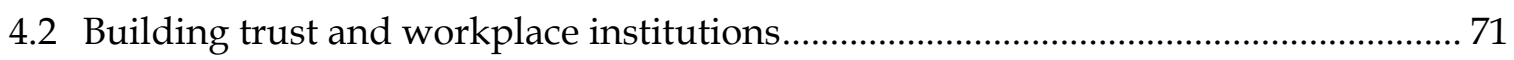

4.3 Overcoming risk aversion and lack of information .................................................. 72

4.4 Overcoming regulatory barriers and uncertainty …................................................... 73

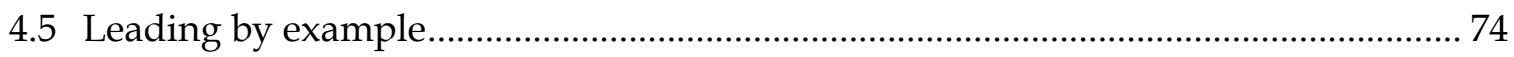

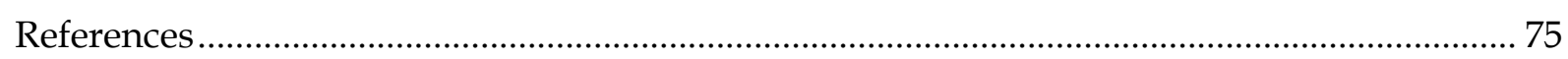

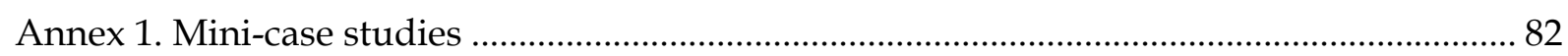

Annex 2. Examples of recent information technology products to support WPI .................... 84

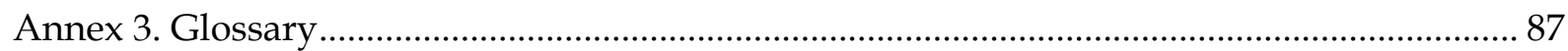




\section{List of Tables}

Table 1. Correlation coefficients: Workplace innovations and macroeconomic variables....... 25

Table 2. Self-assessment of changes in performance and QWL ............................................... 28

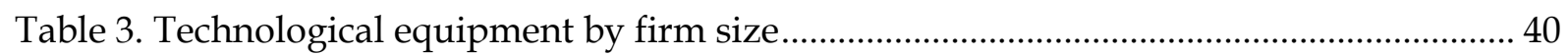

Table 4. Workplace innovation in EU27 - share of workers affected (\%) ................................. 45

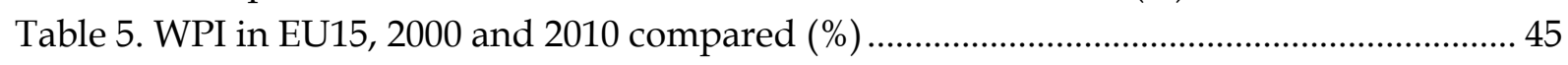

Table 6. Correlation coefficients between quantitative and qualitative aspect of WPI ............ 51

Table 7. Fears associated with WPI, expressed by level of actor .............................................. 54

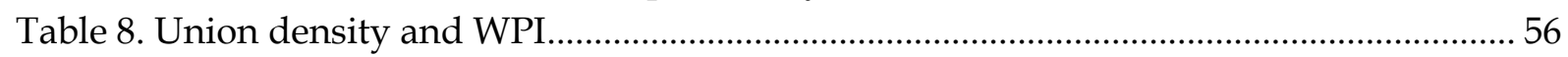

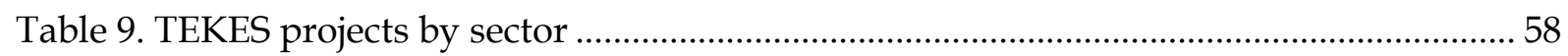

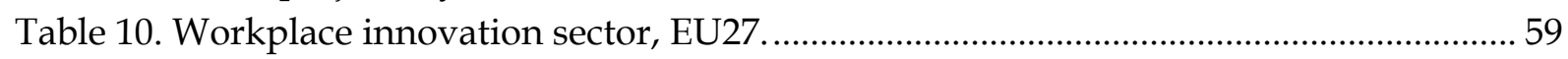

Table 11. Workplace innovations (as share of workers) by education level .............................. 60

Table 12. Workplace innovation by company size, EU27, share of workers .............................. 61

Table A1. Examples of user-friendly technologies at the workplace .......................................... 84

\section{List of Figures}

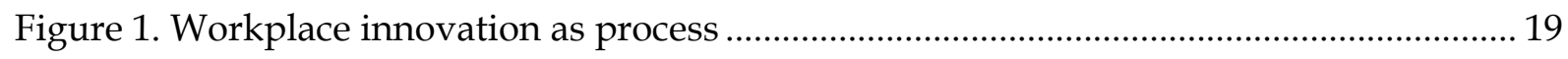

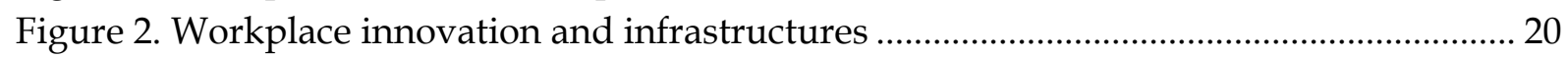

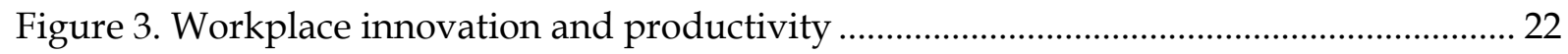

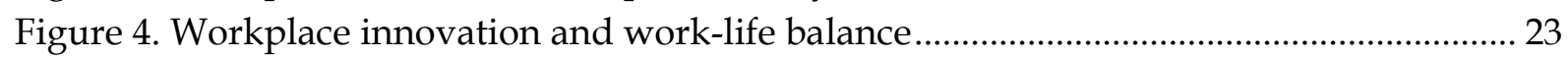

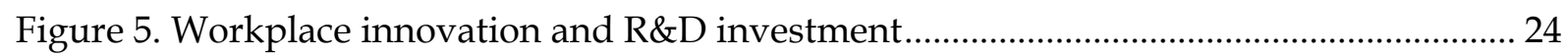

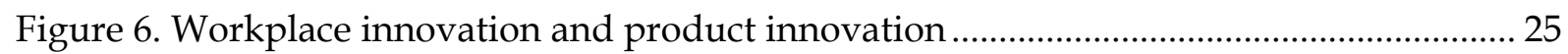

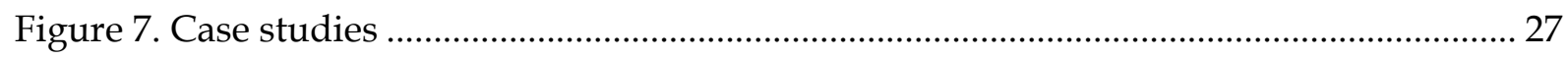

Figure 8. Workplace innovation, impact on employment ........................................................ 29

Figure 9. Self-assessment of productivity at FPS Belgium - positive answers .......................... 30

Figure 10. During the last month have you invested in any of the following ICT technologies? (percentage responding in the affirmative) .................................... 40

Figure 11. Ranking of EU27 countries by WPI diffusion (higher ranking corresponds to

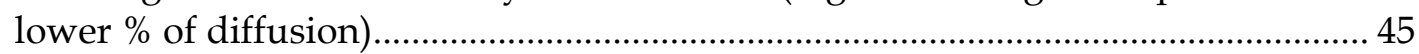

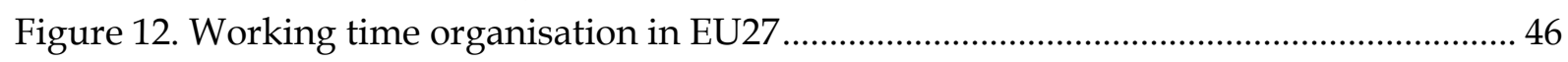

Figure 13. Do you work the same number of hours every day/week? 'NO' answers ............. 47

Figure 14. Percentage of office workers that also worked from home ..................................... 48

Figure 15. Share of workers that receive partial performance-linked remuneration ............... 49

Figure 16. Share of workers that receive partial remuneration linked to performance,

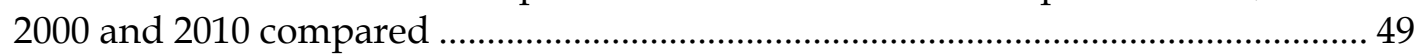

Figure 17. Share of workers involved in qualitative aspects of WPI........................................ 50

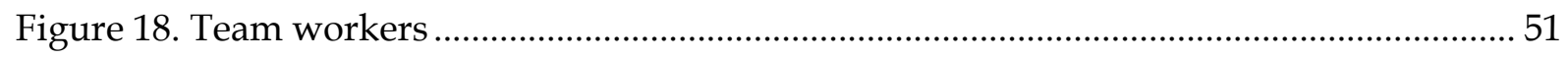

Figure 19. Workplace innovation: Nordic vs. Mediterranean countries ................................... 52

Figure 20. Do you trust your colleagues to be productive when they work flexibly or

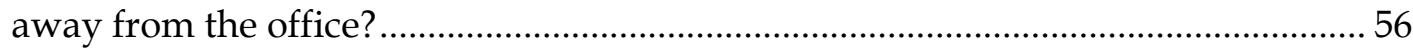

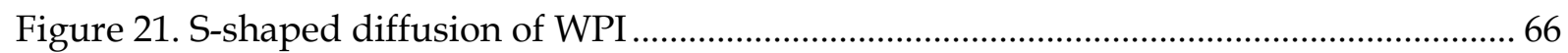





\title{
Workplace Innovation and Technological Change
}

\author{
Miroslav Beblavý, Ilaria Maselli and Elisa Martellucci* \\ CEPS Special Report No. 65/September 2012
}

\section{Executive Summary}

\section{Why this report?}

This report took its inspiration from the remark by Nobel laureate Robert Solow: "You can see the computer age everywhere but in the productivity statistics." In a similar vein, workplace innovation (WPI), especially technology-driven innovation, is a much discussed phenomenon, but one that is not so frequently experienced in reality. Is it one of those fashionable things that one reads about in management books, but that rarely if ever actually happens? Or could it be one of the answers to Europe's long-term social and economic challenges that stem from an ageing workforce and the need for more flexibility to stay competitive? Do we actually know how widespread it is? What is holding WPI back outdated public policies, old-fashioned managers or conservative workers? Or common sense? And what should be and can be done about it?

This report attempts to answer these important questions in the European context, proceeding to explore WPI on the basis of several steps:

- What is workplace innovation?

- Is it beneficial?

- What is the role of technology?

- How widespread is it?

- Why do organisations adopt it?

- What are the barriers to its more general dissemination?

- What can policy-makers do to foster WPI?

Thanks to the European Working Conditions Survey conducted every five years by the Dublin-based European Foundation for the Improvement of Living and Working Conditions (Eurofound), we have access to some basic data. However, since statistics always lag behind reality when it comes to disruptive change, we decided to conduct a series of case studies to supplement the quantitative information and to look at the problems encountered in introducing workplace innovation and possible solutions. These, together with our statistical analysis, constitute the main empirical value added of the report. One set of case studies examines the following organisations: SGI/GI (Slovak Governance Institute (Slovakia), as representative of the world of small- and medium-sized enterprises; Oticon (Denmark) as representative of manufacturing companies; the Open University (UK), as representative of educational organisations and FPS Social Security (Belgium) representing the public sector. The remaining two case studies focus on the country-level, one looking at of how a specific innovation can become fully mainstreamed (in the Netherlands and the "part-time economy") and the other (Finland and TEKES) looking at how a government programme can help disseminate workplace innovation.

\footnotetext{
* All three authors are economists at CEPS in the Economic Policy research unit. Miroslav Beblavý is also Associate Professor of Public Policy at the Comenius University in Bratislava and a Member of the Slovak Parliament (since 2010).They wish to acknowledge the valuable contribution of Mikkel Barslund in the case studies on the Dutch part-time economy model and Oticon. They also thank Peter Totterdill for insightful comments on an earlier version of this study.
} 


\section{What is workplace innovation?}

There is a family of related terms or concepts, all attempting to capture the changing nature of work and the workplace. These include terms such as: workplace innovation, highperformance work systems, high commitment workplace practices, high involvement workplace practices and alternative workplace practices.

While each of these concepts is distinct from the others, they all represent alternative ways of organising work that emphasise flexibility of work organisation, empowerment and the autonomy of employees, with a focus on performance and outcomes.

For our purposes, we decided to look at the following practices:

- flexi-time

- teleworking

- alternative payment schemes

- employee empowerment and autonomy

- task rotation and multi-skilling

- team work and team autonomy

The list of practices is not sufficient to understand what constitutes an innovative workplace. It is important to clarify that WPI lies at the intersection of skills, technology and human resources (HR) management. The three elements co-exist and are interdependent; where technology adoption is driven by HR strategic policies, managers are likely to create enough momentum to change the work process and consequently to invest in training and upgrading of skills to support the innovation. Conversely, the lack of skills, coupled with a static HR management will most likely represent a barrier to technology adoption, and hence to workplace innovation. The figure represents the dynamic interaction between internal and external factors affecting the WPI. Depending on the country context, competition policy together with market openness and regulatory reforms exert external pressures which can act as drivers or barriers for specific organisational changes.

Figure 1. Workplace innovation as a process

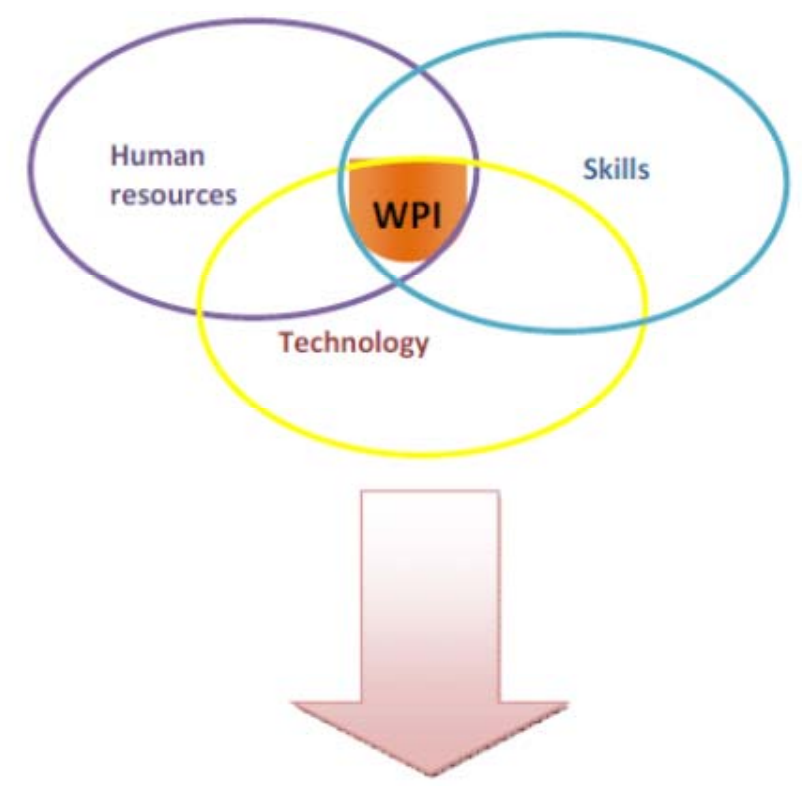

Productivity

Innovation

Source: Authors' own elaboration. 


\section{Is workplace innovation beneficial?}

In this part of the report, we developed our analysis at two levels: the country level and the organisational level.

For countries, we performed simple correlations of the relationship between several aspects of workplace innovation and other variables of interest - such as labour and total productivity, work-life balance and innovation. For each variable, scatterplot figures are presented in the main body of the report showing the following relationships:

- There is a strong relationship between internet and broadband penetration on the one hand and the percentage of people who work from home, on the other. Indeed, differences in broadband penetration explain about $60 \%$ of cross-country differences in Europe with regard to how many people work from home.

- Teleworking and working time flexibility are associated with higher labour productivity at the country level.

- Working time flexibility is associated with higher satisfaction with work-life balance, which in turn is associated with a higher employment rate, for men as well as for women.

- Countries with higher penetration of employee and team autonomy have higher levels of patents and R\&D investment and the relationship is much stronger for team autonomy.

- There is a very strong relationship between technological and organisational change: countries with more technological innovation - where firms introduce more new processes or technologies - are also countries where more restructuring or reorganisation takes place.

These findings were supplemented by an analysis of correlation between specific workplace innovation practices and productivity and innovation variables. At the country level, the extent of individual workplace innovation practices is correlated or strongly correlated with labour productivity, internet and broadband penetration, R\&D expenditure and outputs as well as work-life balance.

In other words, there is a strong correlation between country-level presence of various aspects of workplace innovation and technological and economic progress (Table ES1). Of course, and this is a very important caveat, correlation does not prove causation. Nonetheless, it seems safe to conclude, and we come back to this point later, that workplace innovation and several other phenomena tend to evolve together as a package at the country level.

Table ES1.Correlation coefficients: Workplace innovations and macroeconomic variables

\begin{tabular}{|c|c|c|c|c|c|c|c|c|c|c|}
\hline & & $\begin{array}{l}\text { Flex- } \\
\text { itime }\end{array}$ & $\begin{array}{l}\text { Tele- } \\
\text { work }\end{array}$ & $\begin{array}{l}\text { Alterna- } \\
\text { tive pay }\end{array}$ & $\begin{array}{c}\text { Flat } \\
\text { hierc. }\end{array}$ & $\begin{array}{l}\text { Employee } \\
\text { empow. }\end{array}$ & $\begin{array}{l}\text { Employee } \\
\text { autonomy }\end{array}$ & $\begin{array}{l}\text { Team } \\
\text { work }\end{array}$ & $\begin{array}{c}\text { Team } \\
\text { autonomy }\end{array}$ & $\begin{array}{c}\text { Task } \\
\text { rotation }\end{array}$ \\
\hline \multirow[t]{2}{*}{$\begin{array}{l}\text { Produc- } \\
\text { tivity }\end{array}$} & $\begin{array}{l}\text { Labour productivity per } \\
\text { person employed, Index } \\
\text { EU27 }=100\end{array}$ & 0.59 & 0.44 & 0.32 & 0.22 & 0.41 & 0.32 & 0.05 & 0.35 & 0.24 \\
\hline & TFP, EU27=100 & -0.06 & -0.09 & 0.17 & 0.04 & -0.39 & -0.33 & 0.01 & -0.01 & -0.13 \\
\hline \multirow[t]{2}{*}{$\begin{array}{l}\text { Infrastruc- } \\
\text { ture }\end{array}$} & $\begin{array}{l}\text { Broadband penetration rate } \\
(\%)\end{array}$ & 0.71 & 0.78 & 0.46 & 0.52 & 0.59 & 0.63 & 0.45 & 0.65 & 0.55 \\
\hline & $\begin{array}{l}\text { Level of Internet access of } \\
\text { households, \% }\end{array}$ & 0.73 & 0.73 & 0.62 & 0.50 & 0.39 & 0.58 & 0.45 & 0.74 & 0.45 \\
\hline \multirow[t]{3}{*}{ Innovation } & R\&D investment & 0.73 & 0.72 & 0.54 & 0.42 & 0.29 & 0.45 & 0.46 & 0.76 & 0.48 \\
\hline & Share of innov firms in total & 0.38 & 0.37 & 0.11 & 0.24 & 0.38 & 0.36 & 0.24 & 0.40 & 0.29 \\
\hline & $\begin{array}{l}\text { Patent applications to the EPO } \\
\text { per million labour force }\end{array}$ & 0.81 & 0.72 & 0.52 & 0.43 & 0.28 & 0.48 & 0.44 & 0.72 & 0.50 \\
\hline $\begin{array}{l}\text { W-L } \\
\text { balance }\end{array}$ & & 0.54 & 0.66 & 0.37 & 0.52 & 0.28 & 0.29 & 0.53 & 0.66 & 0.45 \\
\hline $\begin{array}{l}\text { Employ- } \\
\text { ment rate }\end{array}$ & Total & 0.71 & 0.75 & 0.45 & 0.45 & 0.42 & 0.27 & 0.34 & 0.47 & 0.62 \\
\hline & Female & 0.57 & 0.71 & 0.46 & 0.56 & 0.26 & 0.16 & 0.48 & 0.55 & 0.61 \\
\hline Average & & 0.56 & 0.58 & 0.40 & 0.39 & 0.29 & 0.32 & 0.34 & 0.53 & 0.41 \\
\hline
\end{tabular}

Sources: Authors' own elaboration based on data from the $5^{\text {th }}$ European Working Conditions Survey (Eurofound, 2010a) and Eurostat. 
At the organisational level, the literature and our case studies generally lend support to the thesis that workplace innovation yields beneficial results.

In the mid-1990s, Finnish policy-makers created a programme to foster WPI under the responsibility of the Finnish Innovation Agency (TEKES). According to ex-post evaluation, based on questionnaires distributed to companies and workers, there was no short-term impact on employment growth for most firms, but the minority that had job growth (13-14\%) outweighed the minority that experienced job losses (4-5\%). Over the long term, the percentage of companies with job growth significantly outweighed those with job losses. Even more importantly, it turned out that innovative workplaces recorded at the same time an increase in the performance of companies and extended employees' working lives. In 70\% of the 409 projects analysed, there was indeed a positive association between improvements in these two areas.

In the case of the Belgian social security agency (FPS), ex-post staff surveys and productivity indices showed improvements in productivity, work-life balance and job satisfaction. According to an internal survey conducted within one of the main FPS unit (DG for disabled persons), since the adoption of workplace innovations in 2009, the DG increased its productivity by about $20-22 \%$. Consistently, according to an internal survey done in 2010, $91 \%$ of the staff evaluated themselves more productive and $77 \%$ of the project leaders evaluated the staff members more productive.

For the Danish OTICON company, workplace innovation as a part of its overall restructuring was followed by a dramatic and sustained improvement in business performance. For two organisations in our sample of case studies (SGI/GI in Slovakia and the Open University in the UK), workplace innovation, augmented by technology, has been essential to their continued existence and business models.

The organisations and countries examined in the case study were selected randomly from a list of institutions and countries known to be engaged in workplace innovation. Nonetheless, this does not guarantee the absence of bias. It proved impossible to track examples of unsuccessful innovation, and we abandoned the effort. Therefore, our arguments are based on a combination of positive impact of workplace innovation as suggested by the literature, the association at the country level between workplace innovation and economic and technological progress as shown in this study and the data from the Finnish TEKES programme. The message is that not that all attempts at workplace innovation are beneficial, but that when workplace innovation is successful, it brings significant benefits.

\section{How widespread is WPI?}

To measure how widespread are the various forms of workplace innovation and how they are changing, we use data from the European Working Conditions Survey. We focused on the 2010 wave to determine the current situation and compare its dynamics with that of the 2000 wave.

Probably the most widespread workplace innovation is the ability of workers to choose their working time, which affects, in one way or another, $40 \%$ of European workers. The second type of workplace innovation that we examined was telework, measured as the share of workers who have as their main place of work their employers' or own business premises and their home as a second option. The European average is $12 \%$, but there are major crosscountry differences. In the Netherlands, Sweden and Denmark, this share exceeds 30\%, whereas employers in Italy, Bulgaria, Hungary and Cyprus provide this alternative for less than $5 \%$ of their workers. EU27 aggregate data by sector illustrate that workers who are allowed to work from home are more numerous in four sectors: real estate, professional and scientific activities, education, and information and communications. 
Figure ES2. Share of office workers who also work from home (\%)

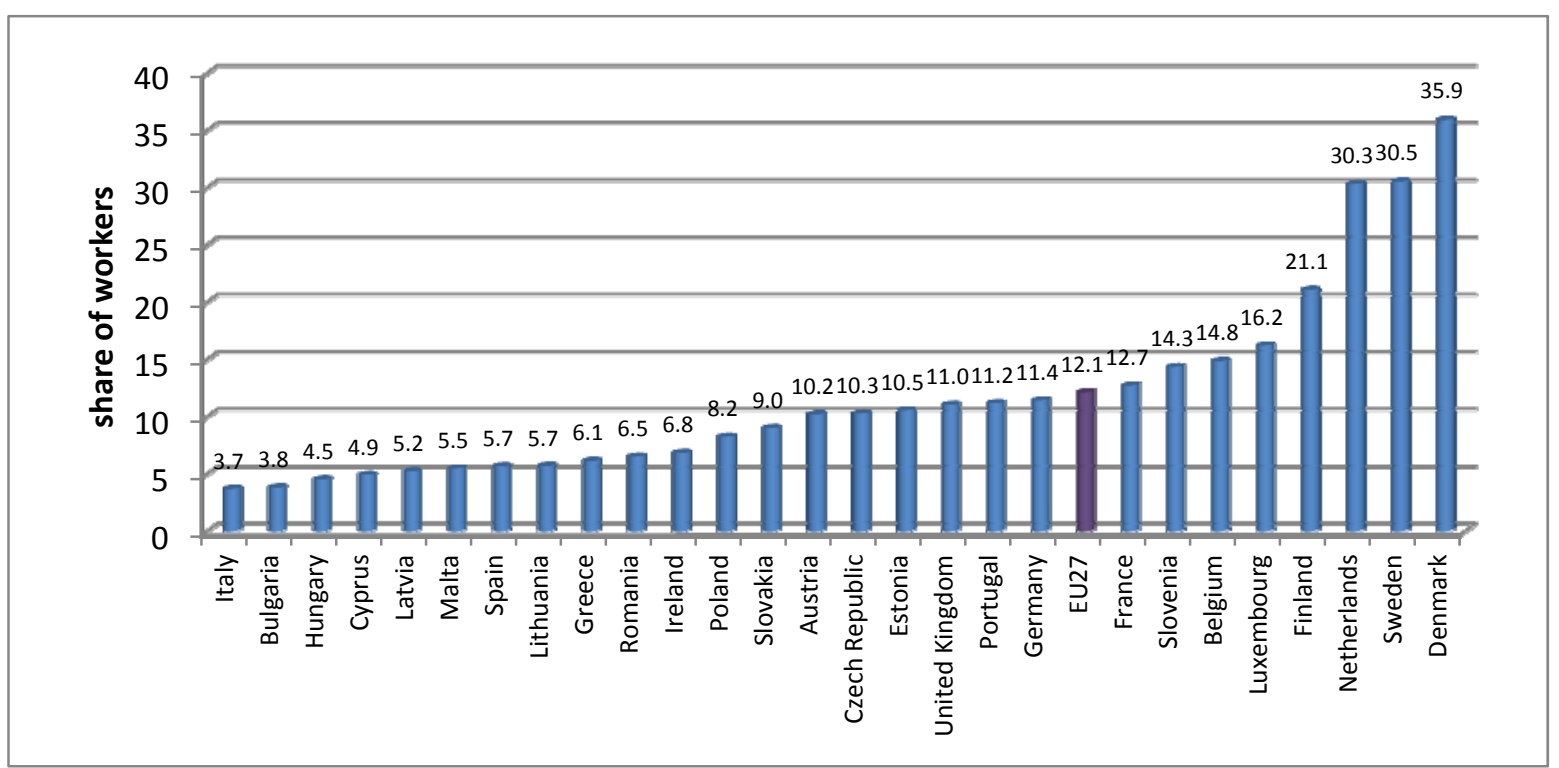

Source: Authors' own elaboration based on data from the 5th European Working Conditions Survey (Eurofound, 2010a).

Among the various elements of quantitative flexibility at the workplace, alternative payment schemes are perhaps the most controversial. How many workers receive as part of their salary alternative forms of compensation linked to their performance as individuals or as a member of a team? Figure ES3 plots the share of workers that receive, as part of their remuneration, shares in the company in which they work and/or payments based on the overall performance of the company (profit-sharing scheme). Such a practice is more widespread in France, where almost one-third of workers receive part of their salary linked to the performance of the company. The other countries above the European average of $15 \%$ are a mix of Nordic and Eastern European countries (France, Sweden, Slovakia, Slovenia, Finland, the Netherlands, the Czech Republic, Luxembourg and Denmark).

Figure ES3. Share of workers receiving part of their compensation linked to performance

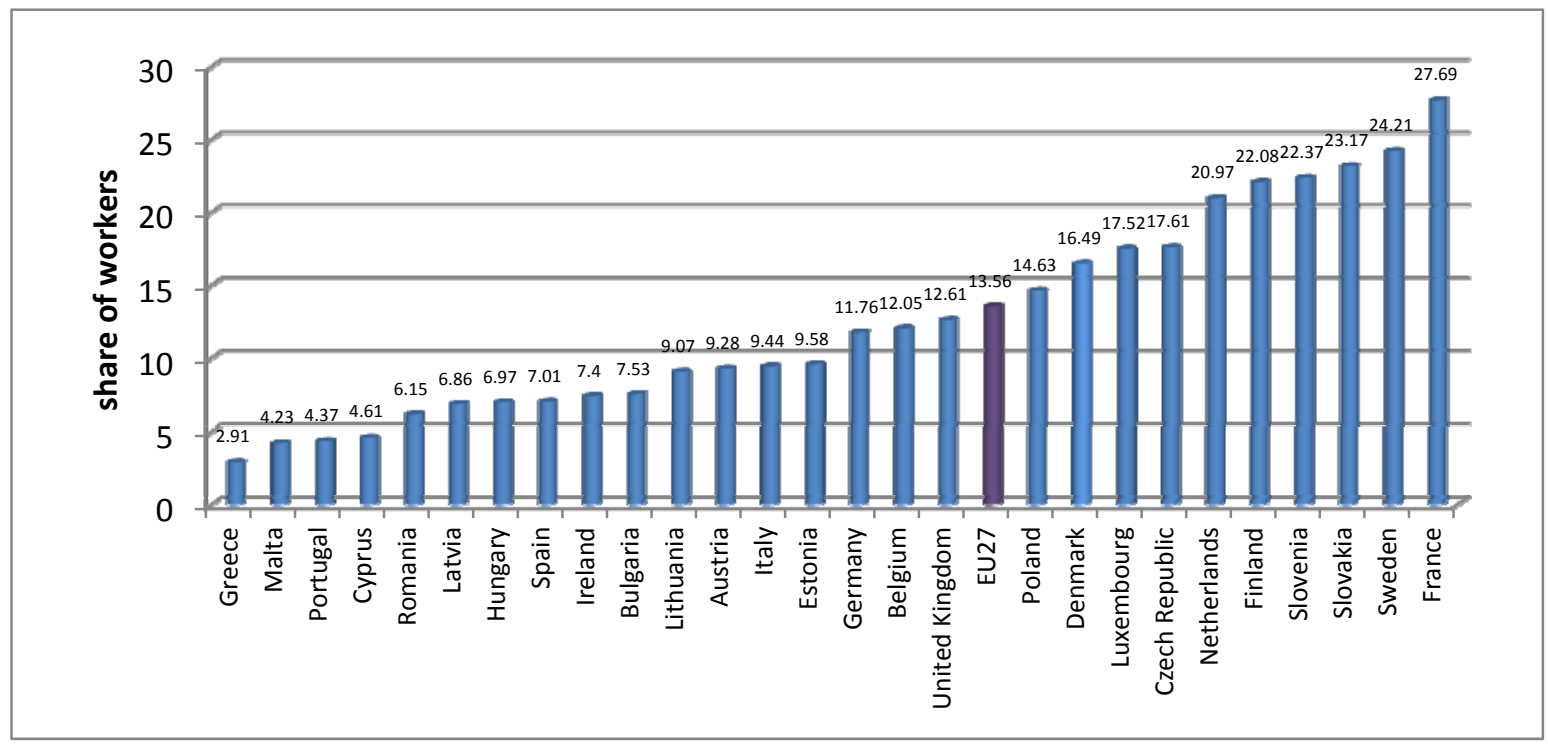

Source: Authors' own elaboration based on data from the 5th European Working Conditions Survey (Eurofound, 2010a). 
The next issue we examined was employee and team autonomy. To measure the degree of adoption of innovative practices in Europe, we used the answers to three questions in the working conditions survey:

- At your workplace, does management hold meetings in which you can express your views?

- Are you involved in improving the work organisation or work processes of your department or organisation?

- Are you able to choose/change your methods of work?

Data indicate that more than $60 \%$ of workers enjoy some degree of autonomy because they are able to choose or change the method of their work. The capacity to influence decisions of the company, however, is more limited: even though one-half of EU companies have a mechanism whereby employees can express their views, only $40 \%$ of workers declared being involved in the organisation of the work process. The replies to these three questions are positively correlated (between $41 \%$ and $53 \%$ ), implying that it would be very difficult to empower workers by allowing one of these WPIs and not the others.

Another element of qualitative flexibility at the workplace is task rotation. It has its raison d'être in the acquisition of workers of multiple skills, which facilitates the distribution of tasks. This practice involves at least one-third of European workers in all countries. The EU27 average is $44 \%$ and in countries like Sweden and Denmark task rotation is expected of more than $70 \%$ of the work force. Of these workers involved in rotating tasks, approximately $80 \%$ declared that different skills are needed to cope with the full range of job requirements.

Team work and team autonomy are the last elements of qualitative flexibility. Team work concerns more than $50 \%$ of workers, with only half of them also enjoying autonomy in terms of the internal division of tasks. This latter dimension of team work is highly differentiated by country: once again Denmark, Sweden and Finland classify in the top position given that more than two-thirds of team workers also enjoy great autonomy in the division of tasks. Common team tasks and joint planning are also more highly present in Bulgaria, Hungary, Lithuania and Latvia, where more than $50 \%$ of workers report participation.

Figure ES4. Team work in Europe

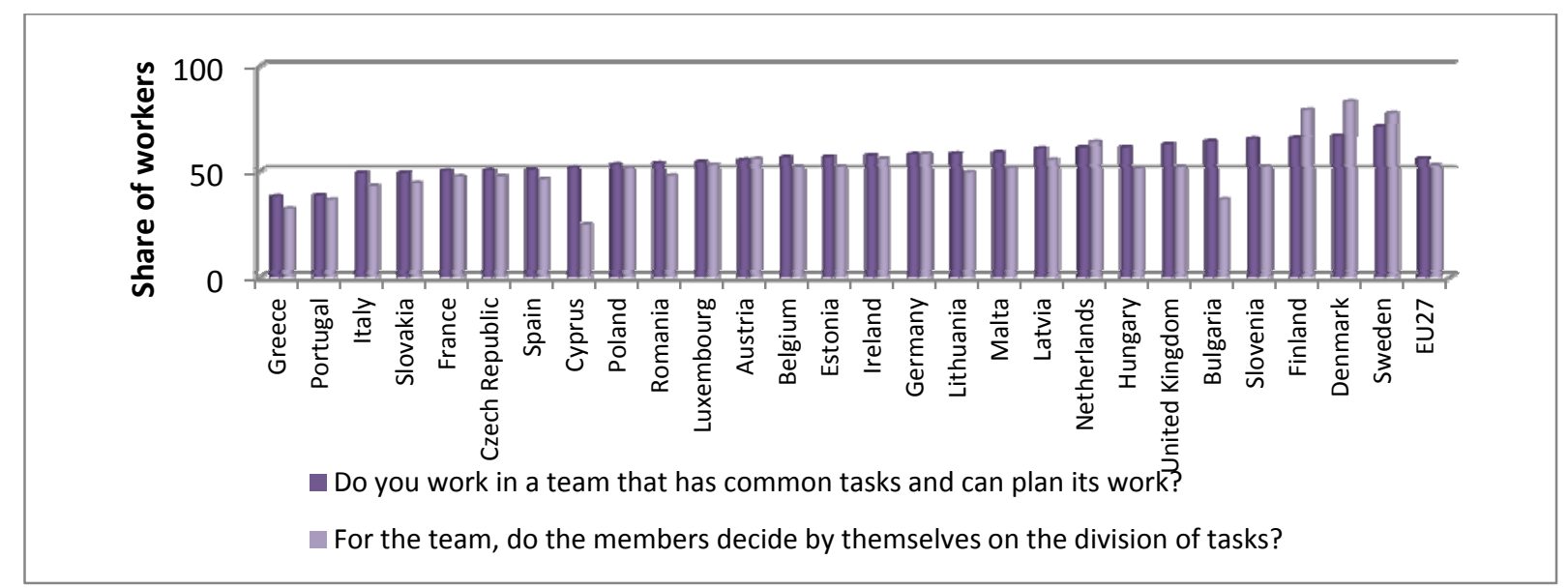

Source: Authors' own elaboration based on data from the 5th European Working Conditions Survey (Eurofound, 2010a).

Another important aspect is the complementarity between and across qualitative and quantitative elements of innovative workplaces. Correlation coefficients indicate that flexitime and teleworking are positively correlated with all qualitative elements. In the case of 
alternative payment schemes, the signs of the coefficients are the same but the relationship is strong only with flat hierarchies and team autonomy. Signs entail that not only there is no trade-off between telecommuting, for instance, and employee empowerment, but, in some cases, there is a strong interdependence.

Table ES1. Correlation coefficients between quantitative and qualitative aspects of WPI

\begin{tabular}{|l|c|c|c|c|c|c|}
\hline & $\begin{array}{c}\text { Flat } \\
\text { hierarchies }\end{array}$ & $\begin{array}{c}\text { Employee } \\
\text { empowerment }\end{array}$ & $\begin{array}{c}\text { Employee } \\
\text { autonomy }\end{array}$ & $\begin{array}{c}\text { Team } \\
\text { work }\end{array}$ & $\begin{array}{c}\text { Team } \\
\text { autonomy }\end{array}$ & $\begin{array}{c}\text { Task } \\
\text { rotation }\end{array}$ \\
\hline Flexi-time & 0.49 & 0.51 & 0.51 & 0.34 & 0.71 & 0.50 \\
\hline Teleworking & 0.62 & 0.54 & 0.58 & 0.48 & 0.78 & 0.62 \\
\hline $\begin{array}{l}\text { Alternative payment } \\
\text { schemes }\end{array}$ & 0.42 & 0.16 & 0.20 & 0.36 & 0.52 & 0.32 \\
\hline
\end{tabular}

Source: Authors' own elaboration based on data from the $5^{\text {th }}$ European Working Conditions Survey (Eurofound, 2010a).

Table ES2 synthesises the percentage of workers across the EU27 who benefit from one form or another workplace innovation. Taking the average across Europe, we observe that different practices have a different type of penetration: almost $70 \%$ of workers, for instance, enjoy autonomy but only $12 \%$ have access to teleworking.

Table ES2. Workplace innovation in EU27 (average share of total workers)

\begin{tabular}{|ccccccccc|}
\hline $\begin{array}{c}\text { Flexi } \\
-\end{array}$ & $\begin{array}{c}\text { Tele } \\
\text { workin } \\
\text { time }\end{array}$ & $\begin{array}{c}\text { Alternative } \\
\text { payment } \\
\text { schemes }\end{array}$ & $\begin{array}{c}\text { Flat } \\
\text { hierarchie } \\
\text { s }\end{array}$ & $\begin{array}{c}\text { Employee } \\
\text { empowerment }\end{array}$ & $\begin{array}{c}\text { Employee } \\
\text { autonomy }\end{array}$ & $\begin{array}{c}\text { Team } \\
\text { work }\end{array}$ & $\begin{array}{c}\text { Team } \\
\text { autonomy }\end{array}$ & $\begin{array}{c}\text { Task } \\
\text { rotation }\end{array}$ \\
\hline 37.8 & 11.7 & 12.5 & 56.8 & 43.9 & 67.4 & 56.4 & 52.0 & 43.6 \\
\hline
\end{tabular}

Source: Own elaboration based on data from the $5^{\text {th }}$ European Working Conditions Survey (Eurofound, 2010a).

Taking the average across all items by country, we discover that Nordic countries play a leading role: Denmark, Sweden, Finland and the Netherlands rank first, which implies that the diffusion of new ways of working in these countries is wider, compared to, for instance, the Mediterranean countries of Spain, Portugal, Greece and Italy. In between are the new member states: Latvia, Estonia and Lithuania, in particular; occupy the middle of the ranking, creating a model of 'post-communist almost Nordics'. The most interesting case is Slovenia: it ranks fifth, right after the Nordics, and has the same type of widespread diffusion across all elements. We also find a strong positive correlation between trust and labour union density on the one hand and workplace innovation practices on the other. This correlation tends to reinforce the 'package' argument and to suggest, at the corporate and national level, the need to build and sustain trust and social dialogue as preconditions of workplace innovation (a point to which we will return). 
Figure ES5. Ranking of EU27 countries by WPI diffusion

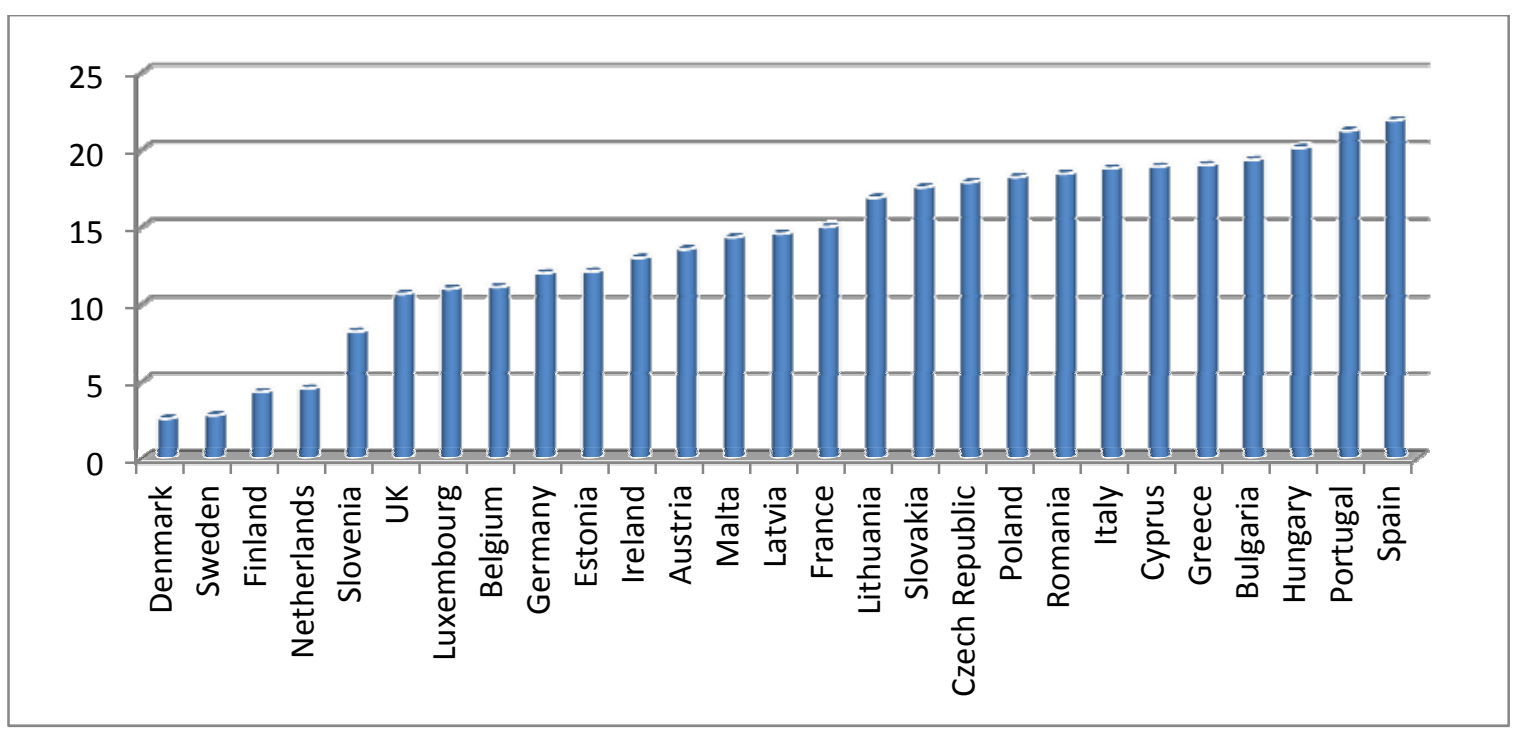

Source: Authors' own elaboration based on data from the $5^{\text {th }}$ European Working Conditions Survey (Eurofound, 2010a).

As far as old European countries (EU15) are concerned, it is possible to make a comparison with 2000 for some of the WPI items listed above in order to observe whether any substantial change occurred over the decade and whether there is evidence of convergence across Europe towards more workplace innovation.

Table ES3. WPI in EU15, a comparison of 2000 and 2010 (\% of total respondents)

\begin{tabular}{|clccccc|}
\hline \multirow{2}{*}{2000} & Average & 88.3 & 5.2 & $\begin{array}{c}\text { Employee } \\
\text { autonomy }\end{array}$ & $\begin{array}{c}\text { Team } \\
\text { work }^{\mathbf{b}}\end{array}$ & $\begin{array}{c}\text { Task } \\
\text { rotation }\end{array}$ \\
\cline { 2 - 7 } & st dev & 5.0 & 2.4 & 69.1 & 41.9 & 44.1 \\
\hline \multirow{2}{*}{2010} & Average & 84.3 & 13.7 & 8.2 & 10.4 & 8.7 \\
\cline { 2 - 7 } & st dev & 10.4 & 7.5 & 69.3 & 42.3 & 46.0 \\
\hline
\end{tabular}

a Percentage of workers who do NOT telework.

b Percentage of workers who do NOT work in teams.

Source: Authors' own elaboration based on data from the $5^{\text {th }}$ European Working Conditions Survey (Eurofound, 2010a).

It is interesting to note that the only major change across the decade is in the share of workers who receive part of their compensation linked to performance: the percentage of workers who answered positively to this question went from $5.2 \%$ in 2000 to $13.7 \%$ ten years later. Surprisingly, the remaining WPI elements are consistently static. On top of this, for all items except for team work, there is a divergence rather than a convergence across the EU15 countries (standard deviation coefficients mostly go up between 2000 and 2010).

\section{What is the role of technology in workplace innovation?}

With regard to the role of technology in changes related to work organisation, we draw the following conclusions:

- Technology is an important enabler of workplace innovation,

- but it is not always indispensable for workplace innovation - it can frequently occur without it, as was discovered in the case study of part-time work in the Netherlands. 
- However, it is indispensable for some types of organisations, notably those that construct their business model around it, such as Open University or SGI/GI

- $\quad$ and for certain types of workplace innovation practices (crowdsourcing).

- It is also vital for lowering the costs of workplace innovation.

In a more dynamic and future-oriented perspective, we also identify three trends that converge at the intersection of workplace innovation and technology:

- Fragmentation and disaggregation. This can be understood in several ways: in terms of the spatial-geographical dimension it concerns those workers who no longer work just from 9 to 5 . There is also a reorganisational dimension which is related to the re-distribution of these tasks to different workers/software/machines, rather than to different times of the day or locations. In the words of Couclelis (2003), it is "a process whereby a certain activity is divided into several smaller pieces, which are performed at different times and/ or locations". ICT certainly plays a strong role in this process. Nonetheless, according to Alexander et al. (2010), if usage of ICT is certainly associated with fragmentation, the causal relationship is not clear and the results indicate that work, personal and home-related factors play a much stronger role.

- Crowdsourcing. The definition of crowdsourcing can be quite broad and embraces many forms of work, but we focus on crowdsourcing as paid labour that gives the possibility to assign a specific task - from the creation of a code for a web programme, to a translation or data collection - to a worker in an unspecified location. An alternative term used by the US National Institute of Standards and Technology (NIST) is 'cloud labour', which has five characteristics: "On-demand self-service, broad access, resource pooling, rapid elasticity and measured service."

- 'Virtualisation'. This trend can involve virtual teams, but also teleworking, co-working and the use of social media in the workplace. Virtual teams can be defined as "groups of geographically, organisationally and/or time dispersed workers brought together by information technologies to accomplish one or more organisation tasks" (see Powell et al., 2004).

\section{Why do organisations adopt it?}

Drawing on the literature and our case studies, we investigated the motivations driving organisations to adopt workplace innovation practices. We found that the impetus for change usually comes from the top, frequently from the CEO in person. In other words, workplace innovation is 'top down' in terms of trigger, which is ironic given that the concept is about empowerment of workers. As we shall see, however, it is actually quite logical given the risks and uncertainties associated with change.

While there is a plethora of potential organisational motivations for workplace innovation, they can be collect into three broad groups. The first one concerns direct financial savings. SGI/GI exemplifies this motivation, where savings in office space and equipment played a prominent role in initiating the change. Savings concerned not just office space, but also telecommunications and IT costs.

The second group of incentives for change are expectations of productivity increases due to an improved ability of staff to organise their time and work and enjoy a better life-work balance. In the Finnish TEKES programme, a significant majority of workers involved in the change answered positively to the question of whether they are more productive. For instance, in a survey of organisations involved in the programme between 1996 and 2003, $60 \%$ of the respondents indicated an improvement in work productivity. 
While there is no general data available specifically for productivity performance, the overall transformation of the Danish OTICON was led by the need to extract much higher performance from the workforce. In the disability unit of FPS Belgium, productivity increased by $20-22 \%$ following the introduction of changes.

The last group of motivations concerns access to talent that would otherwise be unavailable. There are several groups of potential employees for whom more flexible working practices are frequently either a must or very important, for example, students, older workers and individuals with caring responsibilities as well as people who have more than one job or combine self-employment with part-time employment. FPS' primary reason was indeed to change their culture and to focus on recruitment attractiveness and retention management. The Slovak SGI/GI, as a voluntary organisation lacking funds, based its HR strategy on the ability to attract highly qualified people that it would otherwise not be able to recruit through very high levels of flexibility. In some cases, workplace innovation augmented by technology even allows recruitment regardless of boundaries. The Open University tapped a potential of teaching academics across the world through its use of technology. Since demographic change is going to dramatically affect European labour markets in the coming decades, the ability to access talent that would otherwise not be available can become an important comparative advantage for employers.

\section{What are the barriers to its more general dissemination?}

Given the benefits reaped by countries and organisations that successfully implemented workplace innovation, a pertinent question is why has it not spread more widely, particularly given the progress in technology to support it. We have identified four key issues, which together can create a formidable barrier to change.

The first is uncertainty about the success of the project. Even though the case studies presented here as well as the broader statistical data show positive outcomes when workplace innovation is successfully implemented, they do not and cannot capture the number of failed attempts where it was attempted, but not implemented in the end.

This leads to the second factor, which we could call the 'first-mover cost'. In network industries, the term 'first-mover advantage' is used to denote the competitive benefit derived from being the first to enter a given field. However, with workplace innovation, it appears to be the opposite, given all the costs and risks associated with being the first in a country or a given field to implement a given aspect of workplace innovation. This is true with regard to regulatory and legal uncertainty, but also new, informal norms as well as technological change.

Even when the organisation in question is not a pioneer, there are significant costs of transition, ranging from investment in new equipment, through disruption of work and productivity to training costs.

There is also an ex-ante uncertainty about the distribution of costs and benefits, which can be amplified by a lack of trust between managers and workers or among workers, leading to risk aversion and resistance by the parties involved. The reason why trust is so important in designing and implementing workplace innovation is two-fold. First of all, it touches upon the very core of the employer-employee/trade union relationship. Secondly, evidence shows that such a change constitutes a highly incomplete contract - i.e. it is impossible to precisely specify its terms and conditions in advance and there is a significant learning and adaptation process involved. With incomplete contracts, the presence of trust and/or of formal and informal institutions is crucial for whether parties decide to collaborate or not even if there are mutual benefits to be obtained. 
There are some also some genuine risks in workplace innovation, particularly with regard to the blurred boundaries between work and private life and the potential for intensification of work instead of increased productivity. Again, this can be amplified if there is a lack of trust between employers and employees or their representatives.

\section{What can policy-makers do?}

We identified five areas for potential action by policy-makers wishing to promote workplace innovation:

- Building trust and workplace institutions

- Overcoming risk aversion and lack of information

- Overcoming regulatory barriers and uncertainty

- Leading by example

- Taking action at the EU level

\section{i) Building trust and workplace institutions}

The importance of trust for workplace innovation has been presented above. Operationalisation of this approach solely for the purpose of workplace innovation presents some difficulties, but two recommendations can still be made:

- Overall support for building trust and social dialogue can be instrumental in supporting workplace innovation.

- Policy-makers should look for ways to stimulate long-term 'preventive' social dialogue specifically on the issue of workplace innovation.

Finland provides, once again, a good example: The TEKES programme enjoys a very high legitimacy among key stakeholders, including the social partners which share the view that there is no trade-off between productivity and quality of working life. There is also a link to the European level via EU directives on information and consultation and their utilisation, which is described in more detail in the section on EU level action.

\section{ii) Overcoming risk aversion and lack of information}

There is a role for a direct government action to disseminate knowledge and assist organisations in using workplace innovation. Policy-makers can lower the risk aversion of individual companies/institutions by providing funds and knowledge and also by creating networks of companies/individuals involved in workplace innovation.

In this respect, a clear example of good practice is the Finnish TEKES agency. The role designed for TEKES, as public agency, has been not only to provide funds and knowledge for this or that company. Two other important functions have been: a) pushing people involved in the same area towards the creation of networks and b) the mobilisation of resources towards the creation of expertise through universities and consultants and awareness among the public.

The experience of TEKES can certainly be inspirational for similar institutions across European countries, but it is not possible to speak about 'exporting' it because it requires a long-term view and because the outcome is conditional on the presence of certain institutional elements. On top of this, in times of tight budget constraints, it is even more difficult for government to raise funds.

Of course, creating an integrated, large-scale programme or a dedicated agency is not the only possible way to go forward. Specific elements of this approach can be used in an a la carte approach to include, inter alia: 
- promoting more research in the field aimed at studying and analysing the pros and cons,

- private/public collaboration (sharing best practices) between companies that successfully implemented the process and public entities that want to increase simplification/cut red tape,

- training for private/ public managers, the key drivers of change, and

- increasing the awareness for start-up companies/small- and medium-sized enterprises.

However, the Finnish case also shows the synergistic effects of an integrated approach.

\section{iii) Overcoming regulatory barriers and uncertainty}

Overcoming regulatory barriers and uncertainty is an important topic and, unlike the previous two areas, it is one where the role of policy-makers is irreplaceable.

It is a tricky issue because it involves a complicated balancing act. On the one hand, it requires fighting for equality for all types of work in labour law and welfare systems to avoid marginalisation and segregation of 'atypical' work, but, at the same time, it also requires taking into account the very different nature of work under the conditions of workplace innovation, which might require different treatment in the very same systems for example, more flexibility in labour law (leaving room for agreements between employers and employees on specific issues regarding work organisation) as well as taxation issues (e.g. tax implications of employers' expectations that employees will supply their own e-devices, such as smart phones).

In this respect, the Dutch case study showed that a wholesale adoption of a new form of work (part-time work in this instance) can be facilitated by establishing a true equality in the labour laws and welfare systems governing this form with more traditional ways of working. This was a significant factor in gaining wider social acceptance of part-time work and its transition from being an exception to a part of the norm.

On the other hand, our research and previous experience points to an apparent puzzle. Many organisations contemplating workplace innovation believe that inflexible labour laws or collective agreements create significant obstacles for change, but a detailed analysis of these shows that these perceived obstacles are frequently more easily identified in general than specifically. The real problem seems often to be their uncertainty rather than negative certainty.

Labour legislation on teleworking and other atypical forms of labour resulting from workplace innovation are often a legal afterthought with considerable regulatory uncertainty involved.

This fact can also explain some of the cross-country differences and cumulative nature of change within countries. Once a limited number of companies become trailblazers and resolve these issues internally and with the authorities, thus bearing the costs of change and uncertainty, others can follow with these costs much diminished. This also points to a need to have explicit pilots and precedents.

Therefore, a key role for the authorities is to provide assistance in identifying barriers in the form of legal/regulatory uncertainty and trying to provide clear, binding answers. This concerns issues ranging from general labour legislation through health and safety at work to data protection and fiscal/social security issues. A proactive approach by the authorities could involve appointing liaisons for workplace innovation at key regulatory agencies labour inspectorate, social security agency, tax administration - with a clear mandate.

Additionally, based on concerns raised by such pilots, individual agencies and government as a whole should regularly review legislation and identify specific barriers that cannot be 
dealt with at the regulatory agency level, but require a government decision or a legislative decision.

\section{iv) Leading by example}

The public sector plays an important although varying role as employer in all the EU member states. Therefore, one of the ways policy-makers can encourage wider adoption of workplace innovation is for them to encourage public sector institutions to lead by example. Public sector institutions are generally perceived as facing more difficulty in shifting to new forms of work organisation compared to the private sector. Therefore, successful change in such an environment can send an important message to the wider corporate world that it is possible. Additionally, they might find it easier to resolve the regulatory uncertainty issues with other authorities than private companies might.

The FPS example also shows that since the benefits of such a change can be tangible in financial terms, using public expenditure to support such projects can be more easily justified for public institutions and does not run into the state aid problems. Therefore, specific government initiatives to explicitly encourage/foster change in the public sector and its specific subsectors - e.g. public administration or education - can be one of the ways forward if a TEKES-type approach is not feasible or desirable in a given country.

\section{v) Taking action at the EU level}

Of course, workplace innovation is a policy issue of relevance not only for national governments, but also at the EU level. We mainly draw on of the European Economic and Social Committee (ECOSOC) recommendations, while adding a few of our own. Three main areas can be identified.

The first one is to make workplace innovation a basic building block in the implementation of the 'Europe 2020' strategy and other EU initiatives that influence innovation policies. For example, as ECOSOC emphasised, innovation policy should concentrate more on how the different partners can work together more effectively to promote innovative workplaces. The issue is broader than that however: as we saw, access to and the availability of the internet and broadband can have substantial influence on spreading workplace innovations.

The second area bears more directly on the issue of workplace innovation and its place in EU policies. The European Commission should open public consultations at the EU level on the issue of workplace innovation and consider creating and/or supporting stakeholder networks on this issue. This may sound like a proposal to only pay lip service to the issue, but experience suggests that policy change at the EU and national levels begins with naming and measuring. Alternatively, the consultation could be linked to the experience with implementation of Directive 2002/14/EC on employees' rights to information and consultation.

A similar logic is behind the third set of proposals. The European Commission should also consider launching a pilot project on innovative workplaces. This could include detailed studies on the relationship between the quality of working life, innovativeness and productivity, more data collection in the field at the European level, including ad hoc surveys from Eurostat and even, potentially, the introduction of a European index describing the quality of working life and its effects on innovativeness and productivity. These could be linked to the overall focus on social innovation that the Commission is currently pursuing. This could also be pursued through use of European research funds. 


\section{Introduction}

This report took its original inspiration from the well-known quote by Nobel laureate Robert Solow (1987): "You can see the computer age everywhere but in the productivity statistics." In a similar vein, workplace innovation (WPI), especially technologically driven innovation, is a much discussed, but far less frequently experienced phenomenon. What does it mean? Is it one of those fashionable things that one can frequently read about in management books, but that actually rarely if ever happens? Do we actually know how widespread it is? What is the role of technology in workplace innovation? What is holding the changes back outdated public policies, old-fashioned managers or conservative workers? Or common sense? And what should and can be done about it, if anything, by policy-makers?

This report is the result of CEPS' investigation into these questions in a uniquely European context. It proceeds by exploring several key questions:

- What is workplace innovation?

- Is it beneficial?

- How widespread is it?

- Why do organisations adopt it?

- What are the barriers to its more general dissemination?

- What is the role of technology in all of this?

- What can policy-makers do about it?

As always, statistics lag behind reality when it comes to disruptive change. It is therefore not surprising that there are insufficient quantitative data on:

- the extent of workplace innovation in Europe,

- the role of technology and particularly

- the underlying problems and causalities.

However, thanks primarily to the European Working Conditions Survey (EWCS), conducted every five years by the Dublin-based European Foundation for the Improvement of Living and Working Conditions (Eurofound), we have some basic data. We also decided to do a series of case studies to supplement this quantitative information and to look at barriers and possible solutions. These, together with our statistical analysis, constitute the main empirical value added of the report. We begin the study with an in-depth review of the literature.

The European Working Conditions Survey is rich in information regarding aspects of work related to organisation, type of activity, health, work-life balance and quality. The sample size consists of 1,000 observations in most countries. In the larger countries, it reaches up to 2,000. ${ }^{1}$ We use EWCS data to understand the extent to which workplace innovations are spread throughout Europe and to put them in relation to macroeconomic variables such as productivity and employment, statistics for which we take from Eurostat.

In parallel with analysing the data, we conducted six case studies, which are meant to complement the statistics and investigate more in depth on the one hand which elements of

\footnotetext{
${ }^{1}$ Moreover, three countries decided to finance larger national samples resulting in a target sample sizes of 4,000 in Belgium, 3,000 in France and 1,400 in Slovenia. The total number of interviews conducted in 2010 was 43,816 .
} 
new technologies foster the adoption of flexible workplaces and on the other which barriers limit their use. The key research questions are:

1. What is the role of technological change in workplace innovation? Is it a necessary and/or sufficient condition?

2. Why don't we see more workplace flexibility? Which barriers stand in its way? What is the role of policy?

The 'micro' case studies analyse private and public institutions. They have been selected in such a way that both small and large companies are included in the sample, with an appropriate geographical coverage and differentiation by sector. The case studies shared the same research questions but followed different methodologies with a mixture of data collection, semi-structured interviews and desk research.

Cases studies were conducted on the following organisations: Slovak Governance Institute (SGI/GI) (Slovakia), as representative of the world of small- and medium-sized enterprises; Oticon (Denmark) as representative of manufacturing companies; the Open University (UK), as representative of educational organisations and FPS Social Security (Belgium) representing the public sector. The remaining two case studies, Finland and the Netherlands, look at workplace innovation from a national perspective.

The four organisations examined in the case studies were selected randomly from a list of institutions known to be engaged in workplace innovation, while the two country-level case studies were selected as the only two known examples (to the authors). Nonetheless, this does not guarantee the absence of bias. The study was not able to track examples of unsuccessful innovation, which was abandoned. Therefore, our arguments are based on a combination of positive impact of workplace innovation as documented in the literature, the association at the country level between workplace innovation and economic and technological progress as shown in our analysis and the data from the Finnish TEKES programme. The message is that when workplace innovation is successful, it brings significant benefits, but that not that all attempts at workplace innovation are inevitably beneficial.

Basic information regarding each institution is contained in Annex 1.

The report is organised as follows: in the first chapter, after a brief analysis of the concept and definition of workplace innovation, we investigate, based on data and case study results, the costs and benefits of workplace flexibility. We clearly list the advantages and the disadvantages of new ways of working and find that there is no trade-off between higher productivity and better quality of working life. Also we argue that the equilibrium between negative and positive consequences is balanced towards the latter. In chapter 2, we examine the role of technology and argue that its role is to facilitate workplace innovation. It is sometimes indispensable but still constitutes neither a necessary nor a sufficient condition. We also provide a picture of more recent trends, such as fragmentation and virtualisation of work.

In the third chapter we examine barriers to further adoption of innovative work practices, such as risk aversion, costs, sector of production, size of the company and age/skills of the workforce.

The final chapter is dedicated to an analysis of what policy should/could do to help spread workplace innovation more widely in European countries. We structure our recommendations into five areas, based on the findings presented in the previous chapters. 


\section{Conceptualisation of workplace innovation}

\subsection{Conceptualisation}

Increased global competition and rapid developments in information technology have induced managers to rethink the way work has traditionally been organised. The OECD (2010) identifies four models of work organisation that have been adopted by firms over the years: i) the 'Taylorist' model, calling for little discretion and low problem-solving, ii) traditional forms where methods are informal and non-codified and the work repetitive, iii) the learning organisation that adapts and competes through learning and iv) the lean model where some workplace innovations are spread, leaving low levels of discretion to employees.

Several books and articles have been published (e.g. Arthur, 1994; Pfeffer, 1994; Huselid, 1995; MacDuffie, 1995; Appelbaum et al., 2000; Guthrie, 2001) and different labels have been used to differentiate the traditional forms from the new trends of work organisation: "innovative", "high performance", "new" or "flexible" workplace organisations (Bauer, 2004).

The core feature of these numerous concepts is the idea of moving from a hierarchical type of organisation to flatter and more flexible structures where teams and individual workers can contribute new ideas and practices to the improvement of the institution they work for.

Despite the appearance of different names in the literature, the most commonly used notions are: high-performance work system (HPWS) and workplace innovation (hereafter also WPI).

Workplace innovation can be generally seen as the conscious effort from workers and management to develop solutions to workplace problems. Technology, knowledge development and getting the customer perspective in the company represent the core elements of WPI (Dhondt, 2004). Pot et al. (2011) propose the definition of WPI as strategically induced and participatory adopted changes in an organisation's practice of managing, organising and deploying human and non-human resources that lead to simultaneously improved organisational performance and improved quality of working life (Eeckelaert et al., forthcoming).

To explain WPI, Totterdill refers to the 'high road' of work organisation. High road suggests the possibility of convergence between values and objectives previously seen as being in opposition to each other. Can developed countries achieve sustainable competitiveness and high levels of employment through the enrichment of working life? In short, can customer satisfaction and job satisfaction be united?

The importance of the 'high road' approach is that it seeks to identify the potential for winwin outcomes - the scope for convergence between organisational performance, employment and quality of working life (Totterdill, 2009).

When we talk about high-performance work system (HPWS), we refer to a particular type of human resources (HR) system made up of new forms of work organisation and flexible HR practices based on employee involvement and empowerment (Ferreira et al., 2010). One of the first conceptualisations of this new work organisational approach belongs to Lawler who points as the main characteristics to the implementation of the high-involvement management, job design, problem-solving groups, a reward system, personnel policies, a career system, a selection system and training orientation (Lawler, 1986 and Ferreira et al., 2010).

Appelbaum et al. (2000) identify four drivers of action for an HPWS: involvement, training, incentives and support technology to make it fully compliant to the demands of modern HR management (Ferreira et al., 2010). An HPWS means: 
A change from a Tayloristic work organisation, characterized by task specialization, a pyramidal hierarchical structure, and a centralization of responsibilities, to a holistic organisation featuring flat hierarchical structures, job rotation, selfresponsible teams, multi-tasking, a greater involvement of lower-level employees in decision-making, and the replacement of vertical by horizontal communication channels. These innovative workplace systems are often accompanied by complementary human resource management practices. In addition, firms relying on innovative workplace systems often give employees the appropriate incentives to participate in decision-making through the use of alternative payment schemes. Furthermore, these firms often implement special training measures and appropriate hiring strategies to ensure a workforce with the necessary skills to work in these innovative organisations through employer provided training and appropriate hiring strategies (Bauer, 2004).

Eurofound defines an HPWS as the combination of:

o "practices that structure work organisation and job design - for example use of teams and working time arrangements;

o practices that ensure high quality of labour input into the production process, for example careful recruitment and selection, training and development, appraisal and performance management;

o practices that provide opportunities for employees to contribute to organisational decision-making, for example collective bargaining, direct representation and communication between staff and managers, and individual working groups to improve quality or solve workplace problems;

o practices that provide rewards for performance, for example variable pay, employee benefits and career progression opportunities;

o Flexi-time."

Among other varieties of practices that can be associated with HPWS we find as well highcommitment employment practices (HCEP), high-involvement workplace practices (HIWP) and alternative workplace practices (AWP).

As their names suggest, both HIWP and HCEP emphasise the engagement of nonmanagerial employees in the production process, bringing out their human relations skills as well as knowledge skills (Godard, 2004).

Cottini et al. (2009) describe HPWS as a variety of HR policies and workplace practices that aim at taping into the ability of frontline workers to produce valuable local knowledge through their efforts and share it with management, and to deal with local shocks on their own.

Similarly, alternative workplace practices include: i) alternative job design practices, including work teams (autonomous or non-autonomous), job enrichment, job rotation and related reforms and ii) formal participatory practices, including quality circles or problemsolving groups, town hall meetings, team briefings and joint steering committees. Of these practices, work teams and quality circles can be considered as most central to high performance (Godard, 2004).

Almost all HPWSs are based on the so-called 'ability, motivation and opportunity' or AMO model, 2 either explicitly or implicitly (Boxall \& Macky, 2009). According to the AMO model,

2 The AMO model was first developed by Bailey (1993) and has since been used in a number of key pieces of HPWS research (for example, Huselid, 1995 and Appelbaum et al., 2000). 
HPWSs increase the use of employees' discretionary efforts. In the right circumstances, employees have the motivation to go beyond the terms of their job description and to contribute more to the organisation by trying to be more creative, helpful, paying extra attention to detail or taking additional tasks (Appelbaum et al., 2000). The use of discretionary effort is strictly linked to employees' motivation; firms can encourage employees to think of themselves as creating an atmosphere of trust (intrinsic factors) or implement incentive pay schemes, such as employee share-ownership programmes, individual performance pay or commissions and group-based performance pay (extrinsic factors).

In this report we will primarily refer to the notion of WPI. As Pot (2011), suggests the idea behind workplace innovation is to combine economic and social goals, whereas in the concept of 'high performance workplaces' the objective of quality of working life is not always considered.

Although there are several definitions in the literature, we opted to look upon all the practices considered as WPI:

o Flexi-time

o Teleworking

o Alternative payment schemes

o Flat hierarchies

o Employee empowerment and autonomy

o Task rotation and multi-skilling

o Team work and team autonomy

The first three are the 'quantitative' items (or employment practices), whereas the remaining items refer to qualitative/functional aspects of workplace innovation. Our main challenge is to capture the role that technological change plays in the diffusion of these practices, whether it is as the main source for their introduction or rather whether technology is an enabler, with other factors playing a key role.

As Cressey \& Keheller (2003) pointed out, innovative work practices represent a radical change in the production process and its management. This implies the shift from a static type of organisation where tasks and processes are continually replicated to a transformative learning organisation where relationships and connections matter and the action is at the core of the process. "Transformative action requires a focus on human beings and the organisation must be viewed not as a machine but as 'living' entities" (ibid.).

Like many other types of innovation, changes in work practices do not have immediate results. Both employers and employees need to learn how the new practices can be properly used (Totterdill et all, 2002). "The 'high road' of work organisation is a continuing journey, not an end state. It is a process of innovation, reflection and learning across the whole organisation" and simultaneously of interaction with its external work context (ibid.).

The perspective of Swart et al. (2004) is in some ways similar. He indeed argues that it is essential to examine the network of relations to understand how a firm operates. "We cannot understand the links between HR policies and processes and the performance of the firm without taking into account the nature of the external environment" such as, clients, suppliers, partners and other collaborators" (ibid.).

Picking up on that theme, Keheller \& Cressey (2003) stressed the role of social dialogue, as a decisive factor in the process of competence development, re-skilling, training and the development of enterprise human investment. Where trade union and employee representatives are embedded into organisational policies, "the results in terms of improved 
industrial relations atmosphere, improved morale, acceptance of change and employee commitment has been clearly identified by social partners" (ibid.).

As we understand it, workplace innovation is at the cross-roads between skills, technology and human resources management. The three elements co-exist and are interdependent; where technology adoption is driven by HR strategic policies, managers are likely to create enough momentum to change the work process and consequently to invest in training and up-skilling to support the innovation. On the contrary, the lack of skills, coupled with a static HR management will most likely represent a barrier to technology adoption, and hence to workplace innovation.

As outlined above, the company environment and the network of relations represent other key features; external innovation, national context, and the market can indeed favour or inhibit innovation.

The figure below diagrams the dynamic interaction between internal and external factors affecting WPI.

Figure 1. Workplace innovation as process

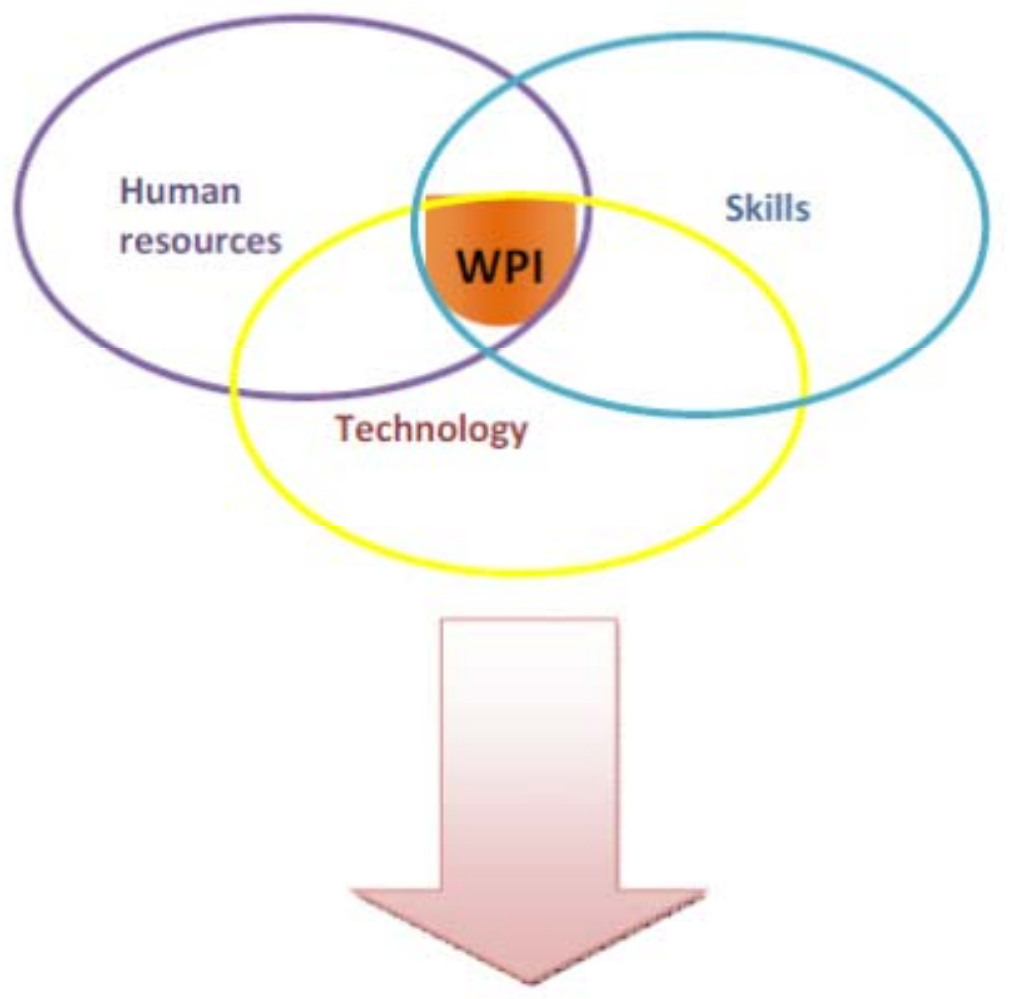

\section{Productivity}

\section{Innovation}

Source: Authors' own elaboration.

Depending on the country context, competition policy together with market openness and regulatory reforms, exert pressures that can act as drivers or barriers for specific organisational changes. 
In the rest of this chapter we focus on the benefits of workplace innovation (from the perspective of both firms and workers), drawbacks and the role of technology in the diffusion.

\subsection{Evidence from the data}

As mentioned in the previous section, the absence of hierarchy, higher independence of single workers and teams, task rotation, flexi-time and employee empowerment are the main features of workplace innovation practices. The limited number of observations and the lack of systematic data regarding this complex phenomenon prevent us from undertaking an indepth econometric analysis of the relationship of these practices with key variables related to productivity and innovation. Nonetheless, using data from the European Working Conditions Survey, complemented with Eurostat data, we are still able to look for correlations to understand to what extent variables co-move and if so, what are the possible explanations for these correlations.

In this section we will try put innovative workplace practices in relation to macroeconomic variables, such as productivity and employment rates. As will be discussed in greater detail below, there is often a positive relationship between the diffusion of high performance workplace systems in European countries and indicators of innovation and productivity. Yet, two caveats should be kept in mind while reading this section:

- Correlation does not prove causation: we can provide arguments to understand if workplace innovation leads to higher employment or vice versa but what we show in this section is that the two variables co-move.

- Cross-country correlations between two variables, like telework and productivity for example, are influenced by other variables (skills of the workforce or occupation, for instance).

We start with the facility endowment because it makes sense to believe that the quality of infrastructure influences the capability to work remotely; on the other hand, it is also true that even if all workers were properly equipped, they would still not be able to work from another location than their employers' premises if other barriers exist.

Statistics confirm that teleworking is much more diffused in countries where workers use a computer and internet for work at least $3 / 4$ of the time. The relationship between teleworking and internet access/broadband penetration is even stronger.

Figure 2. Workplace innovation and infrastructures
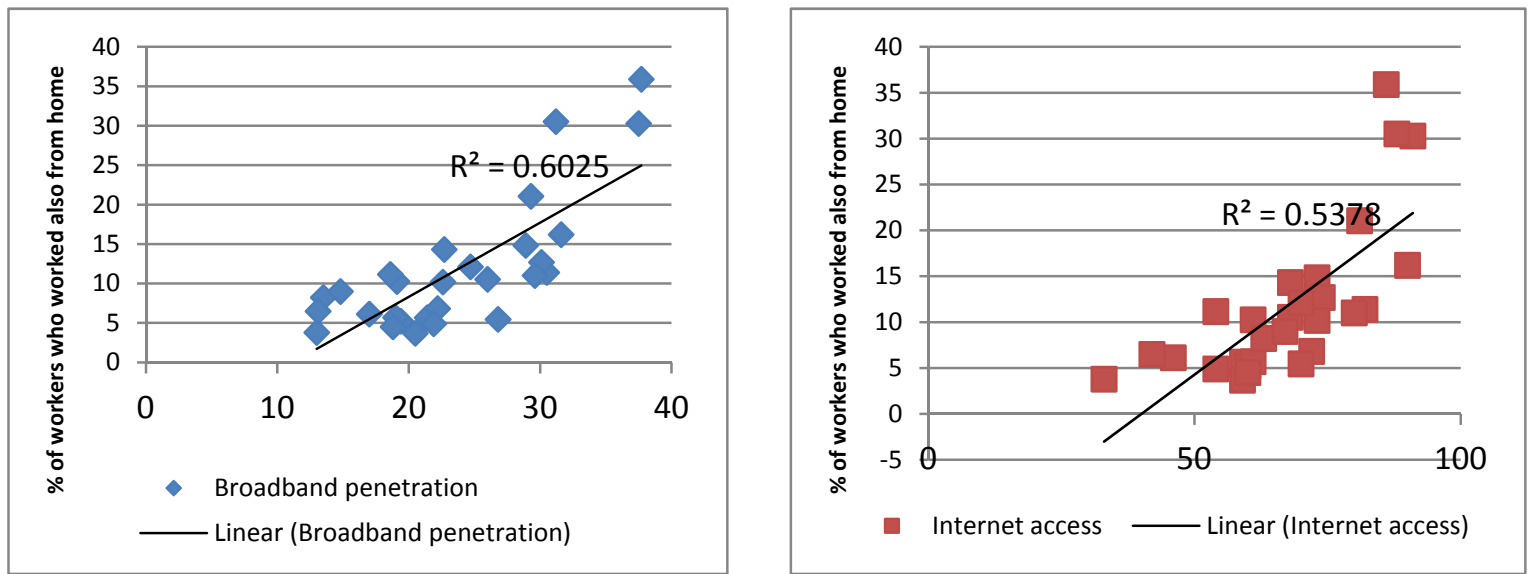

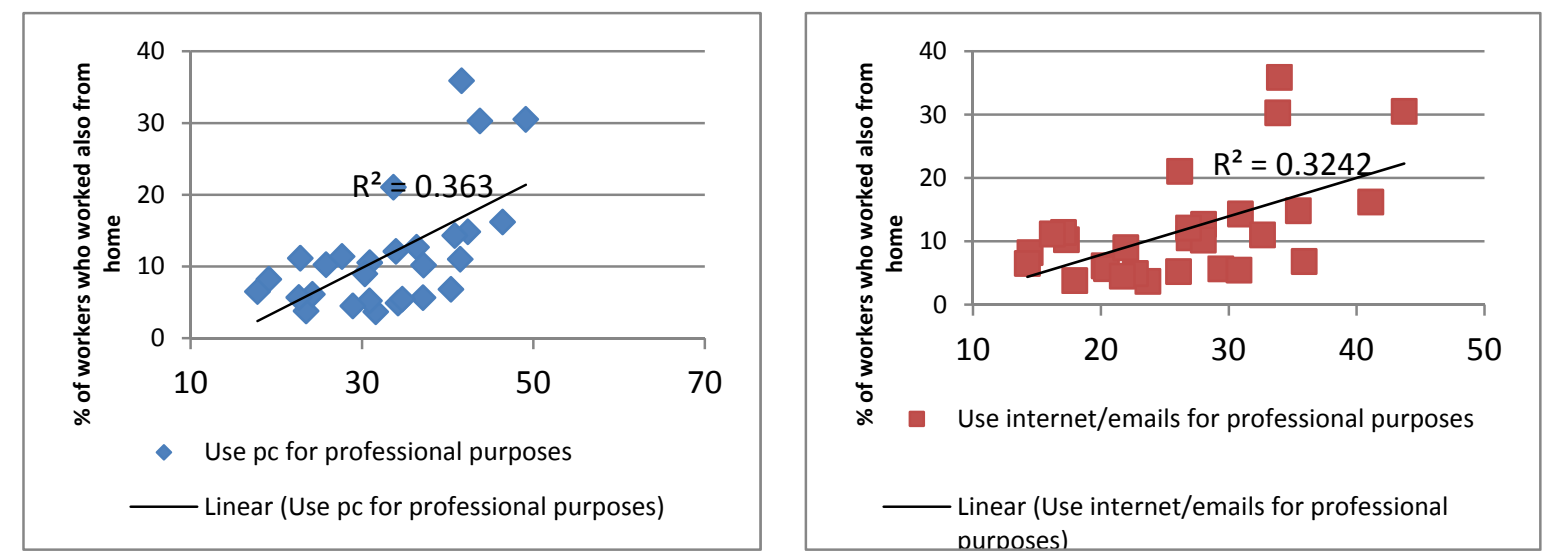

Sources: Authors' own elaboration based on data from the $5^{\text {th }}$ European Working Conditions Survey (Eurofound, 2010a) and Eurostat.

Arundel at al. (2007) emphasise that "broadband connections also increasingly allow people to carry out tasks at times and places they could previously not. For example, people can make phone calls and check their e-mail while travelling or while waiting. As some say, "the professionals are going Bedouin", facilitated by a corporate culture which is increasingly output-oriented rather than location- or time-oriented". ${ }^{3}$

A strand of the literature argues that workplace re-organisation plays a significant role in rising productivity (Lynch, 2003 and Pozzoli, 2010) and keeping turnover and absent rates lower (Heywooda, et al. 2008). In an early article on telework, Westfall (2004) chops up the different channels in principle responsible for the increase in labour productivity: hours or amount of work, intensity and efficiency of work. In terms of hours, there would be a gain only if the time normally spent travelling is used to work. In terms of intensity and efficiency, labour productivity would increase for those who can concentrate better far away from the distractions of the office or in schedules different from 9 to 5 . He concludes that part of this gain would probably be balanced out by the expenses for equipment and training (ibid.). On this basis, the author concludes that if telecommuting coincided with a true increase in productivity, then many more companies would have adopted it and made it compulsory.

Nonetheless, statistics contradict this view and show that telework and flexi-time are positively related to productivity: the countries with higher levels of productivity are also those where flexi-time and telework are spread more widely across workers (correlation coefficients respectively equal 0.59 and 0.44 ).

\footnotetext{
${ }^{3}$ Broadband and the economy.
} 
Figure 3. Workplace innovation and productivity
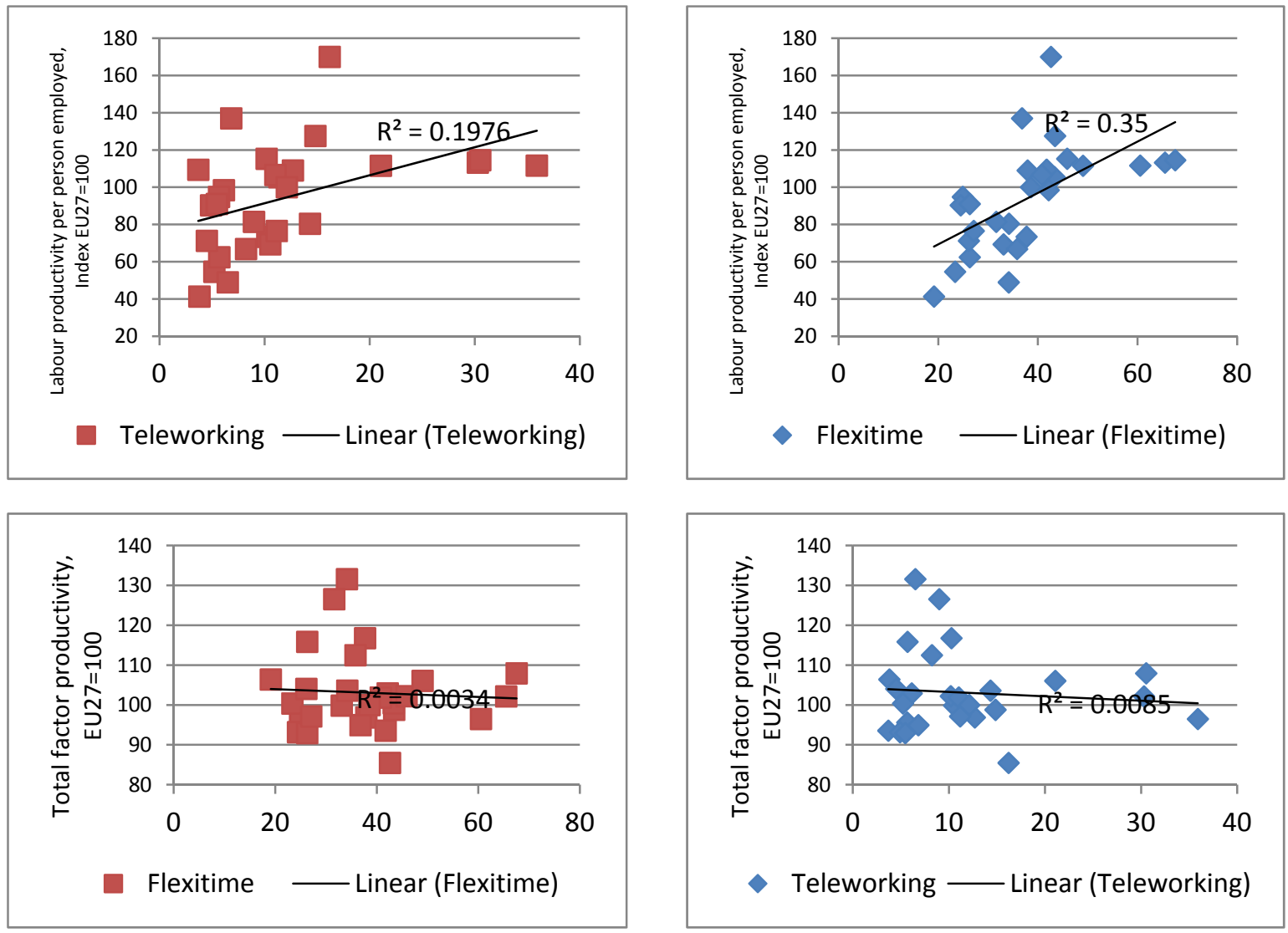

Sources: Authors' own elaboration based on data from the $5^{\text {th }}$ European Working Conditions Survey (Eurofound, 2010a) and Eurostat.

Evidence on total factor productivity (TFP) instead is more mixed: the correlations' coefficients between TFP in 2010 and each potential characteristic of workplace innovation alternate between minus and plus, but they tend to stay low and negative on average. This is puzzling because the principle behind workplace innovation is to allow a better combination between human and physical capital. As a consequence, those countries where participative practices are more widespread should be the same as those with higher total factor productivity. One explanation for this anomaly is that a number of factors influence TFP and therefore no strong evidence can be drawn from limited cross-country correlations.

Workplace innovation also has an environmental appeal: Ruth \& Choudhury (2008) confirm the expectation that telework could significantly contribute to savings of fuel, reduced carbon emissions and the outflow of jobs overseas and increased productivity, inter alia. Yet, they conclude that even the expected impact on productivity and real estate savings alone could more than justify the investment. Along the same lines, a new report by PWC (2011) analyses the benefits of teleworking for Dutch society. Taking into consideration CO2 emissions, noise nuisance, traffic accidents and maintenance of the infrastructure, PWC calculate that the benefits to the environment and health can be valued at between $€ 58.5$ million and $€ 117$ million in 2015. More teleworking will reduce emissions due to less traffic intensity and will also lead to less home-work travels, which in turn will reduce noise nuisance. Other effects will concern the reduction of traffic accidents and the cost for maintaining the infrastructure (e.g. repairing of roads).

This is not a common view: Horvath (2008) underlines that important parameters such as telecommuting frequency, characteristics of the office and home space, climate patterns and 
rebound effects that determine external costs along with the price of gasoline, electricity and natural gas can greatly influence the final results, and should be carefully examined.

In exploring the benefits of WPI, some authors point to the higher job satisfaction associated with increased autonomy over tasks and a flexible work system (Bauer, 2004). Flexibility is a highly heterogeneous concept and should not be adopted as a general policy but rather be targeted to the features of the staff and the organisation. As Origo \& Pagani (2008) observed, there is a positive link between functional flexibility and job satisfaction and either no effect or a negative impact of quantitative flexibility. The effects of innovative work practices can be different among workers; job rotation may provide opportunities for some workers while simply intensifying work for others. Different effects may exist as well on management practices; establishments that adopted job rotation programmes tended to have a greater earnings inequality while those with self-managed teams had a smaller inequality (Shin, 2008).

Flexi-time has also an indirect impact on the employment rate: if workers and especially female workers have more freedom to set working schedules around other commitments, they will more easily be able to supply labour. As a confirmation, we detect a positive relationship between flexi-time and work-life balance and between work-life balance and employment rates (see Figure 4). However it is difficult in this case to detect what causes what: on the one hand, the possibility of working with flexible schedules attracts more people into the labour market, especially women and elderly. On the other hand, their presence in the labour market may be a driver for the higher demand of flexible schedules.

Figure 4. Workplace innovation and work-life balance
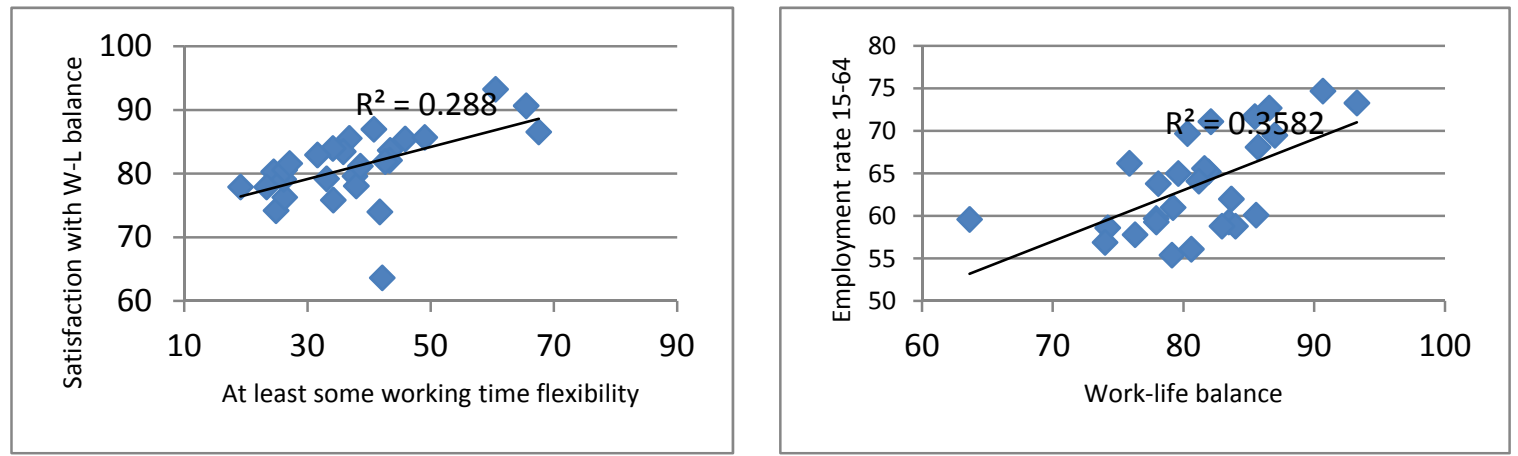

Source: Authors' own elaboration based on data from the $5^{\text {th }}$ European Working Conditions Survey (Eurofound 2010a).

As documented in the review of the literature, the functional elements of WPI offer tools to foster creativity and to let ideas emerge from the bottom. Groups with more complex tasks, i.e., having task variety, autonomy, team-specific goals, and feedback, had higher values on team climate for innovation than groups with more restrictive task structures. Firms with decentralised decision-making, information-sharing programmes or incentive pay plans are more likely to innovate than others (Zoghi et al., 2007). They also reported more innovative behaviour and affective organisational commitment and tended to be more satisfied (Antoni, 2005).

We find a confirmation of this relationship in the positive correlations between measures of innovations, like R\&D investment as a percentage of GDP and the share of companies that innovate and practices to increase employees' and teams' involvement. Figure 5 plots the degree of employee and team autonomy with investment in R\&D and the number of patent applications to the European Patent Office per million of labour force. The positive relation is 
justified by Kristiansen \& Bloch-Poulsen (2011) as follows: independently of his/her education, every employee has an innovative potential, which is more likely to be stimulated with a certain type of teamwork. Petra \& Czarnitzki (2012) also confirm that not only managers' ideas but also the ideas of non-managerial employees have a significant impact on employee performance, especially in small companies. This is probable due to the fact that a direct interaction with customers can lead to improvements in the product.

Figure 5. Workplace innovation and RED investment
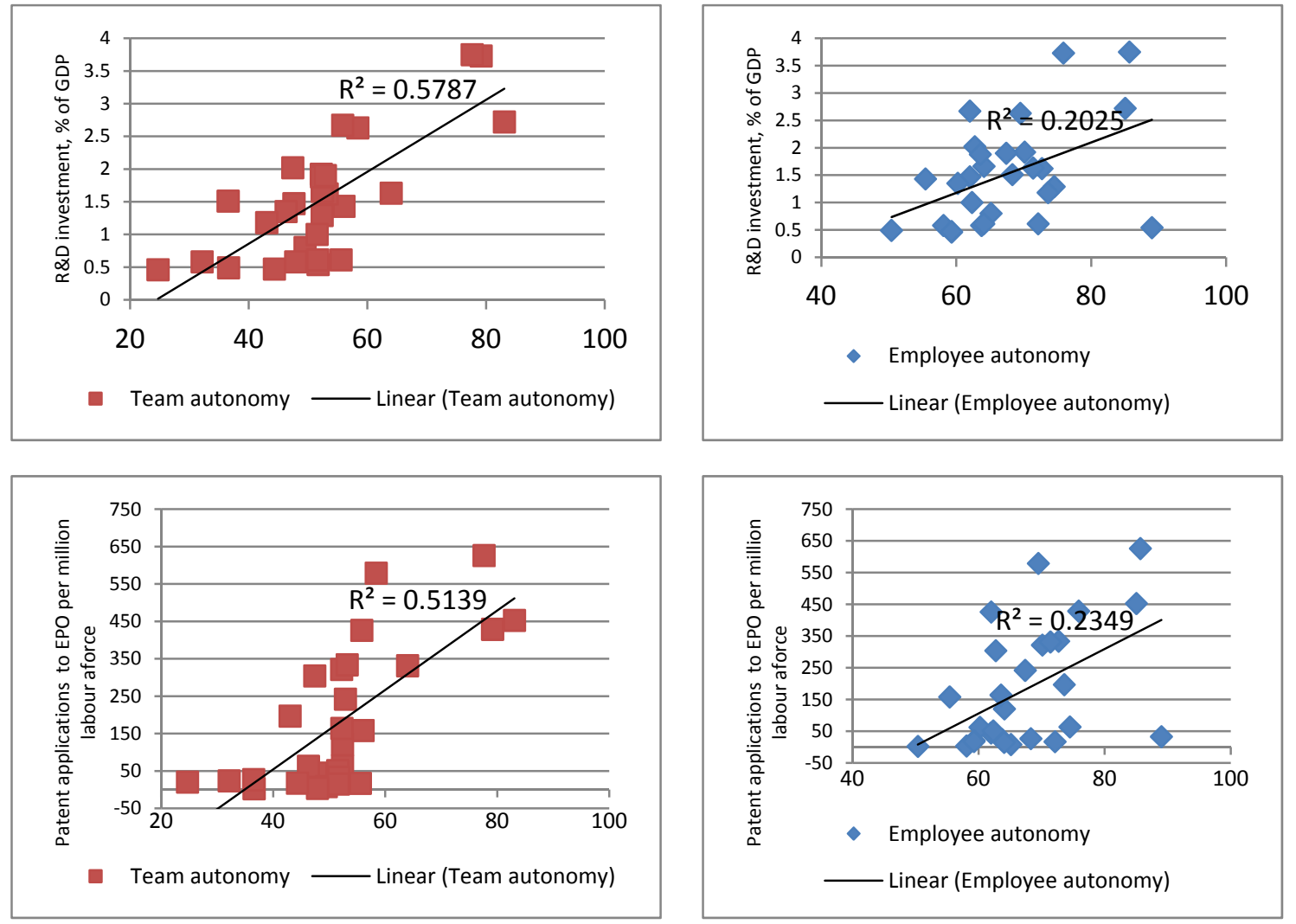

Sources: Authors' own elaboration based on data from the $5^{\text {th }}$ European Working Conditions Survey (Eurofound, 2010a) and Eurostat.

More in general, one can say that there is a strong correlation between the introduction of new technologies and the reorganisation of the work structure. Even if we cannot say what the trigger is, it occurs that new processes run in parallel with substantial restructuring of firms. We find confirmation of this tendency in EWCS statistics where organisations that underwent a strong restructuring are also those that innovate more in terms of products. 
Figure 6. Workplace innovation and product innovation

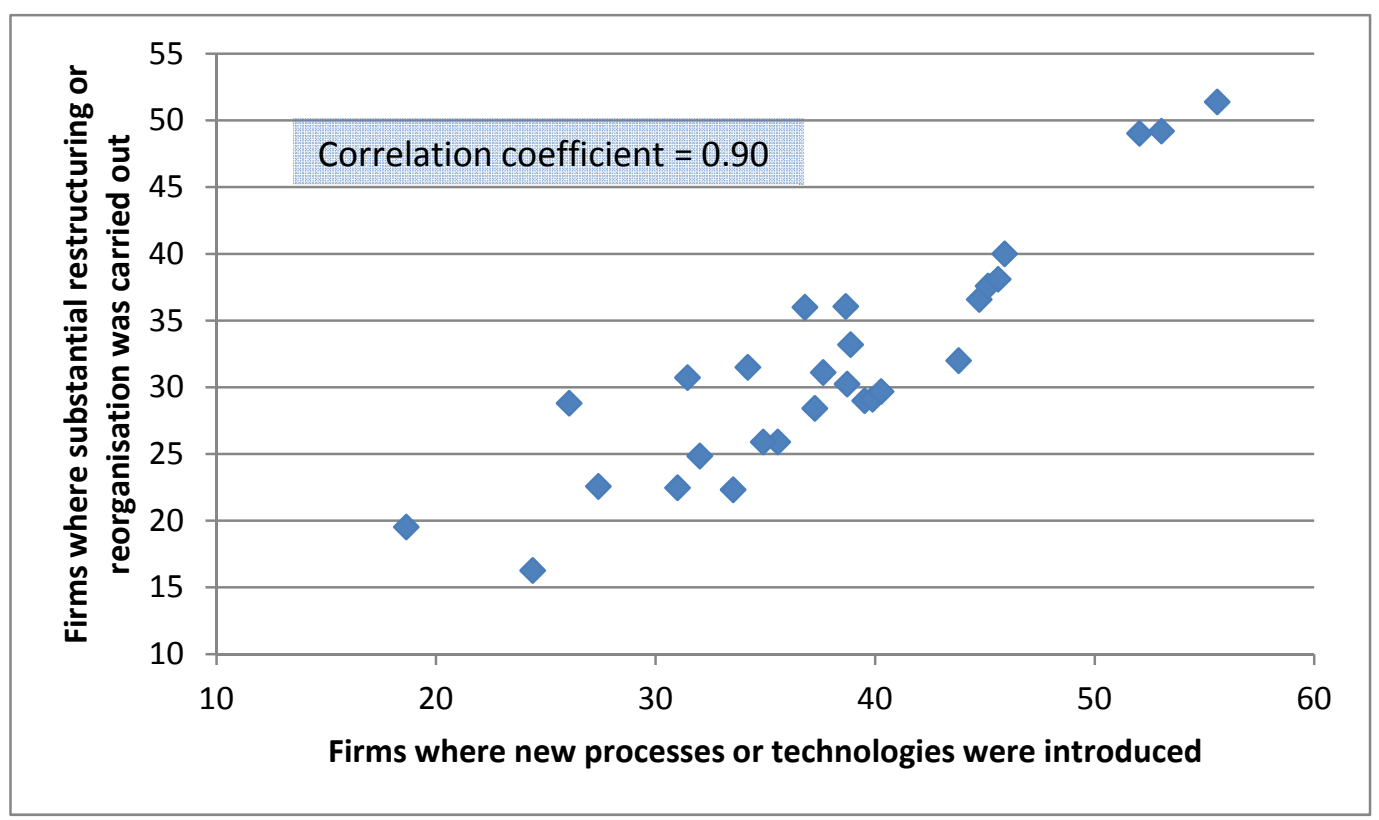

Sources: Authors' own elaboration based on data from the 5th European Working Conditions Survey (Eurofound, 2010a) and Eurostat.

All correlations between the above-mentioned economic variables and elements of workplace innovation are summarised in Table 1. On average, all variables are positively correlated to each other (with the exception of team work): more workplace innovation therefore goes hand in hand with higher recorded innovation, employment rates, productivity and work-life balance. Some features of innovative workplaces have a stronger impact: telecommuting, flexi-time and team autonomy. Whereas employee autonomy, employee empowerment and flat hierarchies have the lowest impact.

To sum up, the strongest linear relationship is represented by patent applications and flexitime (0.81), while for telework the most positive links are with employment (0.75) and broadband penetration (0.78).

Table 1. Correlation coefficients: Workplace innovations and macroeconomic variables

\begin{tabular}{|c|c|c|c|c|c|c|c|c|c|c|}
\hline & & $\begin{array}{l}\text { Flexiti } \\
\text { me }\end{array}$ & $\begin{array}{l}\text { Tele } \\
\text { work }\end{array}$ & $\begin{array}{l}\text { Alterna- } \\
\text { tive pay }\end{array}$ & $\begin{array}{l}\text { Flat } \\
\text { hierc. }\end{array}$ & $\begin{array}{l}\text { Employee } \\
\text { empow. }\end{array}$ & $\begin{array}{l}\text { Employee } \\
\text { autonomy }\end{array}$ & $\begin{array}{l}\text { Team } \\
\text { work }\end{array}$ & $\begin{array}{l}\text { Team } \\
\text { autonom } \\
y\end{array}$ & $\begin{array}{c}\text { Task } \\
\text { rotation }\end{array}$ \\
\hline \multirow[t]{2}{*}{$\begin{array}{l}\text { Producti } \\
\text { vity }\end{array}$} & $\begin{array}{l}\text { Labour productivity per } \\
\text { person employed, Index } \\
\text { EU27 }=100\end{array}$ & 0.59 & 0.44 & 0.32 & 0.22 & 0.41 & 0.32 & 0.05 & 0.35 & 0.24 \\
\hline & TFP, EU27=100 & -0.06 & -0.09 & 0.17 & 0.04 & -0.39 & -0.33 & 0.01 & -0.01 & -0.13 \\
\hline \multirow[t]{2}{*}{$\begin{array}{l}\text { Infrastruc- } \\
\text { ture }\end{array}$} & $\begin{array}{l}\text { Broadband penetration } \\
\text { rate }(\%)\end{array}$ & 0.71 & 0.78 & 0.46 & 0.52 & 0.59 & 0.63 & 0.45 & 0.65 & 0.55 \\
\hline & $\begin{array}{l}\text { Level of Internet access of } \\
\text { households, \% }\end{array}$ & 0.73 & 0.73 & 0.62 & 0.50 & 0.39 & 0.58 & 0.45 & 0.74 & 0.45 \\
\hline \multirow[t]{3}{*}{$\begin{array}{l}\text { Inno- } \\
\text { vation }\end{array}$} & R\&D invest & 0.73 & 0.72 & 0.54 & 0.42 & 0.29 & 0.45 & 0.46 & 0.76 & 0.48 \\
\hline & $\begin{array}{l}\text { share of innov firms in } \\
\text { total }\end{array}$ & 0.38 & 0.37 & 0.11 & 0.24 & 0.38 & 0.36 & 0.24 & 0.40 & 0.29 \\
\hline & $\begin{array}{l}\text { Patent applications to the } \\
\text { EPO per million labour } \\
\text { force }\end{array}$ & 0.81 & 0.72 & 0.52 & 0.43 & 0.28 & 0.48 & 0.44 & 0.72 & 0.50 \\
\hline $\begin{array}{l}\text { W-L } \\
\text { balance }\end{array}$ & & 0.54 & 0.66 & 0.37 & 0.52 & 0.28 & 0.29 & 0.53 & 0.66 & 0.45 \\
\hline $\begin{array}{l}\text { Employ- } \\
\text { ment rate }\end{array}$ & total & & 0.75 & 0.45 & 0.45 & 0.42 & 0.27 & 0.34 & 0.47 & 0.62 \\
\hline & female & 0.57 & 0.71 & 0.46 & 0.56 & 0.26 & 0.16 & 0.48 & 0.55 & 0.61 \\
\hline Average & & 0.56 & 0.58 & 0.40 & 0.39 & 0.29 & 0.32 & 0.34 & 0.53 & 0.41 \\
\hline
\end{tabular}

Sources: Authors' own elaboration based on data from the $5^{\text {th }}$ European Working Conditions Survey (Eurofound, 2010a) and Eurostat. 
All in all, we can conclude that the extent of individual workplace innovation at the country level is correlated or strongly correlated with labour productivity, internet and broadband penetration, R\&D expenditure and outputs as well as work-life balance.

In other words, there is a strong correlation between a country-level presence of various aspects of workplace innovation and technological and economic progress. Of course, and this is a very important caveat, correlation does not prove causation. Nonetheless, it seems safe to conclude, and we come back to this point later, that workplace innovation and several other phenomena tend to evolve together as a package at the country level.

\subsection{Evidence from the case studies}

In this section, we review evidence from the six case studies that were conducted as a part of the research. To facilitate understanding, we briefly introduce the subjects of the case studies below (see also Annex 1).

- $\quad$ FPS Social Security, Belgium's social security agency, with 1,302 employees, including 337 independent contractors and 965 statutory employees. In recent years, FPS has implemented several forms of workplace innovations: teleworking and the possibility to measure work on the basis of performance instead of working hours. These two main initiatives have been accompanied by the digitalization of the processes and the creation of a new working space with dynamic offices and clean desks.

- The Open University, a distance learning and research university founded in 1969 by the Royal Charter in the United Kingdom. OU today has more than 260,000 students and a total income for the year 2009-10 of $£ 450.1$ million. The Open University uses information technology not just to attract and retain students, but also to recruit teachers without the constraints of geographical boundaries.

- Oticon, a Danish hearing aid company founded in 1904 as an importer of hearing aid devices from the United Kingdom. At the beginning of the 1990s, unique organisational changes took place in response to a crisis invoked by the difficulty to move from indiscrete behind-the-ear devices to discrete in-the-ear devices facilitated by technological innovation. The company was comparably smaller then and had around 1,000 employees and the organisational changes described herein concerned approximate 130 workers in the Copenhagen headquarters. Today, Oticon is part of the limited company William Demant Holding and is listed on the Copenhagen Stock Exchange.

- Slovak Governance Institute (SGI), a leading think tank in the areas of education and social policy, good governance and public administration. It has also implemented a series of consultancy contracts, usually funded from multilateral or bilateral aid agencies, in the Western Balkans, the Caucasus and other European countries. SGI/GI has been under severe financial constraints. These factors together led to the development of a unique organisational model based on the utilisation of free or lowcost IT for telework and staff empowerment.

- Netherlands or the part-time economy model. Part-time employment is significantly more prevalent in the Netherlands compared with other European countries. The availability of a rich menu of contracts provides for flexibility whereas attaching social security, supplementary pension and other benefits forms the security part of the 'flexicurity' system. In addition, the pay differential (controlling for the number of hours worked) is relatively small once differences in sectors, occupations and seniority are taken into account. The several pieces of legislation that led to this equilibrium occurred 
in a totally un-strategic fashion making the Netherlands a case of unintended innovation. Yet all this became crucial for bringing the participation of women in the labour force to the highest level.

- TEKES, a government R\&D programme in Finland for promoting both time productivity and quality of working life in public and private workplaces by providing funds and knowhow. Run by the Finnish Funding Agency for Technology and Innovation, the development projects start on the initiative of the workplaces themselves. The minimum requirement is the joint participation of management and employees in the implementation. A group representing both has been established to monitor the implementation. A guiding principle is to avoid financing 'quick fixes' of firms in trouble but rather to pave the way for a long-term fruitful cooperation between management and employees (Alasoini et al., 2010).

\section{Figure 7. Case studies}

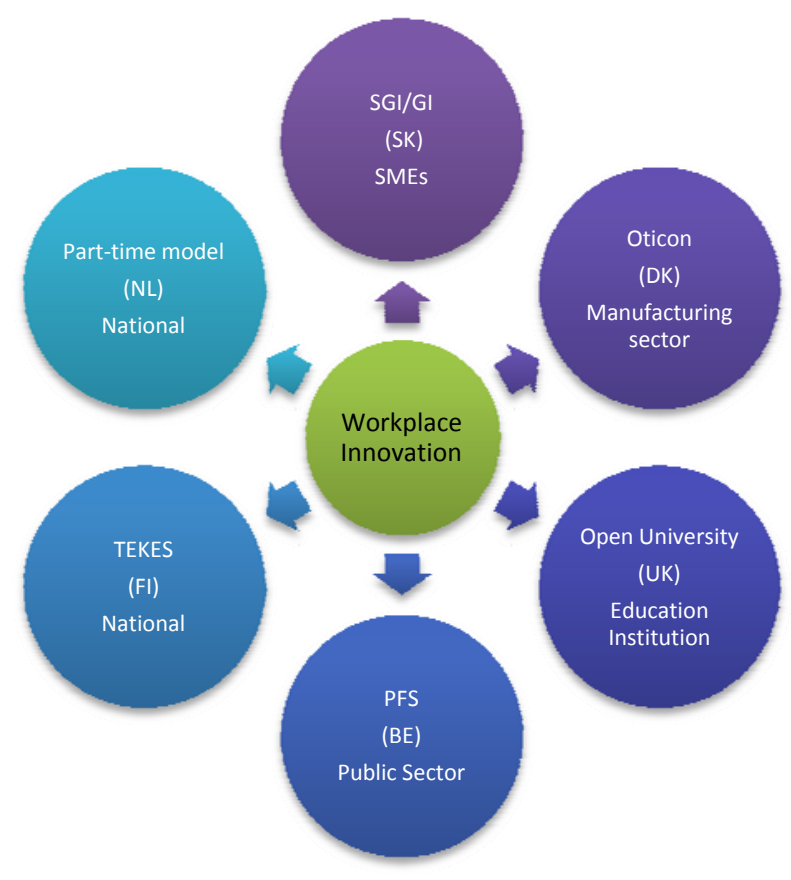

The case studies both confirmed and shed new lights on the positive outcomes of workplace innovation.

The case study on TEKES indicates that, in terms of macroeconomic results, there is no tradeoff between higher performance and employment/quality of life. More specifically, Ramstad (2009) provides an analysis of a survey administered to companies involved in the TEKES project in the period 1996-2005. She clearly concludes that "performance and the QWL \{quality of working life\} can be improved concurrently, and using the same workplace practices. So, there is no need to execute separate projects for improving one or the other". In $70 \%$ of the 409 projects analysed there was indeed a positive association between improvements in the two areas. In another study, Ramstad (2005) conducts an extensive analysis of the self-assessment survey distributed to all participants in the project (whether managers, staff or experts) over the period 1996-2003. She aggregates questions about performance and quality of working life and creates one indicator for each. For the first area, the variables considered are: a) quality of products and services, b) flexible customer service, c) labour productivity, d) smoothness of operations, and e) quality of operations. For QWL: a) cooperation between management and staff, b) team-based working, c) social relations, d) 
mental well-being and e) development of professional skills. The scale goes from 1 to 5 , with 5 indicating the best performance and QWL. Averages are reported in the table below.

Table 2. Self-assessment of changes in performance and QWL

\begin{tabular}{|lll|}
\hline & Performance & QWL \\
\hline Management & 3.92 & 4.06 \\
\hline Staff & 3.72 & 3.7 \\
\hline Experts & 3.97 & 4.13 \\
\hline Total & 3.87 & 3.95 \\
\hline
\end{tabular}

Sources: Ramstad (2005), in Alasoini al. (2005)

It can be observed that the scores are closer to the top than to the bottom, signalling general satisfaction, and they are slightly higher for the QWL index. It is interesting to note that managers' answers are more positive than those of staff. The author observes this everywhere in the survey and offers several possible explanations: one is that management was more deeply involved in the transformation of the work environment and thus may have had a biased impression. Also, management wanted to look good in case of other requests for funds. In other cases it is possible that the results of the change were not disseminated to all staff. More importantly, Ramstad (ibid.) finds a general positive correlation between the two indicators (0.5), with a more marked result for the third and municipal sector and lower for the private service sector and industry. The author confirms the positive relation also by observing that almost three-quarters of the respondents attributed a value of greater than 3.5 to both indicators at the same time.

Regression analysis conducted on the data explains what contributes to a better performance and QWL: Ramstad (ibid.) observes that, although limited, expert advice and internal cooperation are important to achieve successful completion of the project.

Aside from productivity enhancement, another element of general and macroeconomic interest is employment: does WPI contribute to job creation? The survey conducted within the TEKES framework sheds some light on this question. The data make a distinction between the short and long term. In the short term, approximately 7 out of 10 respondents declared that it had no effect on staff numbers. Among the remaining ones, 13-14\% reported an increase and $4-5 \%$ a staff cut. In the long term, proportions change: the 'no effect' category goes down to around $20 \%$, the staff increase reaches $23 \%$ in the first period and $28 \%$ in the second, and a staff decrease was reported by respectively $10 \%$ and $5 \%$. A new category was added, which captured most of the long-term effect: approximately $40 \%$ of the respondents declared indicated that they secured their current jobs thanks to the sustainable productivity projects. 
Figure 8. Workplace innovation, impact on employment

SHORT TERM

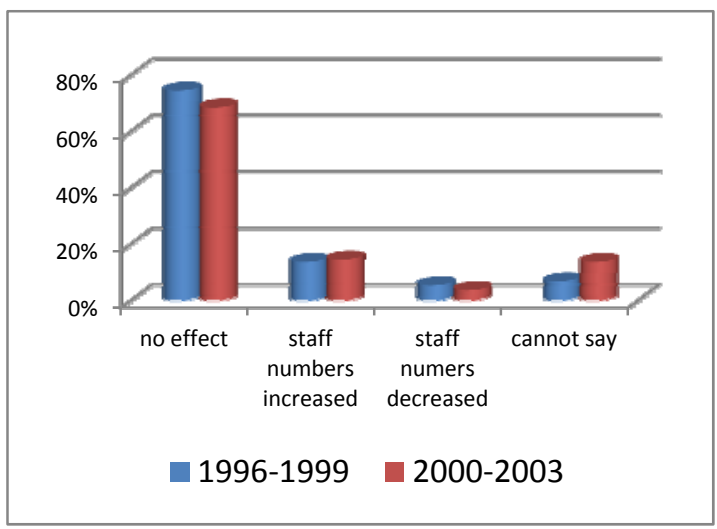

LONG TERM

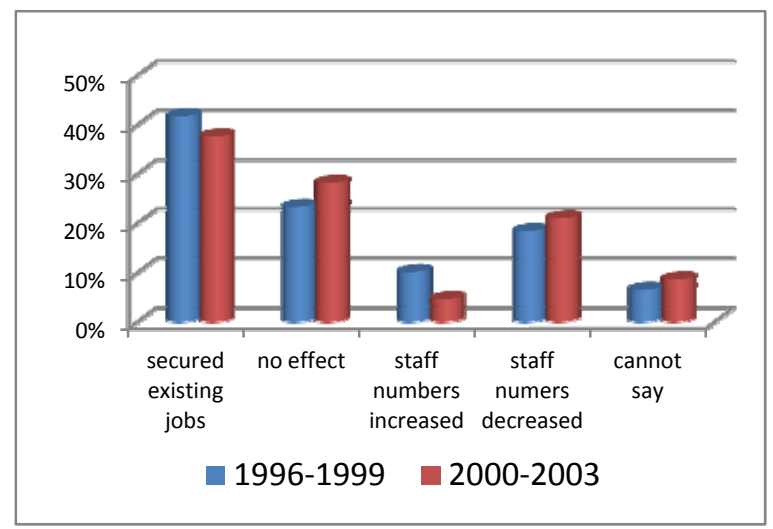

Sources: Ramstad (2005), in Alasoini al. (2005)

All in all, therefore, it can be argued that the balance in terms of jobs is largely positive as far as TEKES project is concerned.

The case study of FPS Belgium confirms that new organisational practices have a positive impact on productivity and improve work-life balance. According to an internal survey conducted within one of the main FPS units (the DG responsible for disabled people), since the adoption of workplace innovations in 2009, the DG increased its productivity by $20-22 \%$. According to an internal survey done in 2010 just on teleworkers, 91\% of the staff consistently evaluated themselves as more productive and $77 \%$ of the project leaders evaluated the staff members as more productive. Teleworking has a positive effect as well on team spirit and work-life balance: $91 \%$ of FPS teleworkers answered that they were under less stress, more committed and had a better balance between their private lives and work. In the internal survey conducted in 2011, the perception of the work-life balance among teleworkers remains constant (around 90\% replied positively). Even if results from the two surveys cannot be directly compared because different questions were asked, a positive trend is observed concerning job satisfaction and autonomy.

It is important to observe that FPS not only consulted and actively involved external experts before adopting WPI practices but also adopted a transparent approach. The new office policies (clean desk; dynamic offices) were the object of a showcase on a group of 40 employees: the positive results demonstrated to the FPS staff the feasibility of the dynamic office system and helped to learn how to improve the future work environment.

The management applied a transparent and open means of communication where the personnel were regularly updated and even consulted on the ongoing and upcoming reforms. 
Figure 9. Self-assessment of productivity at FPS Belgium - positive answers

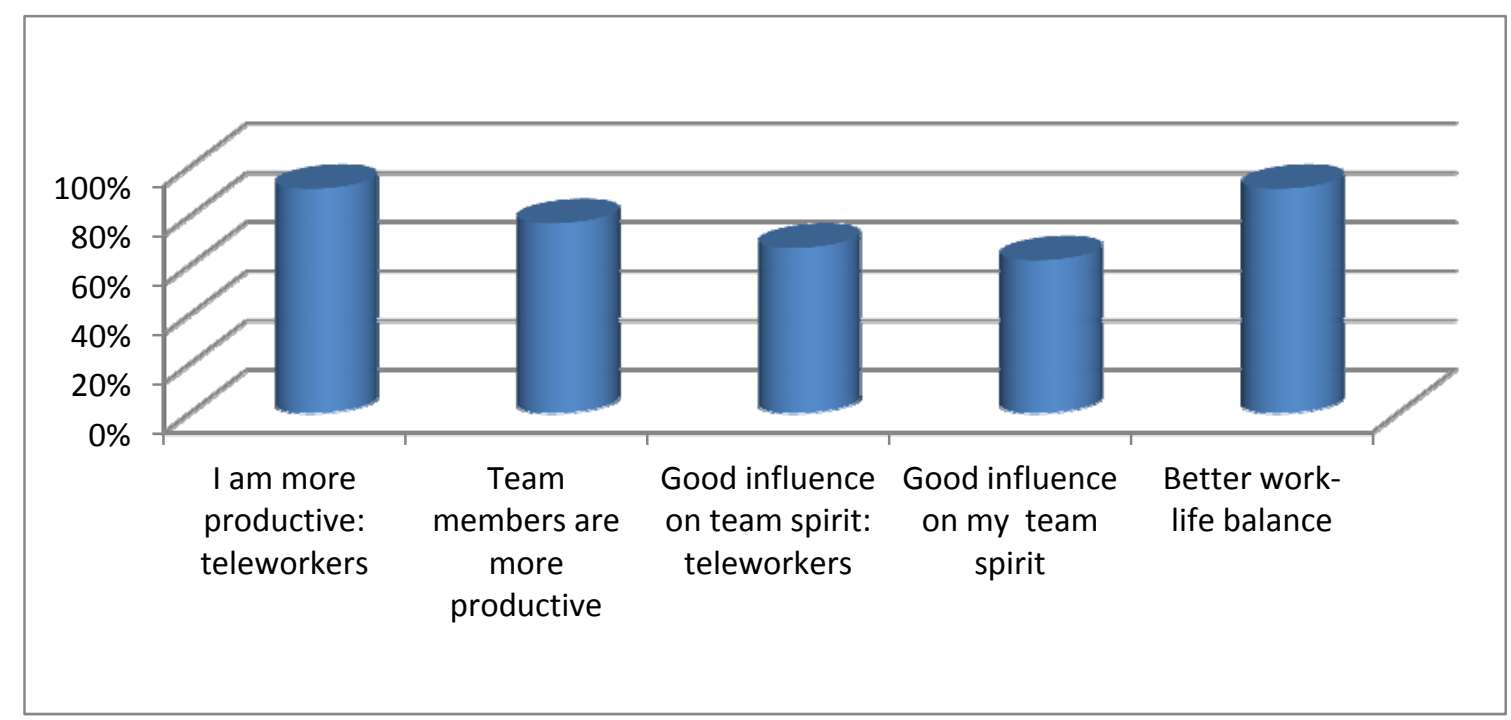

Source: Internal Survey (only teleworkers and their leaders), FPS Belgium 2010.

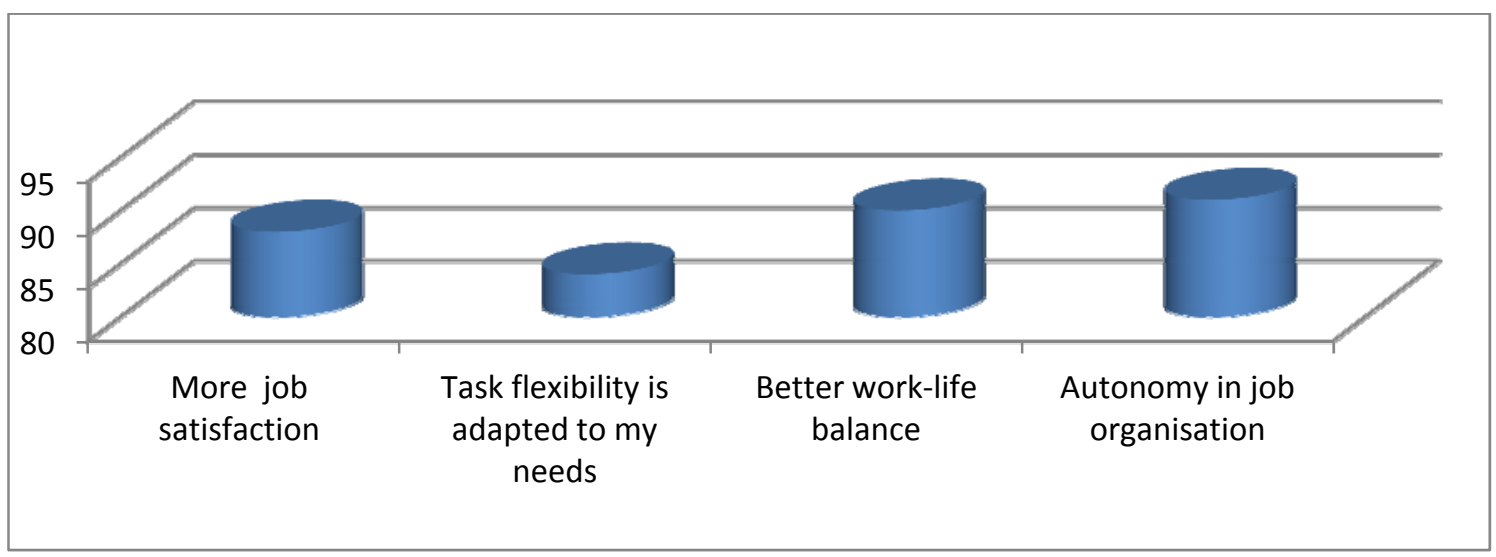

Source: Internal Survey (all staff involved), FPS Belgium 2011.

In the Oticon case, we observed that new technology that revolutionises the form and scope of work can be implemented on a large scale within a short period of time without impeding financial results. While it is difficult to know what portion of the subsequent success of Oticon should be attributed to the complete re-organisation and re-location of the headquarters, it is relatively clear - given the market for hearing aids at the time - that the transformation did not contribute negatively to Oticon's performance.

From the case study analysis we can deduct that innovative workplace practices do not negatively influence performance and their adoption is often accompanied by increased job satisfaction.

\subsection{The Drawbacks of WPI}

There is no common view in the literature on the effects of WPI. The general perspective is positive, but some authors found that isolation among teleworkers is associated negatively with job performance (Golden et al., 2008). Humans are social beings and interaction is an essential part of their health.

Higher job satisfaction practices, such as additional learning possibilities, task complexity and high levels of autonomy, lead to an increased level of stress, work pressure, increased workloads, job insecurity and less-work life balance (Eurofound, 2011). In this regard, Zoll 
(2004) remarks the paradoxical aspect of these new forms of work organisation. It was trade unions that, based on the critique of 'Taylorism', requested more autonomy and control over their tasks, which was welcomed by managers. At the end, also this brought new challenges and threats for the employees: risk of burn-out, necessity to rethink workers' rights and job security.

According to Kalmi \& Kauhanen (2008), if on the one hand workplace innovation gives the possibility to obtain a higher income, more interesting work, higher job discretion and better employment security for less-skilled employees, these benefits come at a price. More critical authors argue that workplace innovation may lead to negative worker outcomes such as stress and increased workload. Ramsay et al. (2000) adopt the view that workplace innovations are implemented to improve performance, but that better performance may be achieved at the expense of employees, and Handel \& Levine (2004) even refer to them as "management by stress". The Karasek Demand-Control Model (DCM) provides a consolidated theory to explain employee well-being in the work context. According to the DCM, it is important to keep a balance between demands in the job (i.e. workload) and the level of autonomy over that job (Verhofstadt et al., 2007). A job with a high workload and low autonomy (a 'high strain job') is supposed to be stressful, whereas a high demanding job with a lot of autonomy (an 'active job') results in learning opportunities. The difference between the two conditions is that, whereas an active job leads to new learning and challenges, to a sense of mastery and self-efficacy, the second one creates a high stress job (Karasek, 1979).

Asked about work well-being, most workers at SGI/GI felt that their personal and professional lives sometimes overlapped, but that the problems could be solved and they did not perceive it in absolute negative terms.

One respondent claimed, that while he/she enjoys the work, the privacy issues do not matter that much. To limit the risk of confusion between work and private life, five out of 13 respondents $(38.5 \%)$ did not have a special rule or set of rules for work/time management. The remaining $61.5 \%$ had some personalised tool or rule, such as:

o "I have a 48 hour rule: if possible I do not work Fridays to Sundays between 5 and 8 pm."

o "I go offline."

o "I try to stick to my plan and also stay out of Facebook because I want to spend more time with people 'live', I also do not have mobile app for Skype so that I am not forced to react on every single action."

o "Create personal and professional social network accounts and email addresses."

The ICT Department of FPS Belgium faced an increased amount of workload probably due to the more demanding network infrastructure (VPN) that was set up after teleworking and other flexible work practices were adopted.

In the case of Oticon, the disappearance of a traditional career path along with the traditional hierarchical symbols was reported as clearly causing problems for some employees. Every Oticon employee was a potential co-worker on a project, and while it previously might have worked to show his capabilities to his next level-manager, it was now necessary to 'market' these skills to a wider circle of potential project managers and co-workers.

Another kind of criticism that has been put forward is that the 'ideas marketplace' created incentives to lobby to be assigned to potentially successful or prestigious projects. This might have been enhanced by the lack of more formal hierarchical symbols, whereby being on the 
projects receiving the most senior management attention was a way to cement one's standing in the internal hierarchy. Some of the effort going into lobbying, making sure one became attached to a 'good' project and avoided the bad ones may have made up for the potential extra resources being available from freeing up the bureaucracy.

As pointed out above, a flexible-type organisation is not without its own problems. In this regard, it is important to note that FPS Belgium took a proactive approach, adopting a riskmanagement process. Three out of the four employees interviewed replied that this initiative was a key element in identifying potential problems and mitigating the eventual costs of the transition.

\subsection{What is the role of technology?}

With respect to workplace innovation, technology can be considered as both an input and an output. We use output in the sense shown in the previous section where we argued that participative practices enhance innovation and productivity. At its core, the idea is that innovation is not exogenous to workplace innovation. But technology is also an input, which, in combination with certain HR practices and appropriate skills, can create a better quality of working life. In this section we deal with the following question: Is technology a necessary and sufficient condition for the diffusion of high performance workplace systems?

A key and clear message from the case studies is that technology is not the only factor that shapes the change. It is certainly not a sufficient condition: it is not enough to provide all employees with laptops and smart phones and wait for the change to happen. In some cases (like in the Netherlands) it is not even a necessary condition. Yet technology remains an important factor in the sense on the one hand that it acts as a facilitator, an enabler (like in the case of FPS Belgium), and on the other hand, in some cases, it is indispensable for the development of certain institutions like the Open University and SGI/GI, as we know them now.

Among the cases mentioned above, how many of them would have materialised in the absence of technological change?

As an early mover, the case of Oticon is extremely helpful for understanding the important role played by technology. In 1990-91, it decided to become a 'paperless office'. Since every employee should have access to all information and be ready to physically move within the organisation within five minutes, the IT requirements were huge given the level of technological development at that time. In addition, a network was used for organising projects: submitting, showing interest in and sharing ideas. Also, an internal email system and distributed groupware for managing projects and sharing material within projects was in place. Hardware and software requirements were on the cutting edge of technology. In fact, Oticon was rejected by several software vendors with the message that the specified requirements simply could not be met. Consequently, the IT-related investments were large, according to Lars Kolind, Oticon's CEO at the time, most probably the largest investments ever in untested technology. He had a firm grasp on what present-day technology could achieve from his previous position as Director at Risoe, the former Danish nuclear research centre. He credits the successful implementation of the IT side to the ability of Oticon to hire staff with cutting-edge knowledge of what was and was not doable.

The importance of the staff's ability to assimilate new technology is also strongly acknowledged in the SGI/GI case. The staff questionnaire revealed that, although the level of active use varied, most workers were familiar with all the tools they were asked to use, such as joint calendar scheduling (Google Calendar, Doodle), joint document production (Google Docs), document sharing (Google Docs, Dropbox), use of social networks for professional 
purposes (Facebook, Twitter), instant messaging (ICQ, Skype, Facebook Chat), free videoconferencing (Skype), project management (Basecamp) and survey tools (Surveymonkey). The fact that the average age of SGI/GI staff is very young surely plays a role in the sense that most young people are familiar with these tools. According to Gagliardi (2011), however, what matters even more is the age of an organisation's executives: information technologies have higher chances of being implemented the younger the management team. This was and still is the case at SGI/GI, where the average age of senior partners never exceeded 35.

Most importantly, given the impossibility to hire an ICT expert and the obligation to keep overhead costs to a minimum, what matters, together with the skills of the workforce, are:

0 the availability of those tools for free or for a very low price and

0 their user-friendliness.

Although in broader terms, the relevance of the ICT skills endowment of the workforce also emerges from the analysis of the TEKES programmes. The challenge in the case of Finland has come indeed more from the human resources management side because the labour force was already quite technologically skilled. Arnkil (2003) finds in fact that the UNDP Human Development Report of 2001 identifies Finland as the most technologically advanced country among the 72 analysed.

The Finnish case study also emphasises the role of technology not only as a tool of the transition to new ways of working but also as a product. Technological change and innovations are not perceived in the traditional neoclassical sense as random, exogenous factors but rather as an endogenous development. As change agencies, firms can influence their own future by engaging in a complex learning process, long-term multi-dimensional interaction and networking. Highly developed learning strategies will give companies a competitive edge, and thus directly or indirectly also secure or enhance positive employment development" (Arnkil, 2003).

Although insufficient on its own, technology remains a fundamental condition for some of the cases we look at in this report. It is true that the Open University, for instance, already existed in the 1970s with an enrolment of 25,000 students, but without technology allowing for mass and efficient distance learning, it would not be as we know it today: the leading university institute on distance-learning with students from many countries. The OU has always pioneered the use of new technologies for studying. Staff at the OU started to use CoSy, an asynchronous text-based communication application, in 1986. By 1988, the University had a Personal Computing policy and had introduced three courses that required the use of a computer. Since 2000, the OU has explored the opportunities of using the internet and made the use of the internet a compulsory element in a course. This led to the openness of the university and to the OU making its materials readily and freely available to a global student body. As a result, OU today has more than 260,000 students and a total income for the year 2009-10 of $£ 450.1$ million.

Thomas et al. (1998), speak as early as 1998 about a "holistic approach to integrating technology into the teaching process which addresses how to provide necessary functions in effective forms - some traditional, some new". They further observe:

Taking a holistic approach to the integration of the electronic tools into the existing administrative infrastructure has proven effective in this case, allowing a better integration of new systems with old than would have been possible piecemeal. Reviewing the whole process from multiple perspectives has paid off, allowing us to provide a relatively simple and economical system which is likely to scale up effectively, although, on the scale of 150,000 students, there is still real concern about 
managing demands on communications and about the consequences of system breakdowns. Supported Internet presentation is not a cheap option, but it may be one that can provide greater flexibility and can shift effort from mundane tasks (administrative details) to teaching. For example, administration is faster and more efficient with electronic assignments. Turnaround time is reduced; less paper is consumed; access to assignments and records is facilitated and automatic logging increases accountability.

Similarly for SGI/GI, most probably it would still exist as a consulting company but would probably take a different shape. It would perhaps look like a more traditional consulting firm with a dedicated building and larger dedicated staff also charging higher prices for its services. It would also operate in a small market, closer to its physical location in Bratislava without being able to reach up to Brussels or Budapest for instance.

More recent trends in work organisation, e.g. fragmentation and virtualisation of work, have to be read in light of this understanding of technology: an enabler but sometimes an indispensable one. For this purpose we provide in the next sections a (non-exhaustive) list and description of these technologies. There are three basic drivers behind phenomena like crowdsourcing, fragmentation and virtualisation of work. The first and perhaps the biggest is the invention of cloud computing. Next to it are the social networks of several types: from Facebook to more professional ones like Linkedin and Yammer. Third are collaborative software programmes (or groupware) to share files and information, project management tools and videoconferencing facilities (from Skype to Nefsis).

At the heart of all this innovation is the widespread diffusion of the internet and the possibility to access it constantly thanks to broadband and $3 / 4 \mathrm{G}$ connections. 


\section{Recent trends in the intersection between technology and WPI}

In this section we explore recent trends in workplace innovation. Academic literature is often scarce because most of these trends are very recent and still developing. For this reason it is not easy to fully capture which role technology plays and what will be its impact on the labour market once its potential is fully exploited. On the other hand it also interesting as well as challenging to explore them. We are talking about fragmentation and disaggregation of work and tasks, crowdsourcing and virtualisation of work. One feature we spot is the fact that some of these trends pull in opposite directions: on the one hand, labour organisation is entering the 'age of hyper-specialisation' and on the other workers are expected to be multiskilled because of task rotations. The same is true for 'teamisation' and individualisation of work. Both the literature and data cited in the previous sections showed the positive effect of the attribution of more responsibilities and independence to teams. Nonetheless this does not concern all workers because the technology available today at a reasonable cost allows working remotely and on very specific tasks, which risks isolating workers away from the general assignment. This trend involves at the same time different types of workers: those that choose to telework a certain number of days per month, a small but growing population of nomad workers and freelancers.

We provide in the following pages a picture of what we consider the most important and innovative trends in work organisation.

\subsection{Fragmentation and disaggregation}

Absorbed by and involved in current trends, we may tend to forget that changes in work organisation are not happening today for the first time. In his book, Greenbaum (2004) recalls:

In the second half of the nineteenth century, work and workers were moved from small farms and shops to increasingly large and centralized factories that were owned not by individuals but by corporations. Steam-powered factories and railroads and steamships and telegraphs were introduced into this pressure cooker of emerging industrial capitalism in order to speed up work, cut time, and increase productivity.

What may be different nowadays is the speed with which these changes occur. Because of this rapidity, it is difficult to track the most recent changes in the data. For this reason we use this section to outline them and describe them even though the state of their diffusion cannot be documented with figures.

The first trend we identify is the fragmentation and disaggregation of work. It can be understood in several ways: in terms of the spatial-geographical dimension, it concerns those workers that stopped working from 9 to 5 . There is also a reorganisational dimension that is related to the re-distribution of these tasks to different workers/software/machines rather than to different times of the day or locations.

Couclelis (2003) defines fragmentation as "a process whereby a certain activity is divided into several smaller pieces, which are performed at different times and/ or locations". ICT certainly plays a strong role in this process. Nonetheless, according to Alexander et al. (2010), while usage of ICT is certainly associated with fragmentation, the causal relationship is not clear and the results indicate that work, personal and house-related factors play a much stronger role.

How many workers are concerned by spatial/geographical disaggregation? A report by KPMG (2011) based on a survey of 608 Australian employees indicates that still $67 \%$ of 
workers are affected only to a limited extent by the phenomenon. They are defined as the 'two-world workers' because they work a standard number of hours and rarely work outside these hours. The remaining 33\% of workers is divided as follows:

o 'distributed schedulers' (14.5\%), who spread hours across the day and fit work around other commitments,

o 'frequent dividers' (5.5), who mix work tasks in short busts with travel and personal time and

o 'fully blended' workers (13\%), who have almost no dividing line between work and personal time.

According to the report, most employees experimenting with some fragmentation declared they were able to make the best use of their time, except 'fully blended' workers, whose experience indicates that an excess of fragmentation can reduce productivity. Among the clear benefits of fragmentation, Australian workers pointed to better work-life balance and the possibility to manage outside work activities and responsibilities. However, they also reported several side effects such as: stress, blurring boundaries between work and personal lives, overtime work and difficulty in keeping track of hours worked.

But the main question is: how important is such a phenomenon? In a captivating article in the Harvard Business Review, Prof Malone (2011) tells the story of the pharmaceutical giant Pfizer. After an internal mapping exercise, it was discovered that most highly skilled workers were spending $20-40 \%$ of their time on tasks like data entry, web research and basic analysis. In the firm's search for efficiency, this constitutes a waste of resources: the same tasks could be performed by one or more specialised workers. This process leads to what he calls "the age of hyper-specialisation", in which "we will now see knowledge worker jobs salesperson, secretary, engineer - atomize into complex networks of people all over the world performing highly specialized tasks".

Two studies by the McKinsey Global Institute $(2011,2012)$ speak about fragmentation under a similar connotation. It is the result of the attempt to increase efficiency by disaggregating jobs into tasks and re-assigning them to different types of workers, software or machines or low-labour cost locations. Part of this process falls under routinisation, where repetitive tasks are automated and others are relegated to new professions. "The classic model of disaggregation is the paralegal, who takes on the time-consuming basic research tasks of a highly paid attorney. This model is being applied in healthcare, engineering, computer science and other fields where highly paid, highly skilled talent is in short supply and where middle-skill specialists can take over some tasks". The redistribution of tasks across doctors and nurses can happen along the same lines: if trained nurses take over some of the routine tasks of doctors, a new role can be created to take over some of the lower-skilled responsibilities of nurses.

\subsection{Crowdsourcing}

A potential consequence of the fragmentation of tasks is the fragmentation of the workforce. Already in 1984, Atkinson rationalised the process of making companies more flexible by identifying three different types of flexibility: functional, numerical and financial. According to the author, the transformation towards the 'flexible firm' goes through the creation of two groups of workers: the core and the periphery one. The two are submitted to different kinds of flexibility strategies: functional flexibility is designed for the core workers, who are more protected from market fluctuations; whereas numerical flexibility becomes more important when shifting to the periphery. Once again, the phenomenon is not new: by the end of the 1980s several forms of flexible types of contracts had emerged in all OECD countries. 
Nonetheless, technology is enabling new forms of outsourcing and freelancing such as crowdsourcing platforms. Among the most popular examples are Amazon's Mechanical Turk (MTurk), CrowdFlower and Odesk.

Odesk, for instance, employs some 643,922 freelancers, of whom only one-half are in the field of web and software development. ${ }^{4}$ After crowdsourcing platforms, software has also been created to mechanically cut work into pieces (tasks) and distributed automatically to different workers. An example is CastingWords, a transcription service that breaks audio files down and distributes them to different people able to put the original wording onto paper in a time shorter than the original file.

Crowdsourcing constitutes a cheap and quicker option for outsourcing but it is not limited to that. The definition of crowdsourcing can be wide and includes experiments like Wikipedia, where the construction of the encyclopaedia is in the hands of the crowd. Here we restrict the focus to crowdsourcing of paid labour which gives the possibility to assign a specific task, from the creation of a code for a web programme, to a translation or a data collection, to a worker in an unspecified location. If the scientific literature on the issue is practically nonexistent, the debate in blogs and newspapers is livelier. Panos Ipeirotis, Associate Professor at New York University, uses "cloud labour" as a synonym for crowdsourcing in his blog. He also tries to provide a more structured definition, paraphrasing the NIST definition of cloud computing:

Cloud labour is a model for enabling convenient, on-demand network access to a (shared) pool of human workers with different skills (e.g., transcribers, translators, developers, virtual assistants, graphic designers, etc.) that can be rapidly provisioned and released with minimal management effort or service provider interaction. This cloud model promotes availability and is composed of five essential characteristics (...):

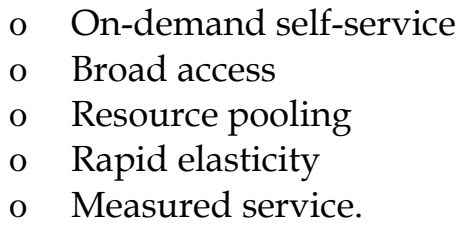

This practically means that the worker is searched for when one is needed from a pool of workers with more or less focused skills and competences, with no human interaction necessary but an expected quick reaction and with the possibility to monitor the activity.

If the idea of being able to outsource a task to the crowd of freelancers, being able to find the right person within hours and get the job quickly done sounds not only very efficient but also fascinating, many challenges are associated with it. One is certainly working conditions. In one article on these new tools ("A clouded future", 13 March 2012), The Economist points out that crowdsourcing platforms operate under no regulation and risk driving down wages. On Amazon Mechanical Turk, workers are paid between a few cents to $\$ 75 /$ hour. $^{5}$ On Odesk, for a random high-skilled task (running a 'maximum likelihood estimation' with Stata $^{6}$ ) the average salary demanded by the twelve applicants was $\$ 12.17$ per hour.

\footnotetext{
${ }^{4}$ As of 22 of May 2012.

${ }^{5}$ This was the pay range as of 12 April 2012. Wide fluctuations can be expected depending on market conditions in the system.

${ }^{6}$ https://www.odesk.com/jobs/Maximum-likelihood-Estimation-STATA_ d99648d41cb0aee3?sid= 53002\&tot $=70 \&$ pos $=7$
} 
On this issue, The Economist quotes Alek Felstiner of the law school at the University of California at Berkeley, who predicts that "some governments will draw up rules that make it harder for firms that regularly tap workers in the cloud to label them as independent contractors rather than employees with more rights". Low wages are not the only aspect. In another post and after trying the platform, Ipeirotis plots the number of active workers by country at different times of the day for various days of the week. Thanks to this data made available by Odesk to clients, he realises that Philippine workers never sleep! Their supply of work is very constant over time, even though there is a 12-hour difference between New York and Manila. On this basis it is therefore reasonable to expect that workers will create new forms of associations to protect their rights.

Another challenge related to cloud labour is the possibility to track work. Odesk, for instance, responded to this possibility by creating a surveillance system by which six random screenshots are captured every hour of work and sent to the employer to check that time is not wasted on other activities than those contracted for. The necessity comes from the fact that work on Odesk is not necessarily paid with a lump sum but can be paid by the hour. On the one hand, this type of monitoring system allows transparency from both sides but on the other it raises concerns from the point of view of privacy and control.

\subsection{Virtualisation of work}

The creation of crowdsourcing calls into question another fundamental trend in workplace innovation fostered by technology: virtualisation of work.

Technologies such as instant messaging, teleconferencing and video calls make it less necessary for co-workers to gather together physically and allow for the creation of virtual teams. Powell et al. (2004) define virtual teams as "groups of geographically, organisationally and/or time dispersed workers brought together by information technologies to accomplish one or more organisation tasks". Ebrahim et al. (2009) review the literature on virtual teams and summarise the key issues. On the positive side there are time and money saved on travel, together with the possibility to rely on a potentially global pool of talents. Drawbacks come from an amplification of traditional team problems like communication, which are aggravated by language and cultural diversities and by the difficulty to introduce new management methods. For these reasons, being equipped with the most recent technology is not enough to overcome these barriers and perhaps, after all, "the trip to the coffee corner or across the hallway to a trusted colleague is still the most reliable and effective way to review and revise a new idea" (Gassmann \& Von Zedtwits, 2003 and Ebrahim et al., 2009). In an article in The New Yorker, Jonah Lehrer digs into the 'brainstorming myth' and uncovers what type of collaboration is actually most fruitful for an organisation. "It turns out physical proximity - something we tend to take for granted in a technologically mediated age makes a huge difference. Individuals who collaborate while working within a close distance of one another produce the best work, and one of the best ways to ensure that people meet (and meet often) is to create environments that facilitate face-to-face run-ins - a tactic that Steve Jobs championed by rearranging physical space to necessitate chance meetings, and thereby spawn impromptu collaboration" (in FT, 9 March 2012). On the same line, Straus \& Olivera, 2000 affirm that "technology may never be able to fully substitute for the richness of interacting face-to-face". Yet, "perhaps advances in handheld electronic devices, inexpensive virtual meeting software supported by super-high bandwidth, or widely accessible mobile networks may eventually serve to alleviate the impact of professional isolation on performance" (Rhoads \& Silver, 2005).

The creation of virtual teams is not the only aspect of the virtualisation of work. Other forms include teleworking, co-working and the use of social media at the workplace. The former 
has been analysed in earlier sections of this report and it is not a recent phenomenon, except for the fact that new technologies make it easier. Co-working is the spontaneous aggregation of workers, often freelancers, who combat isolation, by gathering together in ad-hoc offices where it is possible to rent a desk for a few hours or days per month. The initiative offers many spillovers in terms of new opportunities thanks to networking initiatives. A famous example is 'The Hub', a chain with rentable spaces from New York to Tampere.

Another phenomenon increasing in importance is the use of social media and social networks at the workplace. The spread of social media was initially ignored in its business applications, and then passed through a phase of scepticism where it was banned for security and productivity reasons and now is back as an opportunity. The potential uses of social networks for work business purposes are multiple: they can be vital for marketing and be very helpful to get direct feedback and advice from consumers. Here we focus on uses related to work organisation.

First of all, social media are useful to foster communication, especially in big organisations or small organisations with no common fixed offices. SGI/GI and FPS Belgium provides good examples of this. SGI/GI staff utilises the Facebook chat to communicate instantaneously and researchers are enrolled on Academia.edu, a social network where researchers can upload papers and presentations and get notifications from other researchers in their field of interest. At FPS Belgium, Yammer has been installed, a social network that allows colleagues to collaborate easily and self-organise into teams.

A second potential use is recruitment. The state of the application is still confusing and experimental. There is no common strategy for recruiters and attempts to optimise the selection using social networks go from a quick look at Facebook profiles to the use of applications like Branchout or search functions on Linkedin.

\subsection{Cloud computing and equipment}

One of the main drivers behind recent and, more importantly, future changes is cloud computing. Defined by the US National Institute of Standards and Technology (NIST) "a model for enabling convenient, on-demand network access to a shared pool of configurable computing resources (e.g. networks, servers, storage, applications and services) that can be rapidly provided and released with minimal management effort or service provider interaction", it is considered by many as a 'game changer' because it will dramatically transform the industry. Yet there is nearly no research on it (Fershtman \& Gandal, 2012). Etro (2010) claims that the future impact of cloud computing can be compared to that of telecommunications infrastructures in the 1970s and 1980s and the internet in the 1990s. Using a dynamic stochastic general equilibrium model, Etro (2009) estimates that the diffusion of cloud computing could lead to the creation of one million jobs in the EU. This would mainly come through the creation of small businesses, more strongly in countries where SMEs are important for the economy and/or where IT adoption has been rapid. In more detail, he writes: "Italy is expected to have the largest impact in terms of new business (with about 80,000 new small- and medium-sized enterprises in the medium run under fast adoption), followed by Spain $(55,000)$, France $(50,000)$, Germany $(40,000)$, UK $(35,000)$ and Poland $(32,000)$ " (Ibid.). The creation of SMEs is favoured by a reduction of fixed and variable costs associated with hardware and software adoption, reducing the constraints associated with business creation. Bayrak et al. (2011) call it a "democratising effect" which enables small companies to offer tailored services to relatively small groups and consumers to enjoy more choice. Bayrak et al. also use Fichman's (1992) classification of technology, which distinguishes between technologies that exhibit a lack of user interdependencies and the absence of substantial knowledge barriers faced by potential adopters on the one hand 
and technologies with significant user interdependencies or high knowledge barriers on the other hand. According to Bayrak et al., cloud services are of the latter type and for this reason their diffusion is conditional on the adopters' abilities and willingness.

European-level data on the distribution of the most recent technologies, e.g. tablets, among the employees of European enterprises do not exist. In order to attempt a description, we rely therefore on a small survey run by the management consultant firm Vansom Bourne in 2011 of 1,500 business leaders across 15 western European countries. They were asked whether in the last 12 months their company invested in ITC equipment and in what precisely. Figure 10 summarises the results on average in the countries considered.

Figure 10. During the last month have you invested in any of the following ICT technologies? (percentage responding in the affirmative)

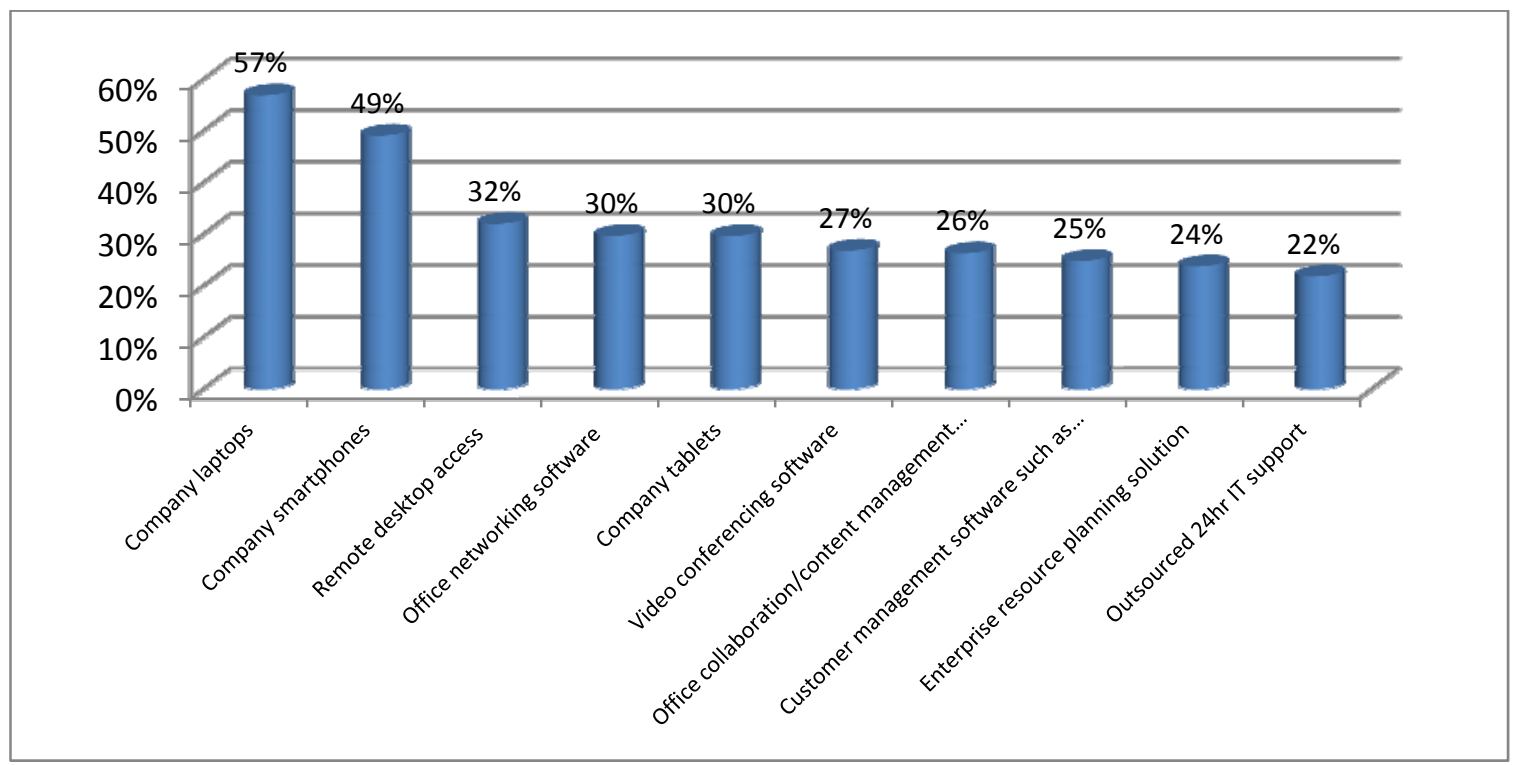

Source: Vansom Bourne.

If laptops and smart phones seem a more common acquisition, no more than one-third of business leaders reported that their company had acquired any of the other technologies, such as video-conferencing software or a 24-hour IT support service. Furthermore, as shown in Table 3 , in all cases, this percentage increases with the size of the company.

Table 3. Technological equipment by firm size

\begin{tabular}{|c|c|c|c|c|c|}
\hline & \multicolumn{5}{|c|}{ Number of employees } \\
\hline & $2-10$ & $11-49$ & $50-500$ & More than 500 & Total \\
\hline Company laptops & $47 \%$ & $54 \%$ & $59 \%$ & $66 \%$ & $57 \%$ \\
\hline Company smart phones & $39 \%$ & $49 \%$ & $52 \%$ & $55 \%$ & $49 \%$ \\
\hline Remote desktop access for remote working & $21 \%$ & $31 \%$ & $32 \%$ & $43 \%$ & $32 \%$ \\
\hline $\begin{array}{l}\text { Office networking software such as instant } \\
\text { messenger }\end{array}$ & $21 \%$ & $25 \%$ & $31 \%$ & $41 \%$ & $30 \%$ \\
\hline Company tablets/slates & $20 \%$ & $29 \%$ & $33 \%$ & $36 \%$ & $30 \%$ \\
\hline Video conferencing software & $18 \%$ & $23 \%$ & $27 \%$ & $38 \%$ & $27 \%$ \\
\hline $\begin{array}{l}\text { Office collaboration/content management } \\
\text { software such as Sharepoint }\end{array}$ & $15 \%$ & $23 \%$ & $27 \%$ & $39 \%$ & $26 \%$ \\
\hline Customer management software such as CRM & $15 \%$ & $21 \%$ & $25 \%$ & $37 \%$ & $25 \%$ \\
\hline Enterprise resource planning solution & $14 \%$ & $21 \%$ & $25 \%$ & $34 \%$ & $24 \%$ \\
\hline Outsourced 24hr IT support & $14 \%$ & $22 \%$ & $22 \%$ & $29 \%$ & $22 \%$ \\
\hline
\end{tabular}

Source: Vanson Bourne. 
It is difficult to say why this is the case, also in light of the data presented in Table 12, where it emerges that the diffusion of workplace innovation differs widely depending on the element considered, whether it is flexi-time or teamwork for instance. One potential explanation is that bigger companies have potentially more resources to keep their equipment up to date. An alternative explanation is that they need it more. However, this second explanation is refuted by the evidence obtained in one of the case studies: tools aimed at facilitating interaction and mobility is vital to the functioning of small companies in the service sector, especially those that are free or very cheap. The key message from the SGI/GI case is that information and communication technologies greatly reduce coordination and transaction costs for small and medium enterprises. Implementation of ICT flattens organisational structure, enhances autonomy, creativity and mobility of workers, eliminates physical distances as a major limiting factor, increases productivity of labour, reduces hiring and recruiting costs significantly and - when used appropriately - could serve as a strategic tool to increase flexibility in relations with customers. ICT offers organisations promising opportunities to cope with the challenges of the ever-changing business environment. Despite the aforementioned efficiency, cost-effectiveness and increasing overall use of ICT in general, SMEs do not maximise the use of ICT to their competitive advantage. The resources issue is crucial because most of this equipment constitutes a fixed cost which means that it is more of a burden for a small company to bear.

Another reason for the insufficient take-up of ICT by SMEs lies in the lack of dedicated IT staff: this is the most important reason why, as emerged in the SGI/GI case, a fundamental characteristic of such a technology is its user-friendliness (as also mentioned in Chapter 3).

Aside from budget constraints, there are other possible reasons: failure of managers and employees to introduce new processes, lack of knowledge and the difficulty for SMEs to afford dedicated IT managers.

\subsection{Is WPI a win-win solution and what is the role of technology?}

There are a number of barriers and potential negative impacts related to workplace flexibility especially vis-à-vis employees; some authors point out the higher job satisfaction linked to more work autonomy whereas others argue that it may lead to negative outcomes for workers, such as stress and increased workload.

Drawing on the FPS case study results, we observe that the employees/ employer perception is positive and the adoption of teleworking had a positive effect on team spirit and work-life balance (for more information see FPS internal survey). Such outcomes were probably affected by a self conscious management team which was able to identify potential risks before the adoption of a new working policy, allowing the company to avoid major drawbacks.

The workplace innovations were indeed strongly supported by the high-level managers of the organisation reflecting their personal conviction and ideas about work, but responded as well to the need to modernise the slow and inefficient public administration.

Following the adoption of flexible work practices, SGI/GI employees, instead, felt that their personal and professional lives were overlapping. However, they did not perceive this effect in absolutely negative terms, and most of the respondents said that they used personal rules to cope with more flexible working schedule.

Despite the complexity of the whole issue concerning the relationship between WPI and performance, the data analysis showed that WPI has the potential to deliver positive outcomes for the organisation. Telework and flexi-time are positively related to productivity: 
countries with a higher level of productivity are also those where flexi-time and telework are more broadly spread across workers.

With the changing nature of the European labour force and greater demand for flexible working conditions, we can also deduce that organisations that embrace change will be best placed to succeed.

The positive correlation between measures of innovation, like investment in $R \& D$ as a percentage of GDP and the share of companies that innovate and adopt practices to increase employees' and teams' involvement, demonstrates that WPI practices, such as flat hierarchies and team autonomy, foster creativity and trigger innovation.

We detect as well a positive relation between flexitime and work-life balance (FPS Belgium) and between work-life balance and employment rates (Otikon).

We can conclude this section by arguing that, all in all, positive aspects of WPI outbalance the negative ones leading to a convergence between organisational performance, employment and quality of working life aspects. As indicated in the FPS and Otikon cases, WPI should be guided by a committed management where innovation affects the entire working culture and process.

If the adoption of flexible working practices is not linked to specific measures aimed at considering employees' needs, there is a risk that conflicting outcomes may occur.

Technology is not a sufficient condition for the adoption of WPI but rather an enabler, in some cases an indispensable one. The division of work into tasks that can be redistributed across more workers can indeed take place independently of technology: the example cited is the creation of the profession of paralegal, a new figure who takes on some of the more repetitive tasks of a lawyer. This can happen without technology but for the redistribution of tasks to spread across a larger geographical area, technology becomes indispensable because it cuts transaction costs linked to organisation and communications at longer distances.

Two other trends described in this chapter may appear as a contradiction. Information and communications technologies can push in two different directions: "teamisation" of work and the creation of virtual teams and, at the same time, individualisation and isolation. Once again, these are not new phenomena: the attribution of more responsibility to teams and the isolation described by teleworkers have already been largely documented in the literature and are reflected in the data presented in the first chapter of this report. Technology enables organisations to break geographical borders and overcome problems created by physical distance, which also means allocating minds where they fit best.

What are the consequences of these trends for the labour market? Forecasting is always a risky exercise, especially when the absorption of new tools is so limited, but some tentative considerations can be made. The first one is that these innovations break a dividing line that used to be very clear: the one between employees (traditionally working from 9 to 5 in an office) and external contractors. Thanks to (or because of?) innovations, this boundary is blurring and one can find in between a set of part-time workers, full-time workers from remote locations and crowdsourced contractors.

It can also be said with a fair amount of confidence that the future workforce will need more lifelong learning to cope with changing technologies, even though they are increasingly friendly and intuitive.

Last, it is possible that the cheap labour available through crowdsourcing will favour job creation. At the same time, history teaches us that these workers will explore new forms of association in order to create and defend their rights and will ask for the intervention of 
regulators to approximate their job security to standard labour regulations, which will increase their cost.

To conclude, only a multilateral approach can create the conditions for a win-win situation for both employer and employee. The role of technology in successful adoption of WPI should be neither underestimated, nor overrated. It is important to determine whether technological innovation is a necessary and / or efficient component of organisational change and then to act accordingly. 


\section{Why is WPI not more widespread?}

Evidence from chapter one suggests that, all in all, the positive sides of workplace innovation outweigh the negative ones. Drawbacks of the adoption of innovative practice include, for instance, the blurring of the border between work and private life and increased level of stress; all issues that emerged from the case studies and from our literature survey. Compared to these drawbacks, gains seem to be higher, both for employers and employees: Data for Finland, for instance, allows us to conclude that there is no trade-off between higher productivity and a better quality of working life.

If workplace innovation constitutes a potentially win-win solution, why is its application still limited? Data suggest that in reality its adoption is fairly widespread, but very unevenly so across countries. We show this using data from the Fifth European Working Condition Survey, which contains data for 2010 and compares it to the 2000 data wherever necessary. We show that each of these practices is present in different European countries in a very uneven fashion, with Nordic countries often being more advanced in their adoption. In particular, in nearly all items of WPI considered, Sweden, Denmark, the Netherlands and Finland score better than other countries. This is consistent not only with the traditional literature on welfare state classifications, but also with studies (Gustavsen, 2007) that argue the existence of a Scandinavian model of work organisation.

At the end of this chapter we analyse the reasons why we do not observe more workplace innovation across Europe. These reasons include microeconomic considerations such as risk aversion, a lack of trust between social partners and costs related to the transition towards a new work environment, and macro explanations related to the national context in which institutions operate.

\subsection{An uneven spread}

According to the literature survey in the previous chapter, and when combining existing definitions of innovative workplaces, we reach the conclusion that the key elements to take into account are:

o Flexi-time

o Teleworking

o Alternative payment schemes

o Flat hierarchies

o Employee empowerment and autonomy

o Task rotation and multi-skilling

o Team work and team autonomy

Table 4 shows the percentage of workers involved in participatory practices in EU27. The first three elements (flexi-time, telework, alternative payment schemes) can be grouped as 'quantitative' flexibility or employment practices, the others as 'qualitative/functional' flexibility or work organisation practices. These may not be all present at the same time in each workplace; this list therefore has to be considered as comprehensive.

The European average shows that different practices have different types of penetration: almost $70 \%$ of workers, for instance, enjoy autonomy but only $12 \%$ have access to telework. 
Table 4. Workplace innovation in EU27 - share of workers affected (\%)

\begin{tabular}{|ccccccccc|}
\hline $\begin{array}{c}\text { Flexi } \\
\text { time }\end{array}$ & $\begin{array}{c}\text { Tele } \\
\text { working }\end{array}$ & $\begin{array}{c}\text { Alternative } \\
\text { payment } \\
\text { schemes }\end{array}$ & $\begin{array}{c}\text { Flat } \\
\text { hierarchies }\end{array}$ & $\begin{array}{c}\text { Employee } \\
\text { empowerment }\end{array}$ & $\begin{array}{c}\text { Employee } \\
\text { autonomy }\end{array}$ & $\begin{array}{c}\text { Team } \\
\text { work }\end{array}$ & $\begin{array}{c}\text { Team } \\
\text { autonom } \\
\text { y }\end{array}$ & $\begin{array}{c}\text { Task } \\
\text { rotation }\end{array}$ \\
\hline 37.8 & 11.7 & 12.5 & 56.8 & 43.9 & 67.4 & 56.4 & 52.0 & 43.6 \\
\hline
\end{tabular}

Source: Own elaboration based on data from the $5^{\text {th }}$ European Working Conditions Survey (Eurofound, 2010a).

Taking the average across all items by country we discover that Nordic countries are in the lead: Denmark, Sweden, Finland and the Netherlands rank first in the diffusion of new ways of work, which in these countries is much more widespread than in Mediterranean countries like Spain, Portugal, Greece and Italy. In between there are new member states: Latvia, Estonia and Lithuania in particular occupy the middle rank creating, a model of 'postcommunist-almost-Nordics'. The most interesting case is Slovenia: it ranks fifth, right after the Nordics, and has the same type of widespread diffusion across all elements.

Figure 11. Ranking of EU27 countries by WPI diffusion (higher ranking corresponds to lower \% of diffusion)

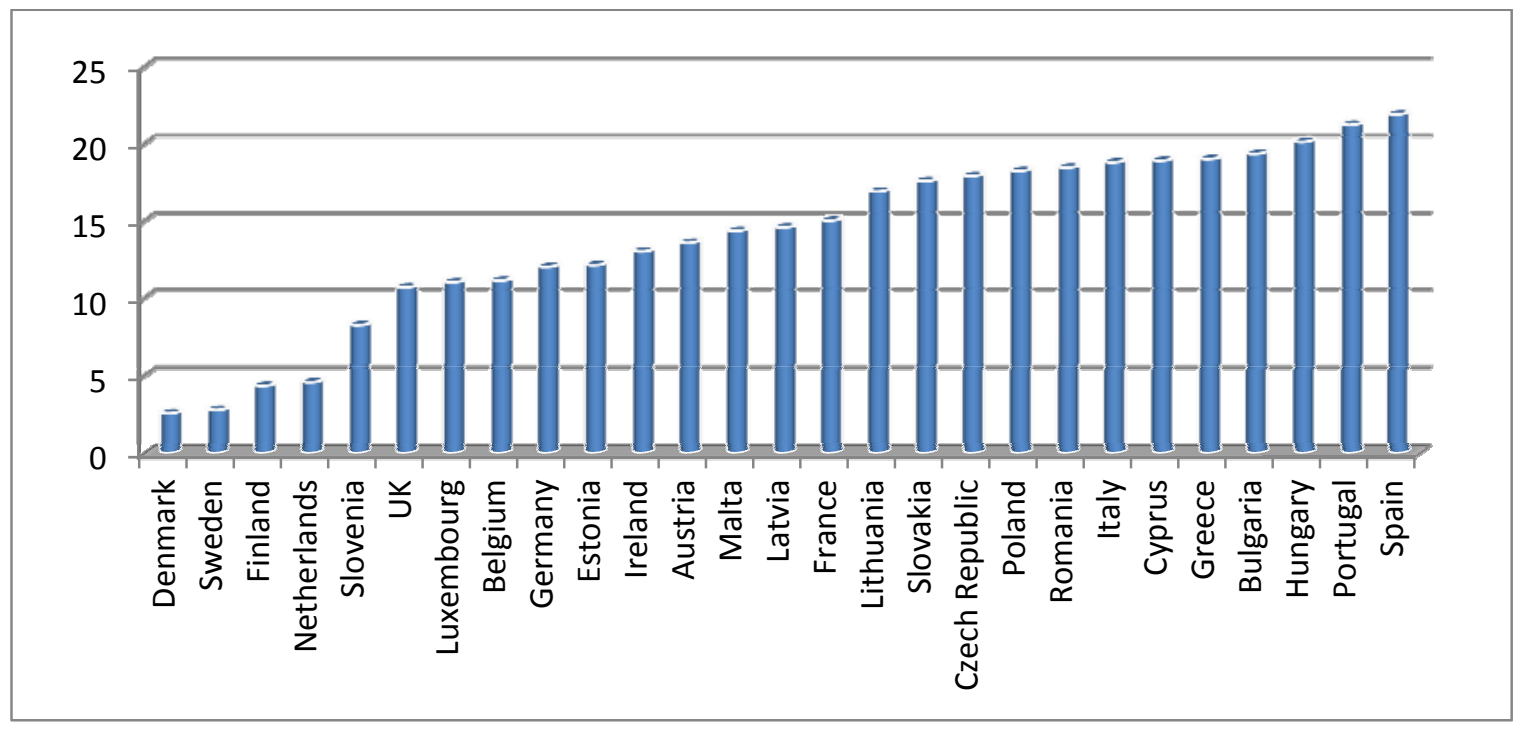

Source: Own elaboration based on data from the $5^{\text {th }}$ European Working Conditions Survey (Eurofound, 2010a).

As far as old European countries are concerned, it is possible to make a comparison with 2000 for some of the WPI items listed above to observe whether any substantial change occurred over the decade and whether there is any convergence across Europe towards more workplace innovation.

Table 5. WPI in EU15, 2000 and 2010 compared (\%)

\begin{tabular}{|clccccc|}
\hline \multirow{2}{*}{2000} & Average & 88.3 & $\begin{array}{c}\text { Alternative } \\
\text { payment schemes }\end{array}$ & $\begin{array}{c}\text { Employee } \\
\text { autonomy }\end{array}$ & $\begin{array}{c}\text { Team } \\
\text { work** }\end{array}$ & $\begin{array}{c}\text { Task } \\
\text { rotation }\end{array}$ \\
\cline { 2 - 7 } & st dev & 5.0 & 5.2 & 69.1 & 41.9 & 44.1 \\
\hline \multirow{2}{*}{2010} & Average & 84.3 & 13.7 & 8.2 & 10.4 & 8.7 \\
\cline { 2 - 7 } & st dev & 10.4 & 7.5 & 69.3 & 42.3 & 46.0 \\
\hline
\end{tabular}

*Percentage of workers who do not telework.

**Percentage of workers who do not work in team.

Source: Own elaboration based on data from the $5^{\text {th }}$ European Working Conditions Survey (Eurofound 2010a). 
It is interesting to note that the only major change across the decade is in the share of workers that receive part of their compensation linked to performance: the percentage of workers that answered positively to this question rose from 5.2 in 2000 to 13.7 ten years later. The remaining WPI elements are remarkably static. Moreover, for all items except team work, there is a divergence rather than a convergence across EU15 countries.

In the following sections of this chapter, we look more closely at each item to understand which countries achieve a wider diffusion of each practice and in the last part of the chapter, we try to explain the better or worse performance of certain countries.

\subsubsection{Quantitative aspects of workplace innovation}

\subsubsection{Flexi-time and telework}

Workers interviewed in the Fifth European Working Conditions Survey (2010 data) indicated that in the great majority $(60 \%)$ of cases their working time is set by the company with no possibility of change. Only in Sweden, Denmark and the Netherlands does this percentage fall below 35\%. The laggards in terms of working time flexibility are the East Europeans, the Spaniards and the Portuguese.

If on average $60 \%$ of workers cannot choose their working time, this also means that the remaining $40 \%$ enjoys at least some flexibility that can take different forms: a small minority $(7 \%)$ can choose between several fixed working schedules; $16 \%$ has a margin for adaptation and $16 \%$ determines his/her working hours, with two thirds of the latter being selfemployed. In Denmark, the Netherlands and Finland, flexi-time is the dominant rule for one third of workers who are allowed to select their work schedule, within certain limits.

Figure 12. Working time organisation in EU27

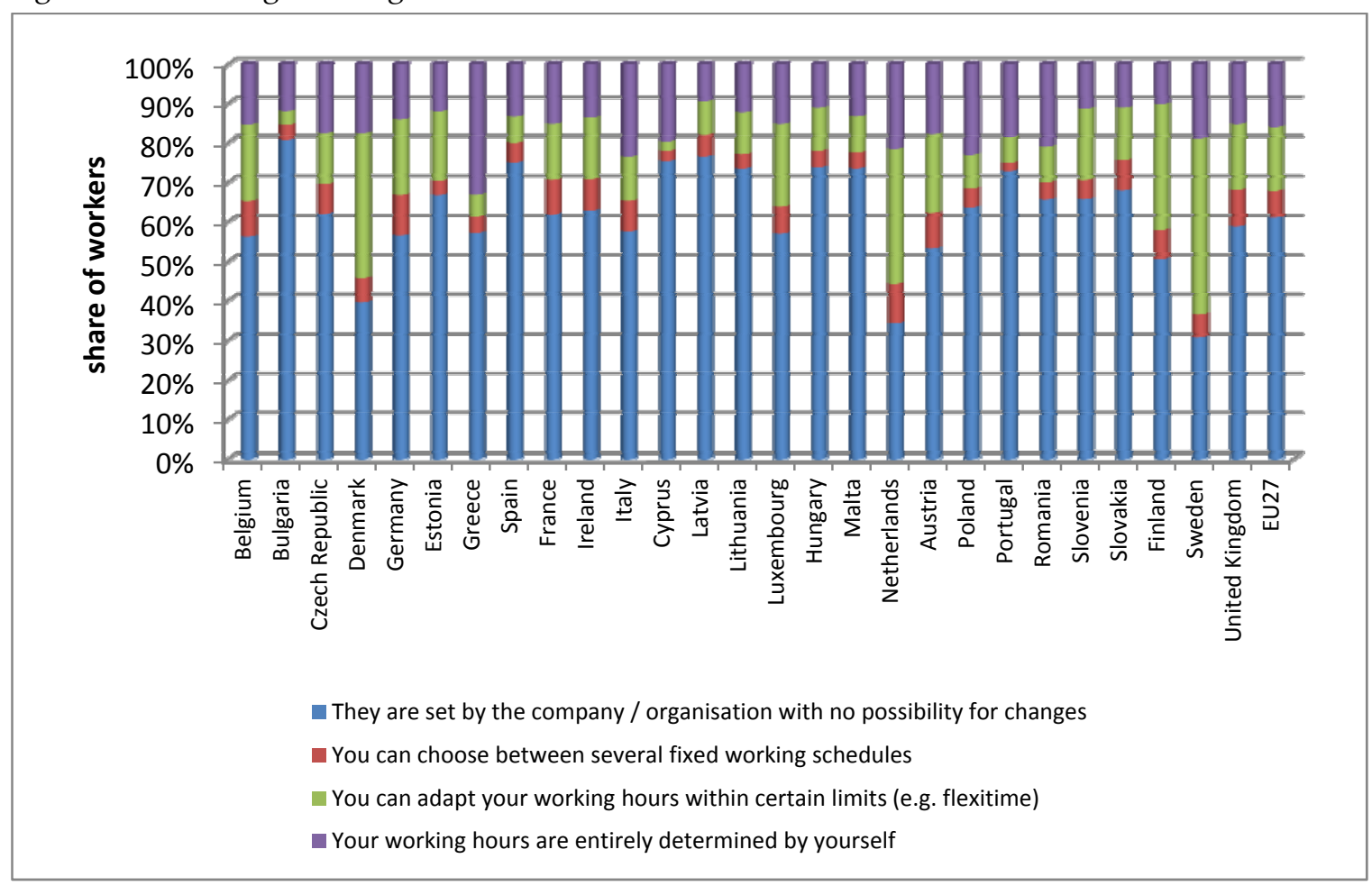

Source: Own elaboration based on data from the $5^{\text {th }}$ European Working Conditions Survey (Eurofound 2010a).

Which type of working time flexibility are we referring to here? The combination of two questions in the survey (Do you work the same number of hours every day/week?) reveals that flexibility "by the day" is more widespread than flexibility "by the week". In other 
words, European workers often have a predetermined amount of working hours per week that are adjustable by the day, with highly skilled clerical workers and self-employed people having more flexible working hours than others. This is true for every country (the pink bar is taller than the blue bar). In terms of levels, workers from northern and continental European countries (Denmark, Sweden, Austria, the Netherlands, Finland, Belgium and Germany) are more inclined to adjust their working time by the day. Flexibility by the week is rather more widespread in a mix of Nordic and Eastern European countries: Czech Republic, Denmark, Sweden, Estonia, Slovenia, Poland and Austria.

Figure 13. Do you work the same number of hours every day/week? 'NO' answers

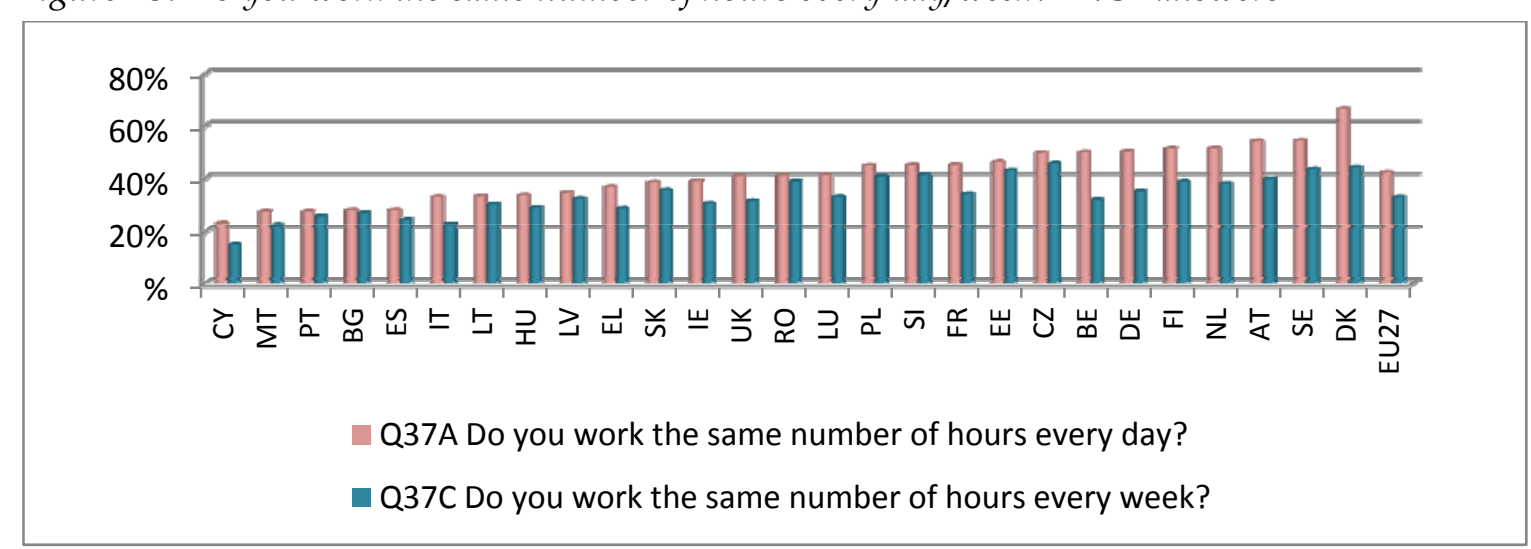

Source: Own elaboration based on data from the $5^{\text {th }}$ European Working Conditions Survey (Eurofound 2010a).

The second element of the definition of WPI we selected for study is telework. The literature survey illustrated all the pros and cons of this practice. On the one hand, teleworkers enjoy a better work-life balance, on the other it may not be suited to everyone because some people do prefer interaction with their colleagues at the workplace rather than working in isolation. In addition, some teleworkers complain about their inability to set a clear dividing line between work and private life. We tried to understand how many telecommuters there are around Europe. Figure 14 shows the share of workers that have as their main place of work their employers' or own business premises and home as a second option. On average, 12 Europeans out of every 100 engage in telecommuting. The difference between countries is very clear: only in the Netherlands Sweden and Denmark does this share exceed $30 \%$. It is not by chance that these are also the countries where workers are more free to choose their work schedules: all in all, Dutch, Swedish and Danish workers have the greatest liberty to set their working time and their place of work. On the opposite side of Figure 14 are Italy, Bulgaria, Hungary and Cyprus where fewer 5 in 10 workers can work from home as an alternative to their business premises. EU27 aggregate data by sector illustrate that greater numbers of workers in four sectors are allowed to work from home: real estate, professional and scientific activities, education, and information and communication. 
Figure 14. Percentage of office workers that also worked from home

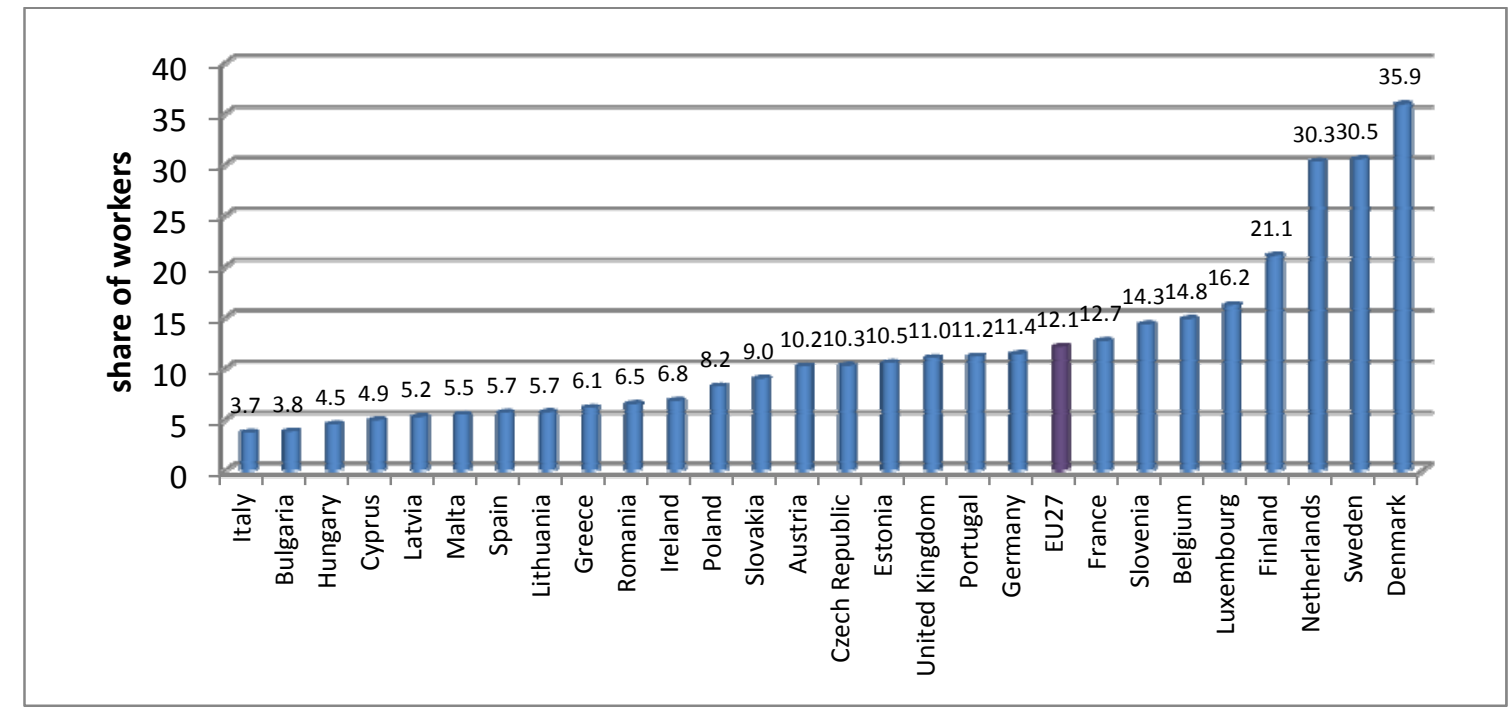

Source: Authors' own elaboration based on data from the $5^{\text {th }}$ European Working Conditions Survey.

\subsubsection{Alternative payment schemes}

Among the elements of quantitative flexibility at the workplace, alternative payment schemes are perhaps to most controversial. Origo \& Pagani (2008) found that the increase in job satisfaction often associated with innovative workplace systems comes more from the qualitative aspects such as team working than the quantitative and monetary ones:

Workers attach great importance also to non-monetary aspects of the job, which are more likely to be improved by many forms of functional flexibility rather than numerical and working time flexibility. Given the same wage level, workers may then be more satisfied (and hence more productive) if they perceive some enhancement in the intrinsic aspects of their job (such as control on their tasks and possibility to use their creativity.

Performance payments have also been roundly criticised by those who argue that this practice is not consistent with the definition of an employee, since dependent work should share risks with the entrepreneur. Very recent research bordering the disciplines of neuroscience and economics has found that if it is true that workers with variable-payment schemes are more productive, this is not only due to the incentive mechanism but to a degree of self-selection (Dohmen Falk, 2011). "When facing the alternative between variable and fixed payments, more productive workers systematically prefer the variable pay". This implies that firms can use sorting to attract less risk-averse but more productive employees.

Interestingly enough, data suggest that this WPI saw the most interesting development over the 2000-2010 decade.

How many workers receive alternative forms of compensation linked to their performance as part of their salary as individuals or team members? Figure 15 plots the share of workers that mentioned, as part of their remuneration, company shares and/or payments based on overall company performance (profit-sharing scheme). ${ }^{7}$ Such a practice is more widespread in France, where almost one third of workers receive part of their salary linked to the

\footnotetext{
${ }^{7}$ If both sub-elements increase in importance over time, payments related to performance remain by far the most important part. Both measures create a stronger link between the fate of the organisation and the worker. However they differ in intent: profit-sharing schemes create an incentive for the worker to make more effort, whereas employee-share ownership reflects trust and inclusiveness.
} 
performance of the company. The other countries above the European average of $15 \%$ are a mix of Nordic and East European countries.

Figure 15. Share of workers that receive partial performance-linked remuneration

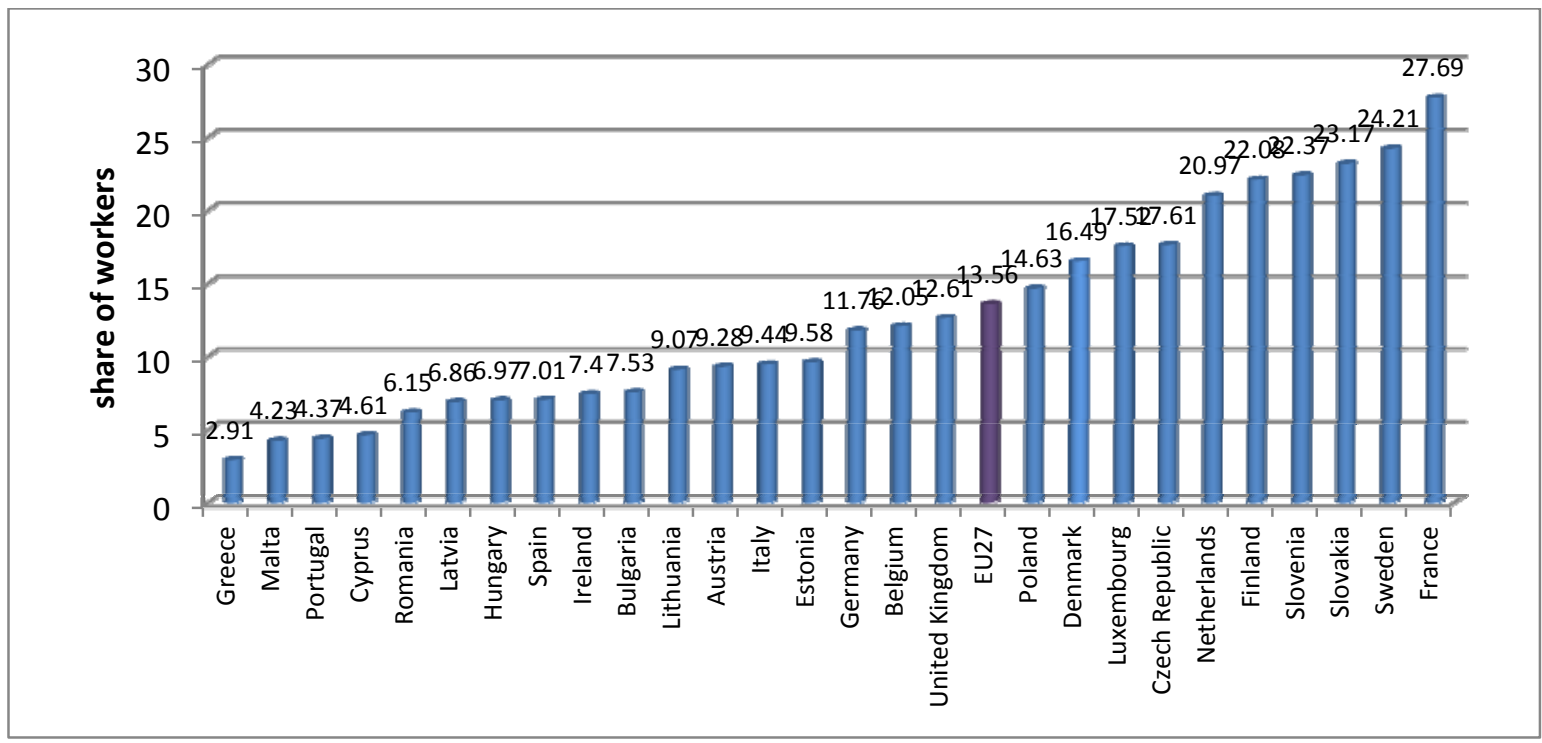

Source: Authors' own elaboration based on data from the $5^{\text {th }}$ European Working Conditions Survey.

The most interesting aspect is the clear trend throughout in Western European countries (with the exception of Greece) towards an increase in the number of workers affected by this practice: over the course of only one decade they increased up to three or four times in Belgium, Denmark, Luxembourg and Finland.

Figure 16. Share of workers that receive partial remuneration linked to performance, 2000 and 2010 compared

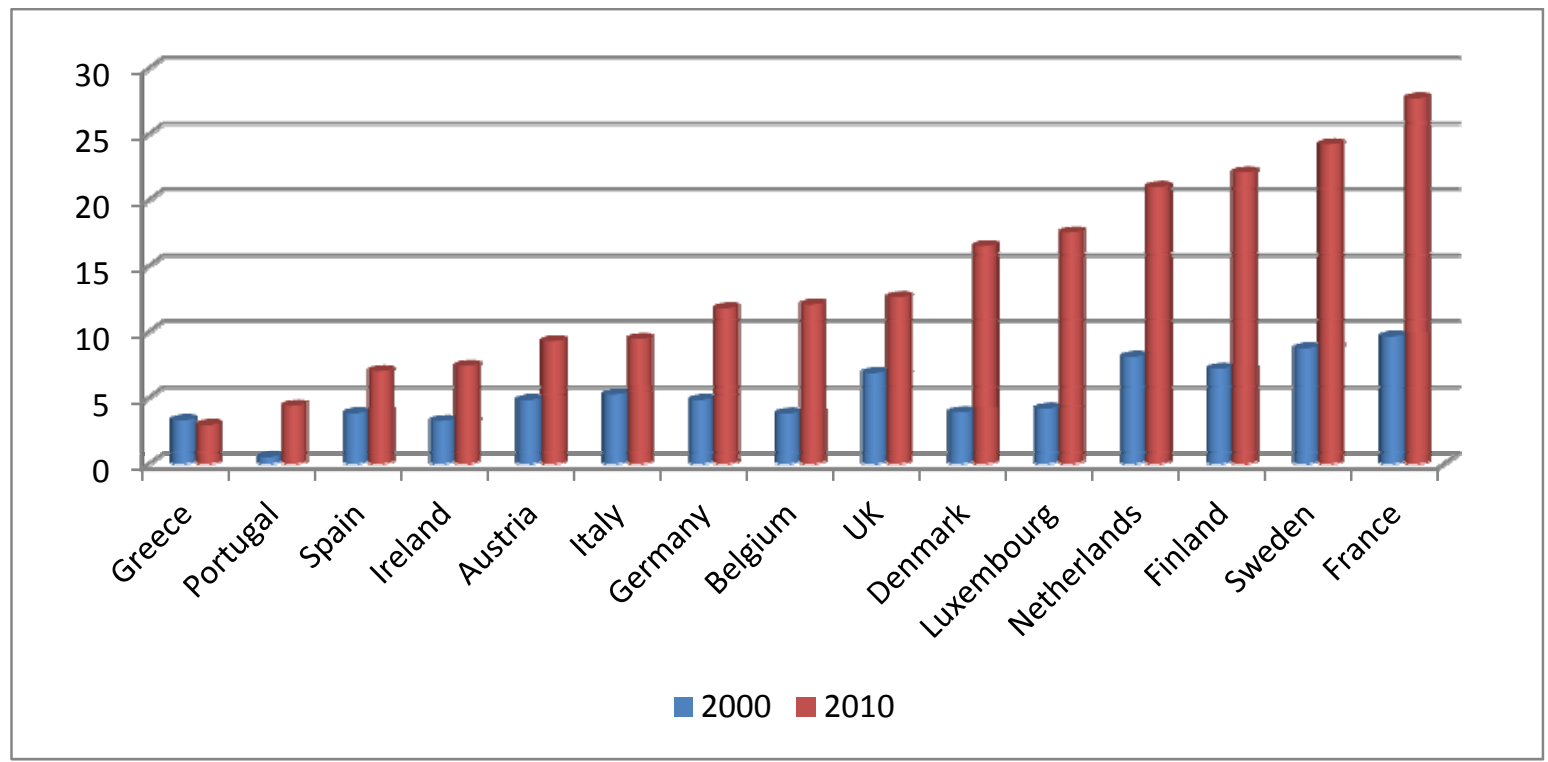

Source: Authors' own elaboration based on data from the $5^{\text {th }}$ European Working Conditions Survey.

\subsubsection{Qualitative dimension}

As indicated at the beginning of this chapter, the seven dimensions that characterise an innovative workplace can be grouped into the quantitative and qualitative. The latter aspects of high performance workplace systems (HPWS) are based on the attribution of higher 
independence to employees, but also more responsibility to single workers and teams. As a consequence, HPWS abandon the rigid pyramidal structure typical of Taylorist organisations and engage in a more flat structure with the intent of making innovation emerge bottom-up, thereby encouraging greater productivity because workers are more enthusiastic about their job. To measure the degree of adoption of innovative practice in Europe, the first two variables taken into account are based on three questions in the survey:

o At your workplace, does management hold meetings in which you can express your views?

o Are you involved in improving the work organisation or work processes of your department or organisation?

o Are you able to choose/change your methods of work?

Figure 17. Share of workers involved in qualitative aspects of WPI

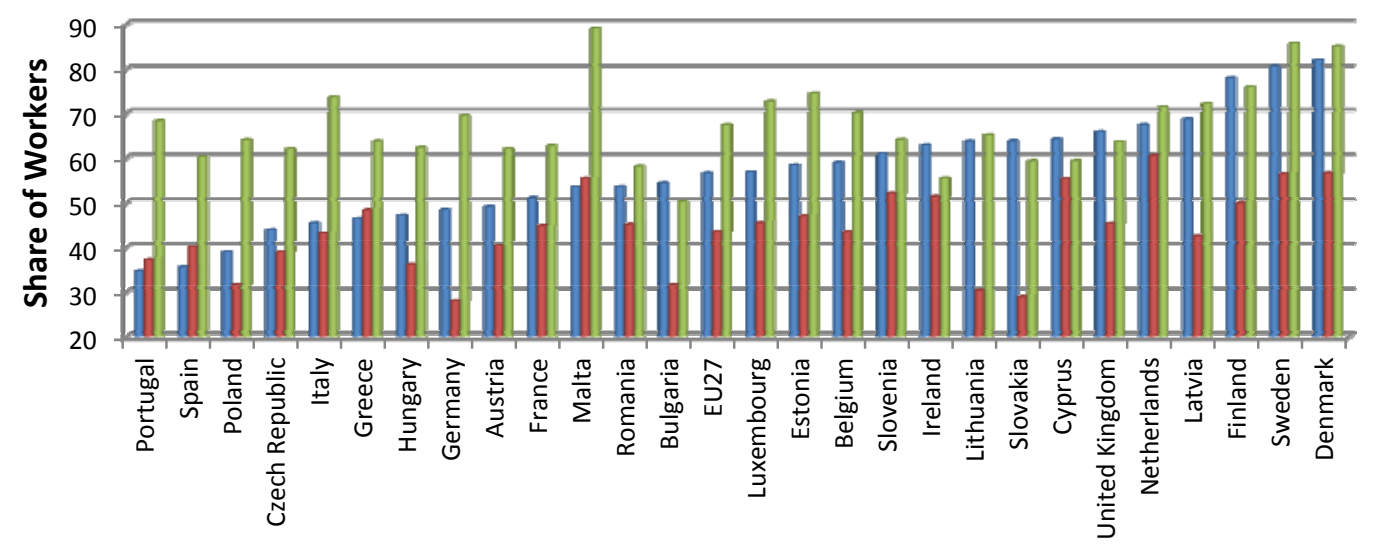

At your workplace, does management hold meetings in which you can express your views?

Are you involved in improving the work organisation or work processes of your department or organisation?

Are you able to choose/change your methods of work?

Source: Authors' own elaboration based on data from the $5^{\text {th }}$ European Working Conditions Survey.

Data indicate that more than $60 \%$ of workers enjoy some degree of autonomy because they are able to choose or change the method of work. The capacity to influence company decisions is rather more limited: even though half of EU companies do have a 'voice' mechanism, only $40 \%$ of workers declared involvement in the organisation of the work process.

The three variables are positively correlated (between $41 \%$ and $53 \%$ ) meaning that it would be very difficult to empower workers by allowing one element and not the others: it would be unnecessarily inefficient if a worker able to change the work method discovers a more efficient process but is not able to communicate it or share it with colleagues and superiors.

Another element of qualitative flexibility at the workplace is task rotation. It has its raison d'être in workers acquiring multiple skills that make them more flexible in the distribution of tasks. This practice involves at least one third of European workers in each country. The EU27 average is $44 \%$, with countries like Sweden and Denmark exceeding $70 \%$. Of the workers involved in rotating tasks, approximately $80 \%$ declared that different skills are needed to cope with all aspects of their work.

Team work and team autonomy is the last element of qualitative flexibility. Team work concerns more than $50 \%$ of workers, with only half of them also enjoying autonomy in terms 
of the internal division of tasks. This latter dimension of team-working is more differentiated by country: once again Denmark, Sweden and Finland rank in the top position given that more than two thirds of team-workers also enjoy great autonomy in the division of tasks.

Figure 18. Team workers

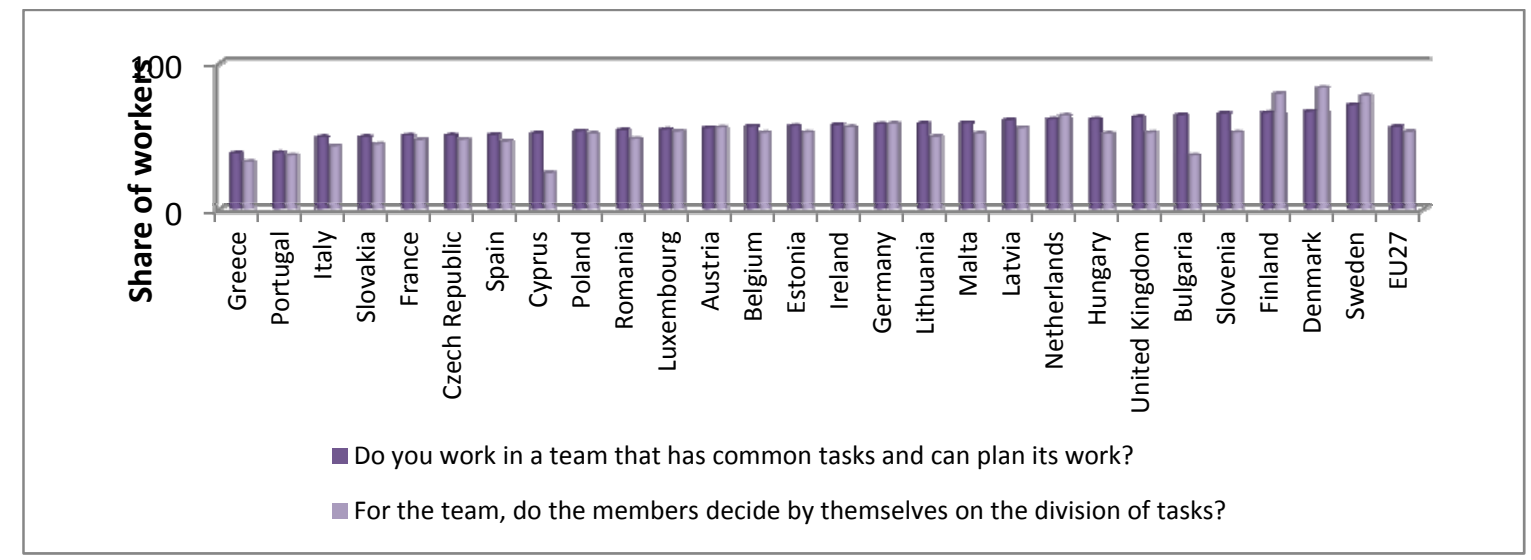

Source: Authors' own elaboration based on data from the $5^{\text {th }}$ European Working Conditions Survey.

\subsubsection{Complementarity between quantitative and qualitative aspects}

All in all, taking into account all the qualitative workplace innovations described, none of the other qualitative elements of workplace innovation shows a clear trend over the last decade. This is to a certain extent puzzling, because given the parallel evolution in technology one would expect more task rotation and team autonomy.

An important aspect is the complementarity between and across qualitative and quantitative elements of innovative workplaces. Correlation coefficients indicate that flexi-time and teleworking are positively correlated with all qualitative elements. One element is particularly interesting: the question in the survey related to team work has three potential answers: Yes in a single team, Yes in several, No. For the purpose of this study we have aggregated the first two answers but if only the first (work in a single team) is considered, correlations with quantitative elements of WPI as well as with macro variables, become negative. This suggests that team work is productive only as long as variety is introduced.

In the case of alternative payment schemes the signs of the coefficients are the same but the relation is strong only with flat hierarchies and team autonomy. Signs suggest that not only is there no trade-off between telecommuting, for instance, and employee empowerment, but in some cases there is a strong interdependence. There is in this an element of fairness: one could not ask employees to accept performance-based remuneration without allowing them to influence how tasks are attributed and methods of work.

Table 6. Correlation coefficients between quantitative and qualitative aspect of WPI

\begin{tabular}{|l|c|c|c|c|c|c|}
\hline & $\begin{array}{c}\text { Flat } \\
\text { hierarchies }\end{array}$ & $\begin{array}{c}\text { Employee } \\
\text { empowerment }\end{array}$ & $\begin{array}{c}\text { Employee } \\
\text { autonomy }\end{array}$ & $\begin{array}{c}\text { Team } \\
\text { work }\end{array}$ & $\begin{array}{c}\text { Team } \\
\text { autonomy }\end{array}$ & $\begin{array}{c}\text { Task } \\
\text { rotation }\end{array}$ \\
\hline Flexi-time & 0.49 & 0.51 & 0.51 & 0.34 & 0.71 & 0.50 \\
\hline Teleworking & 0.62 & 0.54 & 0.58 & 0.48 & 0.78 & 0.62 \\
\hline $\begin{array}{l}\text { Alternative payment } \\
\text { schemes }\end{array}$ & 0.42 & 0.16 & 0.20 & 0.36 & 0.52 & 0.32 \\
\hline
\end{tabular}

Source: Authors' own elaboration based on data from the $5^{\text {th }}$ European Working Conditions Survey.

The importance of a holistic approach to workplace innovation also emerges from the radar charts in Figure 19: not only have the Nordics exhibited wider diffusion across each item 
compared to the southern countries, but they also achieve a better balance between the different dimensions (with the exception of alternative payment schemes and telework, whose diffusion is in general very limited). Altogether they enable workers to decide when to work; to influence decisions relevant for the organisation; work in teams and exchange tasks. In southern countries, however, there is an effort to let workers organise themselves in teams and take more responsibility, but they keep elements of rigidity because the diffusion of flexi-time, task rotation remain limited and hierarchies are not smooth across the different criteria considered.

Figure 19. Workplace innovation: Nordic vs. Mediterranean countries
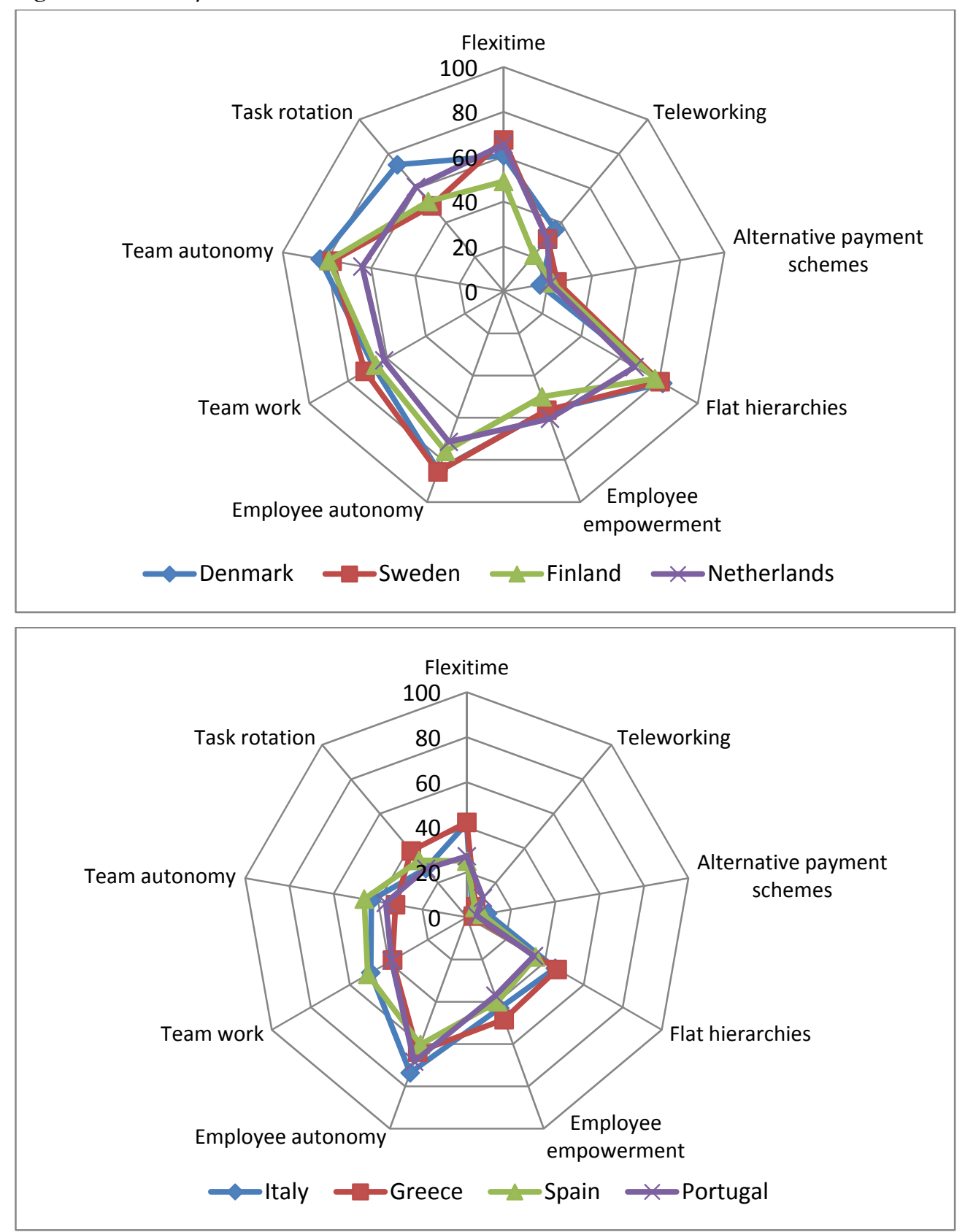

Source: Authors' own elaboration based on data from the $5^{\text {th }}$ European Working Conditions Survey.

Nonetheless, we should keep in mind that part of the positive correlation across different innovative practices is explained by occupational categories: professional well educated workers are more likely to work across disciplinary teams and to enjoy greater autonomy in 
terms of working patterns (see section 2.2.3 for a deeper discussion on the interplay between WPI, skills and sector of production). Yet, a study by the OECD (2010) confirms that the discretionary learning forms of work organisation are most widely diffused in the Netherlands, the Nordic countries and to a lesser extent Germany and Austria, while they are little diffused in Ireland and the southern European nations. The more bureaucratic learning model is most in evidence in the United Kingdom, Ireland and Spain and to a lesser extent in France, while it is little developed in the Nordic countries or in Germany, Austria or the Netherlands. The low-learning Taylorist forms of work organisation show almost the reverse pattern compared to the discretionary learning forms; being most frequent in the southern European nations and in Ireland and Italy. Finally, the traditional forms of work organisation are most in evidence in Greece and Italy and to a lesser extent in Germany, Sweden, Belgium, Spain and Portugal (OECD, 2010)".

\subsection{Barriers to the diffusion of workplace innovation}

We came to the conclusion in the previous section that the adoption of workplace innovation has spread in a very heterogeneous fashion, with Nordic countries and Slovenia leading on most indicators. We also observed that the comparison of 2000 and 2010 data presents a rather static picture: with the exception of performance-related payments, all other elements of WPI almost froze over the decade despite the sizeable diffusion of technology in the workplace. This brings to the mind the words of Nobel Prize economist Robert Solow quoted in the Introduction: "You can see the computer age everywhere but in the productivity statistics". In this case, we can argue that we see workplace innovation everywhere except in the data! This is also the main reason why in this report we complement the data with qualitative analysis and an extensive survey of not only the literature but also of social scientists' commentaries involved in this field.

In the following section we analyse the barriers that prevent workplace innovation from spreading further. They can be divided into two main categories: microeconomic considerations such as risk aversion, lack of trust between social partners and costs related to the transition towards a new work environment, and macro explanations related to the national context in which institutions operate. We also check whether the sector of employment, the size of the company and the age and skills of the workforce constitute a barrier. We come to the conclusion that none of them directly a barrier in the sense that different elements of workplace innovation can fit different contexts.

\subsubsection{Risk aversion, resistance and lack of trust}

Despite the fact that positive outcomes of workplace innovation outnumber negative ones, the literature survey and the case studies reveal that each of potential parties involved in the change has rational reasons to resist the introduction of innovative practices in the workplace: workers, middle-managers and top managers. Gillen Doug (2002) describes this process very well:

When a new technology is introduced factor proportions change, responsibilities are altered and procedures change. There are threats to lines of authority, job security and responsibility. In all cases there are threats and the successful implementation of a new technology into any firm requires that it be managed, it will not happen automatically and ultimate success of the firm will be contingent on the implementation. The adoption of new technologies has always presented challenges for managers, employees, and organisations in general. As the advent of mass production in the assembly line and more recent models of flexible specialisation required planners and workers alike to adapt to and exploit new ways of interacting 
and organising the productive process, so too have advances in Information Technology (IT).

Employee resistance and insufficient management support are, together with inadequate resources investment, the major part of difficulties in implementing of new technology (ibid.). In this section we analyse risks and fears distinguishing three different actors: top managers/owners of the organisation, middle-managers and workers. Table 7 schematises the main problems for each actor.

Table 7. Fears associated with WPI, expressed by level of actor

\begin{tabular}{|l|l|l|}
\hline Top management & Middle-management & Employees \\
\hline Risk aversion & $\begin{array}{l}\text { Job or status losses, future } \\
\text { career path. }\end{array}$ & $\begin{array}{l}\text { Higher workloads, worse pay and working } \\
\text { conditions, more varied and complex tasks. }\end{array}$ \\
\hline
\end{tabular}

Among case studies in this report there is no example of top management resistance: all cases reported ended up with the adoption of WPI, which cannot happen without the approval and the investment of the top management. Yet, readings revealed that management resistance happens often. Out of the entire population of firms that have not adopted innovative practices, it is not possible to say how many times the management resisted this initiative, however. A key factor in explaining this resistance is risk aversion: as explained in the next section, changing the workplace requires an investment in equipment and training and, as an investment, it bears a risk. The payoff for introducing innovative practices is expected to be big (in terms of productivity, innovation capacity and job satisfaction) but uncertain. However, risk aversion is not the only reason: in order to take a decision managers need to be aware of the benefit of WPI and often they are unaware of benefits. And even when they are aware, in some cases they are simply not interested. Among companies interviewed for the Business Decisions Limited study (2002), 30\% of organisations across different EU countries declared being aware of new forms of work practices but were not interested for various reasons, among those cited were: they are not necessary to meet customers' needs, they are not used by competitors and would not be supported by other managers/workers/trade unions.

Middle managers have to be distinguished from top managers because the reasons for their reluctance can be quite different. According to a study by Business Decisions Limited for the European Commission (2002) study scepticism is mainly due to:

o "Fear of job losses due to de-layering of the organisation;

o Fear of loss of status and self-image

o Concern about future promotion prospects in the new organisational structure;

o Concern about the difficulty of fulfilling a "manager-as-coach" role in the new participative culture."

The example of Oticon also gives interesting insights into middle management concerns. One feature of the organisational changes was that the traditional career path within Oticon disappeared overnight. And with it all the traditional hierarchical symbols: larger company car/office, more access to information, a title etc. This is reported as clearly causing problems for some employees. Also, in general, a lot more assertiveness was needed in the new structure. Every Oticon employee was a potential co-worker on a project, and while it previously might have worked to show your next level manager your capabilities, it was now necessary to 'market' them to a wider circle of potential project managers and coworkers. It was also mentioned that the lack of formal co-ordination was a potential source of delays and derailment of projects. One manager estimated that this actually prolonged the 
time to market period compared with previously ${ }^{8}$. For this and probably other reasons, some years later project management has become more professionalised and is now an established career path within the firm. This happened after it was recognised that project management was not being handled satisfactorily.

FPS Belgium, on the other hand, is an example of initial resistance from the bottom: when the idea to move towards a more flexible-type of organisation was first introduced, trade unions reacted with scepticism. A key decision was to abandon working hours and adopt a practice of management by objectives. It is interesting to note that in this case top managers encouraged the adoption of flexible working time, while the trade unions didn't want to abandon the time clock to measure working hours. The freedom of choice system, finally implemented, was a compromise reached after multiple discussions. Out of the $92 \%$ of workers who did not have to be physically in the office from 8.00 to $17.00,41 \%$ used timeclock measurement in September 2009, 27\% two months later and 16\% in 2010. Moreover, as much as $70 \%$ of employees opted for teleworking of which $1 / 3 \mathrm{rd}$ one day per week, $1 / 3 \mathrm{rd}$ two days per week and 1/3rd three days per week. The possibility to choose between the old and the new system paid out in terms of acceptance and paved the way for further support as the months passed.

Fears for employees are not too dissimilar from those of the middle management. According to the Business Decisions Limited (2002) report, these are:

o Fear of job losses

o Fear of detrimental changes in pay or working conditions

o Uncertainty regarding their ability to work effectively in a more demanding environment

o Dissatisfaction with potential increases in accountability, and requirement to fulfil a wider range of more complex tasks

- Fear of a higher work load

o Fear of loss of autonomy or technical status and

o Unwillingness to accept responsibility for quality, continuous improvement or customer satisfaction.

This is rational:

Innovative work behaviour is demanding. It requires a broad variety of cognitive and socio-political efforts and investments which may lead to success or failure, high or low performance in the main task, conflict of cohesion with co-workers, positive or negative job attitudes and high or low levels of well-being (OECD 2010).

One of the key words to summarise this section is trust: research conducted by Eurofound (2011) indicates that even though cooperation between trade unions and employers is fundamental to improve working conditions and favour the enterprises' performance, it often happens that:

the emphasis on innovative forms of work organisation is also subject to important controversies among the social partners in a large number of countries. The main point of disagreement relates to the promotion of flexible forms of work organisation, which is often viewed differently by employers and worker representative organisations.

Lack of trust can be tracked in statistics collected in 2011 in a (non-representative) survey by Vanson Bourne for a study for Microsoft in which they directly ask the question: Do you trust your colleagues/employees to be productive when they work flexibly or away from the

8 Lars Kolind would answer that informal coordination increased much more than potential loss in formal coordination, thereby making the organisation more responsive. 
office? The 'Yes' answers counts for approximately half of the total, with Danes being a strong outlier in terms of exceptional confidence and Germans the lowest. The same question, put to managers gave a more positive result, with positive answers being exactly $70 \%$ of the total. It comes as no surprise that countries with the highest scores of 'yes' are also those where workplace innovation is more present: once again, the Nordics (Denmark, Sweden and Finland) plus the Netherlands. All these countries have a strong tradition of corporatism, meaning that government, social partners and interest groups coordinate to deal with conflicting objectives. Such a system is characterised by a high level of trust and low levels of conflict.

Figure 20. Do you trust your colleagues to be productive when they work flexibly or away from the office?

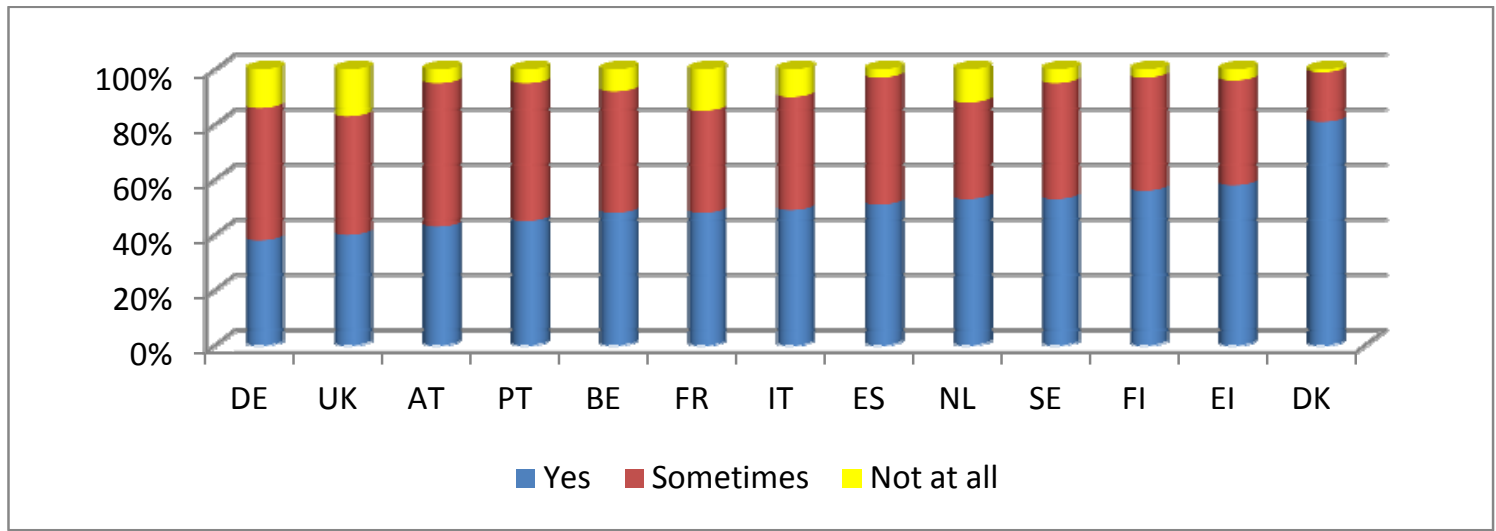

Source: Vanson Bourne.

That said, it comes as no surprise that trade union density (the share of wage and salary earners that are trade union members) is positively correlated with all dimensions of workplace innovation; most of them with a coefficient that exceeds 0.5 (Table 8 ). The only exception is 'alternative payment schemes': the correlation is still positive but drops to 0.21 . Among all elements of workplace innovation this is the most controversial for social partners because, according to the biggest sceptics, workers should not share entrepreneurial risk.

Table 8. Union density and WPI

\begin{tabular}{lccccccc}
\hline & $\begin{array}{c}\text { Flexiti } \\
\text { me }\end{array}$ & $\begin{array}{c}\text { Telew } \\
\text { ork }\end{array}$ & $\begin{array}{c}\text { Alternative } \\
\text { payment schemes }\end{array}$ & $\begin{array}{c}\text { Flat } \\
\text { hierarchie } \\
\mathrm{s}\end{array}$ & $\begin{array}{c}\text { Employee } \\
\text { empowerment }\end{array}$ & $\begin{array}{c}\text { Employee } \\
\text { autonomy }\end{array}$ & $\begin{array}{c}\text { Team } \\
\text { work }\end{array}$ \\
$\begin{array}{l}\text { Union } \\
\text { Density }\end{array}$ & 0.64 & 0.63 & 0.21 & 0.71 & 0.50 & 0.65 & 0.56 \\
autonomy \\
rotation
\end{tabular}

Source: Authors' own elaboration based on $5^{\text {th }}$ European Working Conditions Survey, OECD.

Falk at al. (2011) use a principal agent model to demonstrate that treating employees with respect is not only morally advisable but also economically rational because perceptions and beliefs can have important physiological consequences:

In our representative data we show that on top of actual life circumstances, such as net wages and labour market status, mere perceptions about fair treatment are correlated with adverse physiological responses. Given that health affects labour market outcomes, this suggests an important potential feed-back mechanism: Labour market experience induces fairness perceptions with consequences for health, which in turn affect labour market outcomes. 


\subsubsection{Costs of a transition towards WPI}

From the company's point of view, restructuring the organisation has a cost and this cost can prove to be disincentive to the decision to reorganise the workplace. It is the result of the sum of new furniture, new ICT equipment and related training, and consultants' fees involved in providing expertise. As such it constitutes an investment because it entails an expenditure that is expected to provide future benefits that are greater than its cost, which in this case take the form of higher productivity, better innovation capacity and lower costs. The time horizon in the medium-to-long-term: in the view of the CEO of Oticon the objective behind the creation of the spaghetti organisation was to improve the long-term competitiveness of the company and not to restore its short-term balance. Being an investment, restructuring the company around new forms entails a risk: at the end of the process, the company may produce more or deliver on time and with fewer production errors but it could also result in a totally chaotic process and a situation that is worse than at the beginning of the process. The uncertainty of the expected payoff (higher productivity, innovation capacity and job satisfaction) leads to risk aversion.

One element that reduces this risk is the presence of experts that introduce a professional approach to changes in organisation, especially for big companies. This is witnessed by the fact that most of the funds provided under the TEKES programmes were indeed used by firms to pay consultants to help them move from one system to another. One interviewee also revealed that the unfortunate choice of appropriate consultants can be one of the factors leading to the failure of the process.

Non-monetary aspects related to the cost of transition should not be overlooked. Insufficient training "to overcome skills gaps and to help employees to master the new general skills needed to work in the new environment (e.g. team-working skills)" (ibid.). The third crucial element is the pay system: especially in the public sector, some organisations failed to introduce forms of reward linked to the new performance targets, thereby reducing the incentives to achieve them.

In a careful attempt to understand how the transition towards new form of work organisation happens, Alasoini (2011) distinguishes between design, process and dissemination knowledge which is necessary to design and implement innovative workplace programmes. Design knowledge refers to the type of factors that need to be influenced to achieve a certain objective. The approach can be universalistic, meaning that it is affirmed that this or that practice is the official 'recipe' to achieve sustainable productivity. Alternatively it can be contingent or configurational, meaning that the strategy is tailored around the internal and external environment of the company. Process knowledge is needed to help companies determine the appropriate process to accompany change, whether expertdriven or participatory. Dissemination knowledge is necessary to spread results of different experiences and share good practices. Alasoini one concludes that there is no one-size-fits-all approach: a particular set of workplace innovations that worked for a company cannot be just copied by another. Nonetheless, in general, a participatory approach strongly influences the outcome of the transition. In a report for the European Commission (DG EMPL), Business Decisions Limited (2002) provides insights from a survey of 800 companies/institutions. One of their main findings is that the design of the system change strongly determined its outcome.

\subsubsection{Production sector and skills/age of workers}

The image the term 'workplace innovation' conjures up is one of a modern office where a group of very highly skilled people work equipped with the state of the art technology. If this image is true of certain cases, it also true that it does not tell the whole story. The 
research question behind this section is the following: to what extent do the production sector and age and skills of the workforce constitute a barrier to the adoption of innovative practices at the workplace?

As far as the sector is concerned, the evidence provided by the data collected by TEKES is quite clear: in the three programmes, the share of companies in the industry sector accounted for approximately one third of the total, which is surprising if one has in mind the typical Taylorist model of a traditional manufacturing company. Another important and growing share concerned the public sector, whether at the local or central level.

Table 9. TEKES projects by sector

\begin{tabular}{|c|l|l|l|}
\hline & $1996-1999$ & $2000-2003$ & $2004-2010$ \\
\hline Number of projects & 210 & 310 & 996 \\
\hline Sectoral distribution of funding & & & \\
$-\quad$ Agriculture and forestry & $1 \%$ & $1 \%$ & \\
$-\quad$ Industry & $34 \%$ & $27 \%$ & \\
$-\quad$ Private services & $15 \%$ & $18 \%$ & $37 \%$ \\
- Municipal sector & $36 \%$ & $33 \%$ & $23 \%$ \\
- Central government & $9 \%$ & $6 \%$ & $24 \%$ \\
- Third sector & $3 \%$ & $7 \%$ & $3 \%$ \\
- Multiple sectors & $3 \%$ & $8 \%$ & $12 \%$ \\
\hline
\end{tabular}

Consistent with these data, Jones et al (2008) document a big increase in WPI in Finland, also in the manufacturing sector. Between 2002 and 2005, the incidence of practices like job rotation, profit-sharing, consultative committees, etc, increased by $12 \%$ on average among manufacturing companies with 50 or more employees. Jones et al (2008) also study the impact of workplace innovations on firm productivity and find a positive relationship. Nonetheless, not all practices have the same impact: the most beneficial ones are profitsharing and consultative committees where workers can channel opinions. These two appeared to matter more for productivity than employee presence in the board of directors, team work, job rotation and a formal training strategy.

When considering the four types of organisations previously mentioned, the OECD (2010) observes:

The discretionary learning form of work organisation is especially prevalent in several service sectors, notably business services and banks and insurance, and in the gas, electricity and water utilities. As one would anticipate, the lean model of production is more developed in the manufacturing sector, notably in the production of transport equipment, electronics and electrical production, wood and paper products, and printing and publishing. The Taylorist form is notably present in textiles, clothing and leather products, food processing, wood and paper products and transport equipment, while under-represented in the service sectors. The traditional organisational form is found principally in the services, notably land transport, personal services, hotels and restaurants, post and telecommunications, and wholesale and retail trade.

As far as the sector is concerned, it is possible to affirm that for every two innovative workplaces in the service sector there is one in industry reflecting the general distribution of workers across these two main sectors. ${ }^{9}$ This indicates that the sector of production is not a

${ }_{9}^{9}$ On average in Europe, two thirds of workers are employed in the service sector and one third in industry. 
barrier as such, also because different types of companies will choose different participative practices. As shown in Table 10 the application of each element of our definition of WPI is extremely diversified by sector. In manufacturing, for instance, flexi-time, task rotation and performance payment are common practices, unlike, in telework. Health and social workers are in the opposite situation: they enjoy team autonomy and individual empowerment but have no access to telework and alternative payment schemes (one could hardly imagine a doctor being paid according to the number of lives saved!).

Table 10. Workplace innovation sector, EU27.

\begin{tabular}{|c|c|c|c|c|c|c|c|c|c|c|c|c|c|c|}
\hline & $\begin{array}{l}\text { Pr } \\
\text { im } \\
\text { ar } \\
y\end{array}$ & $\begin{array}{l}\text { Man } \\
\text { ufact } \\
\text { urin } \\
\mathrm{g}\end{array}$ & $\begin{array}{l}\text { Electrici } \\
\text { ty, gas, } \\
\text { and } \\
\text { water }\end{array}$ & $\begin{array}{l}\text { Con } \\
\text { stru } \\
\text { ctio } \\
\text { n }\end{array}$ & $\begin{array}{l}\text { Whole } \\
\text { sale } \\
\text { and } \\
\text { retail }\end{array}$ & $\begin{array}{l}\text { Hotels } \\
\text { and } \\
\text { restaur } \\
\text { ants }\end{array}$ & $\begin{array}{l}\text { Transport } \\
\text { and } \\
\text { communic } \\
\text { ation }\end{array}$ & $\begin{array}{l}\text { Financi } \\
\text { al } \\
\text { interme } \\
\text { diation }\end{array}$ & $\begin{array}{l}\text { Re } \\
\text { al } \\
\text { est } \\
\text { ate }\end{array}$ & $\begin{array}{l}\text { Public } \\
\text { admini } \\
\text { stratio } \\
\text { n }\end{array}$ & $\begin{array}{l}\text { Ed } \\
\text { uca } \\
\text { tio } \\
n\end{array}$ & $\begin{array}{l}\text { Health } \\
\text { and } \\
\text { social } \\
\text { work }\end{array}$ & $\begin{array}{l}\text { Oth } \\
\text { er } \\
\text { servi } \\
\text { ces }\end{array}$ & $\begin{array}{l}\text { Activiti } \\
\text { es of } \\
\text { househ } \\
\text { olds }\end{array}$ \\
\hline $\begin{array}{l}\text { Flexi- } \\
\text { time }\end{array}$ & $\begin{array}{l}31 . \\
23\end{array}$ & 71.01 & 65.56 & 63.68 & 60.11 & 62.79 & 67.39 & 52.01 & 45.5 & 67.68 & $\begin{array}{r}71.9 \\
1\end{array}$ & 61.82 & 50 & 38.75 \\
\hline $\begin{array}{l}\text { Teleworki } \\
\text { ng }\end{array}$ & $\begin{array}{c}19 . \\
39 \\
\end{array}$ & 8.14 & 9.32 & 14.19 & 6.79 & 4.25 & 9.92 & 13.92 & $\begin{array}{r}24.4 \\
1 \\
\end{array}$ & 9.26 & 26.3 & 7.39 & 15.26 & 9.14 \\
\hline $\begin{array}{l}\text { Alternati } \\
\text { ve } \\
\text { payment } \\
\text { schemes }\end{array}$ & $\begin{array}{c}12 . \\
94\end{array}$ & 19.81 & 28.13 & 13.44 & 17.11 & 8.97 & 19.55 & 41.6 & $\begin{array}{r}20.1 \\
7\end{array}$ & 3.9 & 2.37 & 4.71 & 9.72 & 1.41 \\
\hline $\begin{array}{l}\text { Flat } \\
\text { hierarchi } \\
\text { es }\end{array}$ & $\begin{array}{l}44 . \\
97\end{array}$ & 52.79 & 67.38 & 42.7 & 47.37 & 40.13 & 59.38 & 68.3 & $\begin{array}{r}57.2 \\
6\end{array}$ & 63.19 & $\begin{array}{r}77.4 \\
8\end{array}$ & 67.64 & 51.42 & 20.34 \\
\hline $\begin{array}{l}\text { Employee } \\
\text { empower } \\
\text { ment }\end{array}$ & $\begin{array}{r}36 . \\
68\end{array}$ & 38.84 & 47.46 & 40.84 & 41.19 & 42.6 & 35.53 & 49.02 & $\begin{array}{r}45.5 \\
4\end{array}$ & 46.61 & 57.1 & 48.02 & 42.83 & 21.59 \\
\hline $\begin{array}{l}\text { Employee } \\
\text { autonomy }\end{array}$ & $\begin{array}{c}75 . \\
64\end{array}$ & 55.99 & 69.54 & 66.64 & 65.55 & 62.85 & 54.76 & 66.79 & $\begin{array}{r}74.3 \\
1\end{array}$ & 65.31 & $\begin{array}{r}84.0 \\
7\end{array}$ & 68.95 & 72.84 & 80.63 \\
\hline $\begin{array}{l}\text { Team } \\
\text { work }\end{array}$ & $\begin{array}{c}36 . \\
32\end{array}$ & 61.87 & 67.11 & 60.72 & 49.81 & 60.58 & 52.34 & 61.65 & $\begin{array}{r}50.9 \\
1\end{array}$ & 66.25 & $\begin{array}{r}61.1 \\
4\end{array}$ & 67.13 & 46.22 & 10.51 \\
\hline $\begin{array}{l}\text { Team } \\
\text { autonomy }\end{array}$ & $\begin{array}{l}57 . \\
99 \\
\end{array}$ & 44.83 & 54.28 & 51.25 & 51.15 & 46.69 & 43.92 & 50.83 & $\begin{array}{r}55.5 \\
1\end{array}$ & 47.89 & $\begin{array}{r}64.4 \\
3\end{array}$ & 62.83 & 56.48 & 59.65 \\
\hline $\begin{array}{l}\text { Task } \\
\text { rotation }\end{array}$ & $\begin{array}{r}28 . \\
58\end{array}$ & 48.98 & 46.36 & 46.12 & 41.15 & 52.31 & 42.13 & 43.41 & $\begin{array}{r}37.2 \\
2\end{array}$ & 49.7 & $\begin{array}{r}41.6 \\
2 \\
\end{array}$ & 56.4 & 34.89 & 10.89 \\
\hline
\end{tabular}

Source: Own elaboration based on $5^{\text {th }}$ European Working Conditions Survey.

Regarding age and education, is WPI a youth/skills-related phenomenon? It seems that the age of executives, more than the age of workers, is a catalyst for innovation and the use of ICTs, according to Gagliardi (2011), who argues that information technologies have a higher chance of being implemented the younger the management team. Ananian \& Aubert (2004) find that the age of workers is also important: older workers are less numerous in firms that use new technologies and new forms of organisation, independently of their level of education. Statistics from the 5th European Working Conditions Survey do not provide a clear message on the issue of wage: older workers enjoy more autonomy and rotate tasks more often, whereas younger ones are more advantaged when it comes to flexitime.

At the same time, data indicate that for most workplace innovations taken into account, there is a strong skill bias (Table 11): the higher the skill level, the higher the percentage of workers reporting being involved in telework, team work and democratisation of the work environment. The strongest impact is on forms on compensation linked to performance, whereas the strong exception is flexi-time.

The skill-bias may be explained by the fact that more educated workers are better able to cope with changes in the methods of production and organisation. At the same time it is also more likely that these people are young and work in the service sector, which is more involved in re-organisation than industry to a ratio of 2 to 1. 
Table 11. Workplace innovations (as share of workers) by education level

\begin{tabular}{|lcccccc|}
\hline & $\begin{array}{c}\text { Primary } \\
\text { educ }\end{array}$ & $\begin{array}{c}\text { Lower } \\
\text { secondary } \\
\text { educ }\end{array}$ & $\begin{array}{c}\text { (Upper) } \\
\text { secondary } \\
\text { educ }\end{array}$ & $\begin{array}{c}\text { Post-secondary } \\
\text { non-tertiary educ }\end{array}$ & $\begin{array}{c}\text { First stage of } \\
\text { tertiary educ }\end{array}$ & $\begin{array}{c}\text { Second stage } \\
\text { of tertiary educ }\end{array}$ \\
\hline Flexi-time & 60.58 & 65.44 & 64.34 & 64.03 & 52.57 & 29.37 \\
\hline Teleworking & 4.69 & 5.07 & 6.73 & 7.8 & 22.27 & 36.34 \\
\hline $\begin{array}{l}\text { Alternative } \\
\text { payment } \\
\text { schemes }\end{array}$ & 6.56 & 7.64 & 13.96 & 10.81 & 18.11 & 20 \\
\hline Flat hierarchies & 32.78 & 45.85 & 52.35 & 58.69 & 71.82 & 76.67 \\
\hline $\begin{array}{l}\text { Employee } \\
\text { empowerment }\end{array}$ & 32.33 & 33.23 & 39.37 & 43 & 56.72 & 62.96 \\
\hline $\begin{array}{l}\text { Employee } \\
\text { autonomy }\end{array}$ & 62.27 & 62.48 & 61.99 & 65.62 & 78.71 & 85.45 \\
\hline Team work & 41.25 & 52.32 & 56.21 & 58.89 & 60.7 & 60.58 \\
\hline $\begin{array}{l}\text { Team } \\
\text { autonomy }\end{array}$ & 41.1 & 50.22 & 51.18 & 54.16 & 57.32 & 63.32 \\
\hline Task rotation & 30.7 & 44.39 & 44.59 & 44.42 & 44.38 & 36.51 \\
\hline
\end{tabular}

Source: Own elaboration based on $5^{\text {th }}$ European Working Conditions Survey.

In any case, the skills factor is one of the explanations behind the poor performance of southern countries in workplace innovation. In the Nordic countries (plus the Netherlands) people that completed university education amount to $34 \%$ of the total active population (aged 15-64), whereas in the southern and eastern EU members the percentage drops to $24 \% .{ }^{10}$ Moreover, in the south, $42 \%$ of the active population dropped out of high school before obtaining a diploma.

\subsubsection{Small vs. big companies}

When looking at workplace innovation from the point of view of companies, one question immediately comes to mind: does size matter in the decision to adopt more innovative workplace organisation practices? In other words, is the size of the company a barrier to the adoption of innovative practices at the workplace? This issue has been explored in the literature, with some authors explicitly referring to small companies. The rapid spread of information and communication technologies indeed greatly reduces coordination and transaction costs for small and medium enterprises (SMEs). The implementation of ICT flattens organisational structure, enhances the autonomy, creativity and mobility of workers, eliminates physical distances as a major limiting factor, increases productivity of labour, reduces hiring and recruiting costs significantly and - when used appropriately - could serve as a strategic tool to increase flexibility in relations with customers. ICT offers organisations a promising opportunity to cope with the challenges of the ever-changing business environment. De Kok \& Hartog (2006) studying HPWS in small Dutch companies conclude that there is a positive relationship between HPWS and higher labour productivity and innovativeness. "This suggests that HPWS may enhance the ability of small firms to select, develop, and motivate a workforce that produces superior and innovative employee output". More precisely, Coleman, in his paper on enterprise social collaboration argues (contrary to Osimo et al.) that company size has a great effect on how quickly social collaborative tools are used: in general, small companies were quicker adopting social networks. Yet again, enterprise may be cautious to adopt social collaboration tools due to perceived security risks or failure of the senior management to identify their value (Coleman, 2009).

${ }^{10}$ European Labour Force Survey data (Eurostat) for 2011. 
Despite the aforementioned efficiency, cost-effectiveness and increasing overall use of ICT in public, SMEs do not maximise the use of ICT to their competitive advantage. The lack of SME demand is attributed by some to the failure of managers to recognise the value of advanced ICT systems and the lack of product availability (Tan, 2010). Others identify lack of knowledge as the biggest barrier to preventing SME from investment in technology; unless there is a 'go-getter' on the staff, small business owners tend to avoid ICTs altogether (Eisen, 2010). The use of Web 2.0 tools' is also not reaching its full potential; take-up is limited mostly to large corporations, mainly in the United States. Employees' reluctance to take up new tools is also identified as a major barrier (Osimo et al., 2010). An additional barrier lies in the fact that small companies cannot afford to have a dedicated IT person responsible to help them with the transition towards WPI, which requires a combination of proper investment and knowledge. For this reason, as highlighted by the SGI/GI case, two technology characteristics are crucial: it has to be cheap (if not free) and it has to be userfriendly. The issue of cost remains important: the acquisition of equipment for each employee is a fixed cost that in the budget of a small company remains considerable.

Table 12 depicts elements of workplace innovation by company size, going from a 1-person workplace to more than 500. What emerges from the data is an approach 'á la carte': different types of innovative practices are more or less widespread in companies with different sizes. For example, quantitative elements are more common either in very small (fewer than four workers) or in big companies (more than 250). Employee autonomy is more widespread across small companies, where practices like flat hierarchies, team work and task rotation grow along with company size. Interestingly enough, the champions of innovation remain self-employed workers, which at all levels of skills and sector remain the most important source of innovation and could therefore be seen as precursors of future change.

Table 12. Workplace innovation by company size, EU27, share of workers

\begin{tabular}{|lcccccccc|} 
& $\begin{array}{c}\mathbf{1} \\
\text { (interv.) }\end{array}$ & $\mathbf{2}$ to $\mathbf{4}$ & $\mathbf{4}$ to $\mathbf{9}$ & $\mathbf{1 0}$ to $\mathbf{4 9}$ & $\mathbf{5 0}$ to $\mathbf{9 9}$ & $\begin{array}{c}\mathbf{1 0 0} \text { to } \\
\mathbf{2 4 9}\end{array}$ & $\begin{array}{c}\mathbf{2 5 0} \text { to } \\
\mathbf{4 9 9}\end{array}$ & $\begin{array}{c}\mathbf{5 0 0} \text { and } \\
\text { over }\end{array}$ \\
\hline Flexi-time & $\mathbf{7 8 . 9 4}$ & 47.51 & 32.09 & 27.91 & 28.25 & 31.39 & 36.42 & 37.72 \\
\hline Teleworking & 22.62 & 11.49 & 7.72 & 11.3 & 13.6 & 14.06 & 11.96 & 13.92 \\
\hline $\begin{array}{l}\text { Alternative payment } \\
\text { schemes }\end{array}$ & 6.51 & 9.85 & 10.59 & 11.96 & 12.31 & 19.07 & 23.86 & 26.09 \\
\hline Flat hierarchies & 28.32 & 38.57 & 48.55 & 61.37 & 65.12 & 66.11 & 66.13 & 68.24 \\
\hline Employee empowerment & 34.04 & 47.81 & 43.35 & 44.5 & 44.91 & 42.99 & 48.03 & 48.41 \\
\hline Employee autonomy & 84.48 & 72.4 & 64.76 & 64.51 & 65.36 & 63.49 & 61.99 & 62.66 \\
\hline Team work & 8.23 & 49.8 & 62.95 & 65.07 & 64.98 & 66.43 & 69.32 & 72.97 \\
\hline Team autonomy & 61.08 & 59.33 & 53.91 & 52.65 & 51.4 & 49.61 & 52.44 & 50.52 \\
\hline Task rotation & 7.12 & 39.19 & 48.39 & 50.93 & 49.91 & 50.84 & 57.15 & 56.39 \\
\hline
\end{tabular}

Source: Own elaboration based on $5^{\text {th }}$ European Working Conditions Survey.

\subsubsection{The trigger for change}

Our research showed that for change to happen, the simple elimination of barriers is not sufficient. Two more conditions are necessary to trigger change: a sound national context (discussed in the next section) and the coincidence of a contingent obligation, at the national as well as the firm level. For instance, in Finland the TEKES programmes were the fruit of a conscious plan to fight population ageing. At the micro level, the initiative was taken in the context of a major restructuring at Oticon, compared to the moving into new offices at FPS Belgium. Open University and SGI/GI are outliers in this discourse because both were created from scratch.

In Finland, the trigger at country-level was political: in the 1990s policy-makers realised that Finland was on a dangerous demographic path: it was estimated that between 2000 and 2015 
one million people would have left the workforce, meaning almost half of the people employed in 2000 (Alasoini, 2004). This would have meant a rapid shrinkage of labour input. Policy-makers realised that a more rapid growth in productivity would have been necessary to compensate for this and opted for workplace innovations as a solution. It turned out that innovative workplaces allowed the attainment of two goals at the same time: increased performance of companies and extended employee working life (ibid.). The deep recession of the early 1990s also played a role by encouraging employers, employees and government representatives to cooperate (Alasoini, 2011). At the time social partners realised that the only way out of the crisis of the 1990s for Finland was to invest in skills rather than create jobs in low-skilled and low-tech sectors. The underlying assumption was that innovation is not exogenous and that the emergence of new ideas and processes can be stimulated by organising the workplace in a way that gives all workers the opportunity to provide input into the organisation. At the enterprise level, data from the 2000-2003 programme, show that in $60 \%$ of the cases, the initiative to start a process of innovation was taken by the top management. Staff and their representatives accounted for approximately $10 \%$ of initiatives.

This finding does not apply to the Dutch case, where the creation of the part-time economy was not pursued as a strategy and did not result in specific legislation. It is indeed difficult to point to stand-alone policy initiatives or developments, which could explain why Dutch women (and men) turn to part-time employment in much greater numbers than elsewhere in Europe. Visser (2002) argues that public policies reacted to changes in labour market behaviour rather than induced them. A tax reform in 1973 reduced the marginal tax rates on (women's) income considerably. At the same time norms regarding the approval of working mothers changed significantly, with less people expressing disapproval of mothers working outside the home. As in many other European countries the beginning of the 1970s coincides with the rise of feminist movements.

According to Visser (2002) the agreement between trade unions and employers' organisations in 1982 may have played a role. Here part-time work, something the Unions had traditionally been strongly against, was explicitly mentioned as a vehicle for greater work-sharing; meant to address the issue of large unemployment of the time. In the following years - and as a consequence of public austerity measures - jobs in the public sector were often converted to part-time jobs in order to avoid dismissals. However, by 1983 - although the female labour force participation was rather low in the Netherlands at this point - a majority of those women in employment was already working part-time. In fact, the important change in the 1980s and 1990s was that more women entered the labour force; there was little change in the propensity to work part time.

A number of other more recent legislative changes did - if not further spur part-time employment - help to maintain part-time employment as an attractive option. In 1993 the applicability of minimum wages and minimum holiday allowances were extended to parttime jobs. This was followed by a 1996 law, the Equal Treatment (Working Hours) Act, that secured part-time workers equal treatment - on a pro rata basis - regarding wages, over-time payment, bonuses and training. This was followed by the Part-time Employment Act in 2000 which gave part-time workers the right to request up- and downward adjustment of their working hours within their job if such an adjustment did not conflict with business interests (Eurofound, 2007; Bosch et al., 2010).

The initiative of senior managers was a key factor at FPS Belgium, where the introduction of new practices was first proposed by the President of the Executive Committee, Frank Van Massenhove and the Director General, Tom Auwers. The proposition to introduce new ways of work followed the federal administrative reforms named "Copernicus" and a broader 
debate about the malaises affecting public administration: slow operations, dusty organisation, etc.

The two protagonists of the revolution at FPS reached their position at the top of FPS in this new changing context. They supported the change in the work culture and in the work organization. . Another important objective was to make FPS more attractive as an employer in order to compete with the private sector in the attraction of talent.

At Oticon, the initiative to revolutionise work organisation was taken at the management level, by the CEO in person, with a specific target: to improve the long-term competitiveness of the company. In the mid-80s Oticon was struggling under the increased competition from large conglomerate electronics firms. Oticon had a hard time making the transition from indiscrete behind-the-ear devices to discrete in-the-ear devices facilitated by technological innovation. In 1986 the firm reported its first loss ever and in 1988 the management board tasked a newly hired CEO with the mandate of turning round the company. After two years of intense focus on cost-cutting in 1990, the CEO, Lars Kolind, laid out a new plan to revolutionise the way the firm was run by making changes to the organisational setup and IT usage. It might have been enough to stop after the cuts that secured the financial stability of the company but the overarching issue was to ensure its long-term competitiveness by transforming Oticon from a traditional industrial organisation, with clearly defined compartmentalised tasks (design, production, R\&D, marketing, sales) to a modern service organisation only producing hearing aids, but also taking care of servicing and listening to its customers. The central idea behind the creation of the 'spaghetti organisation' was to free up the organisational structure to make it more agile, innovative and productive. It was about creating a more productive environment for employees in the belief that if individuals are allowed to choose the projects they work on instead of being assigned projects by management, they would take on more individual responsibility and be more motivated. The changes in the organisation were supported by the moving to new headquarters without offices, with open floors and without fixed seating.

From this point of view the case of SGI/GI in Slovakia is unique among those analysed: the company did not go through a transition phase in which the organisation moved from the 'Sloan type' to the elastic type: it was created this way. It did not have to rethink the organisation but simply to adjust it around the new workers hired, who brought in a number of the above-mentioned pieces of technology that allowed it to function. The use of Dropbox, for example was proposed by and introduced thanks to a young intern. This means that there was no trigger but rather a strong motivation from the beginning to limit personnel and office-related costs. SGI/GI were indeed selected as examples of an NGO and an SME small institutions that do not have resources to have a dedicated IT department or person, but need to be very flexible to attract $\mathrm{HR}$ and function in a multinational setting. They also have an extremely low budget, particularly for overheads and are based on using people work who do not exclusively for SGI/GI (students, other jobs, the self-employed). They have diffused workplaces. SGI/GI, for instance work both within Bratislava (home work or people working elsewhere) and globally to implement projects in Central and Eastern Europe (Hungary, Croatia, Serbia, Kosovo, Caucasus) which include short-term commutes to Brussels and other European capitals. The organisation within Bratislava is also flexible: to save office space, much of the work has not been done in the office, but from home / other places of employment. This required tools for team coordination and communication, but free or very cheap ones. On the corporate services side, the organisation could only afford to pay a part-time accountant, but often information needed to be exchanged or work done outside the two day week framework, again necessitating flexible communication practices. As a result, senior individuals at SGI/GI usually had no fixed working time, but, as team 
leaders, are responsible for a particular project or activity. They have junior employees with whom they negotiate both working time and office time - where office time can be anything from 20 to $100 \%$ of the working time.

Distance teaching was developed long before computers became part of most people's daily lives. The OU was founded in 1969 and in its first operational year it numbered 25,000 enrolled students. The University introduced a Personal Computing policy and three courses that required use of a computer in 1988. Technology did not serve as a tool to change work organisation but dictated it and allowed OU to multiply its number of enrolments tenfold over its four decades of existence. Unlike the other cases, the key objective was not to increase productivity or cut costs, but to expand. Yet one question remains open: was the use of technology intentional to expand or was the expansion the product of using the new tools?

\subsubsection{Workplace innovation and national policies - Case studies}

The cases studies on the Finnish agency for Innovation and on the Dutch part-time economy model focus the discussion on workplace innovation at the national level. Here what is analysed is not which specific technology worked in a certain case, but rather the role of national policy-makers in understanding, anticipating and driving change. The important question is: would the same company adopt innovative practices at the workplace if it was located in Lisbon rather than in Amsterdam or Helsinki? The truth is that national institutions matter and can matter in different ways. In the case of TEKES, the strategy was to diffuse knowledge and create awareness among the wider public and social partners on WPI, as part of the general innovation strategy. As a complement, the Agency also provided funds to help companies and local governments in the transition process. In the Netherlands, on the other hand, the change emerged spontaneously thanks to an environment that over time built a tradition of non-standard forms of employment around the 'flexicurity' system.

\subsubsection{TEKES in Finland}

Workplace innovation was pursued in Finland as a strategy to increase both productivity and the quality of working life, starting in the 1990s. This was seen as a solution to the snowballing old-age dependency ratio. By making workplaces more enjoyable, policymakers expected to increase productivity, on the one hand and on the other, make people work longer.

The goal was pursued as a two-fold strategy. Firstly the agency provided funds to companies that applied for them with a project of transition. This was not the main tool, however: the idea was also to create networks of companies, local governments, academia, experts and social partners to make the knowledge accumulated reach a critical mass. The investment was justified by the goal to create awareness and support around the idea that there is not a trade-off between higher productivity and better quality of working life. All in all, it paid off since the programme enjoys a very high legitimacy among stakeholders.

The same companies in two different countries but with the same idea to invest in the workplace to increase productivity would have had different starting points: the system in Finland allows companies to access funds and knowledge and forces them to make the effort to prepare an appropriate plan to obtain support from TEKES. The same company, but in another country, would not only face these problems on its own but would also be less likely to come up with the idea of revolutionising work organisation towards more WPI because of a lack of awareness and limited public debate. 


\subsubsection{The part-time economy model}

The Dutch economy is sometimes referred to as a 'part-time' economy (or one-and-a-halfearners economy) because part-time employment is significantly more prevalent in the Netherlands than in other European countries. ${ }^{11}$ This has been the case at least since the late 1980s (Visser, 2002; Eurofound, 2007). In 2010, 49\% of total employment in the Netherlands was part-time. The EU average was $19 \%$, with the UK - the country with the second highest incidence of part-time work - had $27 \%$ of employed people in part-time employment. Both men and women are more likely to be employed part-time in the Netherlands compared with any other European country, but women account for the largest part of the difference; more than three quarters of all women in employment worked part-time in 2009, compared to one quarter of men (Eurofound, 2011).

The tendency for employed women to work part-time is combined with a comparatively high labour market participation rate among women in the Netherlands. Furthermore, parttime employment in the Netherlands is largely voluntary; only $4 \%$ of women in part-time employment report that they would prefer to work full-time (Bosch et al., 2009). This is in contrast to the situation in other EU countries, where part-time employment is more likely to reflect under-employment. Part-time jobs have now entered all professions and are well accepted in all workplaces. The pay disadvantage is small and it is possible to develop a career path on part-time schedule (Anxo et al., 2007). This does more to explain the persistence of part-time employment than its emergence. It seems clear that the Dutch parttime economy is not a transitory phenomenon. In a study of working hours of different cohorts of Dutch women Bosch et al. (2010) find that the average number of hours worked has been surprisingly stable for women born after 1950. This contrasts with the experience in Scandinavia, where women also initially entered the labour market primarily in part-time employment, but where full-time employment for women has gradually became the norm (Bosch et al., 2009). Bosch et al. (2010) conjecture that the Dutch part-time economy probably reflects a societal preference or norm related to (women's) work behaviour.

The part-time model forms part of the Dutch version of the flexicurity system, where contractual types - including temporary contracts and agency work - vary relatively more than seen in other European countries (see Viebrock \& Clasen, 2009; Bekker \& Wilthagen, 2008). One key aspect is the normalisation (or mainstreaming) of non-standard work (Wilthagen, 2007); the fact that the differing contract types give the same social security rights as the traditional full-time permanent contract. The availability of a rich menu of contracts provides for flexibility whereas attaching social security, supplementary pension and other benefits forms the security part of the flexicurity system. In addition, the pay differential (controlling for number of hours worked) is relatively small once differences in sectors, occupations and seniority are taken into account.

Workplace innovations are widespread in the Netherlands and flexibility terms of when and how work is organised even applies to marginally employed part-time workers (i.e. employees working less than 20 hours per week). The only indicator where we find substantial differences is in relation to performance-based pay. Only 1 in 20 employed marginally part-time has pay related to firm performance. The figure is three times higher for substantial part-time workers and extends to 1 in 5 for full-time workers. Overall this

11 Part-time work is defined as employment where a person works fewer hours than a comparable full-time worker. This is in line with the definition used by ILO and within EU. It means that part-time employees form a heterogeneus group of people having a working week from a few hours to close to 38 hours (full time). 
suggests that workplace innovations in the Netherlands are a supplement to part-time work as well as to full-time work.

All in all the Dutch case conveys several messages: the first is about part-time work itself: the share of people working part-time is so high that it is possible to affirm that part-time employment has become an innovation by itself, since work organisation has to be rearranged accordingly. This happened at a very limited cost: despite the part-time 'invasion', Dutch workplaces did not give up other innovations and part-time workers are not discriminated from this point of view (with the exception of performance-based pay). Moreover, discrimination occurred from neither the career path nor the social point of view. The last lesson is the most difficult to draw: several pieces of legislation that led to this equilibrium occurred in a totally un-strategic fashion making the Netherlands a case of unintended innovation. Yet all this was crucial in bringing the labour force participation of women to the highest level in the EU.

\subsubsection{Innovation diffusion theory}

Diffusion of innovation theory provides a helpful framework to understand where we are in the adoption of new ways of working. More than a hundred years ago the French sociologist Gabriel Tarde (1903) theorised that the diffusion of innovation follows an S-shaped path characterised by three phases: innovation, growth and maturity (see Figure 21). Based on this early and still very useful insight and the data observed, we can argue that in no country, with the exception of the Netherlands, has workplace innovation reached the maturity phase. In this country, even though the adoption of each single participative practice does not exceed $70 \%$ of workers, the idea of working in non-standard forms of employment is nowadays rooted in society. This is not really because there is more teleworking or more team work compared to other Nordic countries, but rather because here the fact of working in non-standard 9 to 5 forms is so widespread and consolidated to have become part of the culture, to the point where the country is also known as the 'part-time economy'. Therefore what is important in the Dutch case is not the greater or lesser penetration of participative practices but the creation of a support structure that enables different combinations of new ways of working.

Figure 21. S-shaped diffusion of WPI

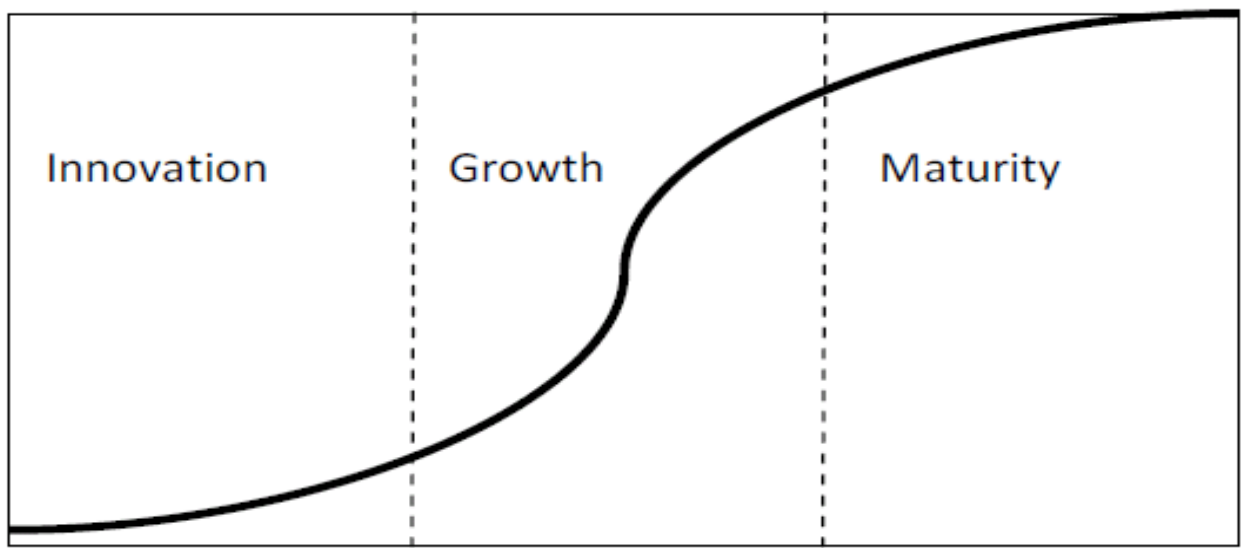

The remaining countries are split between the innovation and the growth phase and, the latter still at a slow rate as indicated by the comparison of 2000 with 2010 data, where we showed that the only substantial change is an increase in the share of workers that receive part of their salary linked to the performance of the company. 
In this group, Finland leads because not only does it rank among the first in the diffusion of innovative practices (together with Denmark and Sweden), but it also has a strategy, through TEKES programmes, to further spread these practices in the country and has already built a solid consensus though social partners This is an example of planned diffusion (Rogers, 1995).

Slovenia also deserves to appear high in this list because in the adoption of participative practices it ranks right after the Nordic countries and has a much wider degree of adoption than to other new member states.

Moving to the micro dimension, we can also argue that two of the four case studies analysed in this report belong to the category of innovators and early adopters, Oticon and the Open University. Geoghegan (1994) clarifies the characteristics of early innovators and lists among them: technology focus, proponents of revolutionary change, visionary users. Oticon 'spaghetti organisation' was implemented during the early 1990s at a time when hardware and software requirements were at the cutting edge of technology. In fact, Oticon was rejected by several software vendors with the message that the specified requirements simply could not be done. FSB Belgium and SGI/GI are an example of early majority, according to Geoghegan a group characterised by: not technically-focused, pragmatic users, averse to taking risks, looking for proven applications. Both organisations indeed implemented participative practices at a time when they could already observe other new forms of organisation and therefore did not need to cope with extreme uncertainty. Nonetheless, they still serve as a model in their societies.

Tornatzky \& Klein (1982) provide a useful list of the attributes of innovation that condition its adoption: compatibility, relative advantage and profitability, observability and communicability, social approval, complexity, some in a positive and some in a negative way. Most of the drivers and barriers analysed so far fit into this categorisation: the fact that workplace innovation fosters product innovation and brings higher productivity corresponds to relative advantage and profitability. Observability and communicability help explain why many companies declare not knowing about WPI, or not being interested. These obstacles justify the policy intervention of TEKES, whose key objective was to overcome this barrier and create networks and knowledge to reach social partners and public opinion. Social approval is related to the issue of trust that we considered as the strongest barrier.

Complexity is related to WPI in a negative way: higher complexity constitutes a barrier to the diffusion and it is the issue that more strongly influences its slow diffusion. This has been documented earlier in this chapter, where we also stressed that higher user-friendliness combined with a young and educated workforce help to reduce complexity (although not to eliminate it, which means that training remains a cost factor when a new form of organisation is implemented).

One question remains to be answered in this section: is workplace innovation a demand or a supply-driven phenomenon with respect to technology? The relationship between technology and WPI has already been explored in section 1.5. Innovation diffusion theory helps to answer this precise question. However, at the time when workplace innovation was introduced by innovators and early adopters, technology was most probably demanddriven: the Oticon CEO was the one to ask high-tech providers to put together hardware and software to make the spaghetti organisation possible. Likewise for the Open University, at a time when learning did not imply an ' $\mathrm{e}$ '. However, as diffusion of participative practices improves, the process becomes supply driven rather than demand-driven because technology already exists and its price decreases as the number of users increase. 


\section{What can and should policy-makers do?}

This report explores the issue of workplace innovation in Europe and the role technological progress plays in its diffusion.

This report proceeded in several steps. We started in chapter 1 by defining workplace innovation and reviewing its pros and cons. We continued with an analysis of the role of technology in workplace innovation. In the third chapter, we looked at the actual situation how widespread is the phenomenon, why do organisations adopt it and what are the barriers to its more general dissemination. This last chapter looks at what can policy-makers do about it. To do so, we need to briefly review our findings from the previous chapters.

We started with a conceptualisation of what characterises innovative workplaces and selected seven elements: flexi-time, teleworking, alternative payment schemes, flat hierarchies, employee empowerment and autonomy, task rotation and multi-skilling, team work and team autonomy. Based on a survey of the literature, analysis of statistics and case studies, we found out that, all in all, positive outcomes of WPI exceed negative ones. More specifically, there is a strong correlation between country level the presence of various aspects of workplace innovation at and technological and economic progress. While correlation does not prove causation, workplace innovation and several other phenomena tend to evolve together as a package at the country level. At the organisational level, literature and our case studies generally lend support to beneficial aspects of workplace innovation.

Looking at the role of technology in workplace innovation, literature and case studies led us to conclude that while technology is an important enabler of workplace innovation, it is not always indispensable for workplace innovation, which can frequently occur without it. However, technology is indispensable for workplace innovation in some types of organisations and in certain types of workplace innovation practices. It is indispensable for the development of certain institutions like the Open University and SGI/GI as we know them today. It is also vital for lowering the costs of workplace innovation. The division of work into tasks, for example, that can be redistributed across more workers can indeed happen independently of technology: the example previously mentioned is the creation of the paralegal profession, in which some of the more repetitive tasks of a lawyer are taken over by a specially trained legal assistant. This can happen without technology but for the redistribution of tasks to spread across a larger geographical area, technology becomes indispensable because it allows cutting transaction costs linked to organisation and communications at longer distances.

Looking at the extent of WPI diffusion across Europe, we found it differs substantially for individual practices. Yet, Nordic countries remain the leaders with more workers involved in most practices, from teleworking to task rotation, while the "South" and some of the new member states lag behind. It is worth noting, however, that Slovenia scores in the top third of the member states, and the quasi-Nordic Baltic states (Estonia, Latvia and Lithuania) also score better than the rest of the new member states despite the fact that they are not more technologically or economically developed.

Most dimensions of workplace innovation froze over the decade 2000-10, with the exception of an increase in performance-related compensation and higher involvement in improving the organisation.

We then tried to understand why, if workplace innovation brings positive results for organisations as well as for workers, it doesn't spread more. We provided five main explanations: 
o Risk aversion, parties' resistance and lack of trust

o Costs of the transition towards WPI

o Sector of production and skills/age of workers

o Size of the company

o National context

In looking at what policy-makers can and should do to promote workplace innovation, we start with how the relevant international organisations - in particular the European Union bodies - look at this issue. Based on this survey, we also present a brief agenda for the EU institutions.

We then progress to four specific types of recommendations. These follow also from previous research (BDL, 2002) that indicates that the barrier to the adoption of workplace innovation is not only a lack of awareness about such practices, but also issues such as 'culture' and 'resistance to change'.

The four types of suggestions - in addition to the proposed EU agenda - address these and other problems by focusing on:

o Building trust and workplace institutions

o Overcoming risk aversion and lack of information

o Overcoming regulatory barriers and uncertainty

o Leading by example

\subsection{What do international organisations recommend and what can the EU do?}

We start with the European Union and its principal policy documents related to WPI.

"Workplace innovation" is not explicitly mentioned in the main EU policy initiatives, such as the EU 2020 strategy. However, in a broader sense, the concept of 'innovative workplace' can be framed within the two flagship initiatives published under the EU 2020 strategy: "New Skills for New Jobs" and "Innovation Union". The aim of the former is to "encourage the strategies of flexicurity, worker and student training, but also gender equality and the employment of older workers". Among others, the document emphasises the need for a "more skilled workforce, capable of contributing and adjusting to technological change with new patterns of work organisation".

The accompanying document to the Flagship Initiative Innovation Union stresses "the increasing importance of non-technological innovation, especially in the burgeoning service sector", such as organisational innovation and the introduction of new business models, marketing strategies, service delivery modes, etc. The document recalls the historical importance of "organisational innovation" in the manufacturing sector involving changes in the way work flows and production have been organised.

The issue of workplace innovation also needs to be understood in the broader context of social innovation of which it is an element. The EU institutions have been recently stressing the issue of social innovation. DG Enterprise, for example, is funding the Social Innovation Exchange project, an online platform that also organises research and events around Europe. DG Research has been funding a number of studies of social innovation in the $7^{\text {th }}$ Framework Programme for Research and Development.

The European Parliament adopted a resolution on 26 October 2011, in which it "considers it advisable to promote an environment conducive to teleworking wherever such arrangements can foster an appropriate work-life balance". 
In 2010, a workshop was hosted by DG Employment, Social Affairs and Equal Opportunities to explore the potential contribution that workplace innovation and new forms of work organisation can make to the realisation of the Europe 2020 strategy. The proposition underpinning the workshop was that appropriate interventions led by public policy and social partners could significantly enhance the adoption of new forms of work organisation; this in turn would lead to measurable increases in productivity, innovation, job quality, employability, the distribution of appropriate skills, workplace health and other measures relevant to Europe 2020.

The issue of workplace innovation has also been discussed by the European Economic and Social Committee (2011a), which adopted an opinion on innovative workplaces as a source of productivity and quality jobs: "The Committee believes that it is the European Union's task to support all Member States and companies in their efforts to increase workplace innovation. Innovation at the workplace is used to try and remodel organisational activities in a sustainable way while at the same time improving both productivity and the quality of work."

The Committee issued the following recommendations:

o The Commission should launch a pilot project on innovative workplaces - including, in particular, studies on the relationship between the quality of working life, innovativeness and productivity.

- A European index should be introduced describing the quality of working life and its effects on innovativeness and productivity.

o Innovation policy should concentrate more on how the different partners can work together more effectively to promote innovative workplaces.

o In general, EU bodies as well as the member states are advised to adopt a long-term perspective, a methodical approach and support in the form of advice and guidance with launching and carrying through improvement projects, which should focus on social partners and civil society and their role in organising training and presenting best practices must be strengthened.

Workplace innovation is also partly related to occupational safety and health policy. In the European Commission's (2007) Community Strategy 2007-2012 on health and safety at work, "Improving quality and productivity at work is mentioned in the title. The common topics in $\mathrm{OSH}$ policy (occupational health and safety) and workplace innovation are such things as job autonomy, teamwork, labour-management cooperation and work-life balance. Job autonomy enhances learning and prevents psychological stress. Better ergonomic conditions increase productivity and reduce physical workload.

The European Union already has adopted some 'hard law' that can facilitate workplace innovation, particularly in terms of promoting social dialogue. Directive 2002/14/EC establishes minimum requirements for the right to information and consultation of employees. The Directive not only requires employers to provide to representatives of employees information on the recent and probable development of the undertaking's or the establishment's activities and economic situation, but also specifically information and consultation, with a view to reaching an agreement, on decisions likely to lead to substantial changes in work organisation or in contractual relations. The Commission's 2008 review found:

Only a few Member States adopted measures to transpose the Directive within the required deadline (FR, HU, NL, PT, SK, FI, UK). Two Member States (DE, AT) notified the Commission that their existing legislation already conforms to the 
Directive's requirements. BG and RO transposed the Directive, as required, before the date of their accession to the EU. Thus, the majority of the Member States failed to transpose the Directive on time" (European Commission, 2008).

At the OECD, the most relevant policy document is the "OECD innovation strategy". It represents the culmination of a three-year, multidisciplinary and multi-stakeholder effort. It provides analysis and policy guidance on a broad range of issues from education and training policies, to policies that provide a conducive business environment and infrastructure for innovation, to policies that foster the creation and diffusion of knowledge. Among the policy principles suggested, the OECD (2010) states:

Education and training systems should equip people with the foundations to learn and develop the broad range of skills needed for innovation in all of its forms, and with the flexibility to upgrade skills and adapt to changing market conditions. To foster an innovative workplace, ensure that employment policies facilitate efficient organisational change.

Based on these initiatives and other findings presented in the rest of this section, we recommend three main actions at the EU level.

The first one is to preserve the focus on workplace innovation specified in the implementation of the Europe 2020 strategy and other EU initiatives that influence innovation policies. For example, as ECOSOC emphasised, innovation policy should concentrate more on how the different partners can work together more effectively to promote innovative workplaces. The issue is broader than that however. As shown earlier, access to and availability of internet and broadband can have substantial influence on spreading workplace innovations.

The second action bears more directly on the issue of workplace innovation and its place in EU policies. The European Commission should open public consultations at the EU level on the issue of workplace innovation and consider creating and/or supporting stakeholder networks on this issue. This may sound like a proposal to only pay lip service to the issue, but experience suggests that policy change at the EU and national levels begins with naming and measuring. Alternatively, the consultation could be linked to the experience with implementation of the Directive on employee rights to information and consultation and its implementation.

A similar logic is behind a third set of proposed action. The European Commission should also consider launching a pilot project on innovative workplaces. This could include detailed studies on the relationship between the quality of working life, innovativeness and productivity, more data collection in the field at the European level, including ad hoc surveys from Eurostat and even, potentially, the introduction of a European index describing the quality of working life and its effects on innovativeness and productivity. These could be linked to the overall focus on social innovation that the Commission is currently pursuing.

\subsection{Building trust and workplace institutions}

As discussed in chapter 3 , one of the main barriers to wider diffusion of innovative practices in the workplace is trust. The reasons why trust is so important in designing and implementing workplace innovation are two-fold. First of all, it touches upon the very core of the employer-employee/trade union relationship. Secondly, evidence shows that such a change constitutes a highly incomplete contract - i.e. it is impossible to precisely specify in advance what it entails and there is a significant learning and adaptation process involved. With incomplete contracts, the presence of trust and/or of formal and informal institutions can be very important. 
Of course, the operationalisation of this approach solely for the purpose of workplace innovation presents some difficulties, but two recommendations can still be made:

- Overall support for building trust and social dialogue can be instrumental in supporting workplace innovation.

o Policy-makers should look for ways to stimulate long-term 'preventive' social dialogue specifically on the issue of workplace innovation.

Finland once again provides a good example: as emphasised by one of the interviewees, the role of the policy-makers has not been limited to providing finance for the projects. One of the key goals was to raise awareness and to promote WPI across the country. In this sense, the 3 TEKES programmes have been very successful: the programmes enjoy a very high legitimacy among key stakeholders, including the social partners which share the view that there is no trade-off between productivity and quality of working life (Arnkil, 2003). Even though the share of firms that have adopted some form of workplace innovation is still small, there is not only a strong political backing but also large awareness of its importance among the wider public. "A clear indication of this success is that the programme has survived the policy debates of tripartite steering and the turbulences of three national government formations, and the resources were almost doubled in the new programme period for 2004-09 (ibid.).

There is also a link to the European level via the EU Directives on information and consultation and their utilisation, which is described in more detail in the previous section.

\subsection{Overcoming risk aversion and lack of information}

One of the key conclusions of this research is that there is a role for a direct government action to disseminate knowledge and assist organisations in using workplace innovation. The rationale for such action is a combination of risk aversion and information costs in the organisations involved. Risk aversion is associated with the incomplete knowledge about and uncertain distribution of benefits from workplace innovation. Therefore, policy-makers can lower the risk aversion of individual companies/institutions by providing funds and knowledge and also by creating networks of companies/individuals involved in workplace innovation.

In this respect, a clear example of good practice is, once again, the Finnish TEKES programme. The role designed for TEKES, as a public agency, has been not only to provide funds and knowledge for this or that company. Three other important functions have been: i) to push people involved in the same area towards the creation of networks and ii) to mobilise resources for the creation of expertise through universities and consultants and awareness among the public and iii) to include WPI as part of the country's general innovation strategy.

The experience of TEKES can certainly be inspirational to similar institutions across European countries, but unfortunately it is not possible to speak about 'exporting' it because it requires a long-term view and because the outcome is conditional on the institutional elements. On top of this, in times of tight budgetary constraints, it is even more difficult for government to raise funds.

The Finnish experience also shows there cannot be one-size-fits-all approach: a particular set of workplace innovations that worked for one company cannot be just copied by another. Nonetheless, in general, a participatory approach strongly influences the outcome of the transition. The presence of experts goes hand in hand with a professional approach to changes in organisation, especially for large ones. This is witnessed by the fact that most of 
the funds provided under the TEKES programmes were indeed used by the firms to pay consultants to help them pass from one system to another. One interviewee also revealed that the unfortunate choice of appropriate consultants can be one of the factors that leads to the failure of the process.

Of course, creating an integrated, large-scale programme or a dedicated agency is not the only possible way to go forward. Specific elements of this approach - for example, creating a dedicated funds for funding the training of managers and/or trade unionists, supporting research on the topic or financing dissemination of information - can be undertaken on their own. However, the Finnish case also shows the synergic effects of an integrated approach.

\subsection{Overcoming regulatory barriers and uncertainty}

Overcoming regulatory barriers and uncertainty are essential steps in the process and, unlike the previous two sections, they require the direct involvement of policy-makers. This is a tricky issue because it involved a complicated balancing act. On one hand, it requires fighting for equality for all types of work in labour law and welfare systems in order to avoid marginalisation and segregation of 'atypical' work, but, at the same time, it also requires taking into account very different nature of work under the conditions of workplace innovation, which might require different treatment in the very same systems - for example, more flexibility in labour law (e.g. that some things can be agreed between employers and employees) as well as taxation issues (e.g. tax implications of "bring your own device").

In this respect, the Dutch case study showed that a wholesale adoption of a new form of work (part-time work in the Dutch case) can be facilitated by the establishment of true equality of labour law and welfare systems of this form with more traditional ways of working. This was then a significant factor in gaining the wider social acceptance of parttime work and its transition from being regarded as an exception to a part of the norm.

On the other hand, our research and previous experience point to an apparent puzzle. Many organisations contemplating workplace innovation believe that inflexible labour laws or collective agreements create significant obstacles for change, but a detailed analysis of these shows that these perceived obstacles are more frequently identified in general than specifically. The real problem seems often to be uncertainty rather than negative certainty.

Labour legislation on telework and other atypical forms of labour resulting from workplace innovation are often a legal afterthought, resulting in considerable regulatory uncertainty.

For example, from the Slovak case study on SGI/GI, we can see that the legal regulation of domestic work/telework has, so far, been a regulatory afterthought that has not caught up with a very dynamic reality. $\$ 52$ of the Labour Code regulates domestic work and telework. Regulation of telework was only added in 2007. \$52 is very general, essentially stipulating that the general Labour Code also applies to this work with minor exceptions related to working time. It also places several wide-ranging burdens on the employer:

o guarantee personal data protection of data used by domestic/telework employee and

o prevent 'isolation' of domestic workers and teleworkers and ensure the possibility of meeting with other employees.

The small company in our case study overcame these risks by a combination of the following approaches:

o avoiding employer-employee relationship through use of 'contractor' or 'supplier' contracts and

o employing staff on a standard contract and then tolerating that they work from home or elsewhere without any formal contract stipulations. 
Obviously, this approach is not realistic for larger companies or even for small institutions without the level of trust present in SGI/GI. Therefore, a key role for the authorities is to provide assistance in identifying barriers in legal/regulatory uncertainty and trying to provide clear, binding answers. This concerns issues ranging from general labour legislation through health and safety at work to data protection and fiscal/social security issues. A proactive approach by the authorities could involve appointing liaisons for workplace innovation at key regulatory agencies - labour inspectorate, social security agency and the tax administration - with a clear mandate.

These obstacles can also explain some of the cross-country differences and varied nature of change within countries. Once a limited number of companies become trailblazers that resolve these issues internally and with the authorities, thus bearing the costs of change and uncertainty, others can follow with these costs much diminished. This also points to the need to have explicit pilots and precedents.

\subsection{Leading by example}

The public sector plays an important although varying role as employer in all EU member states. Therefore, in addition to large-scale interventions of the TEKES kind, one of the ways policy-makers can encourage the wider adoption of workplace innovation is for them to encourage public sector institutions to lead by example. As BDL (2002) shows, public sector institutions are generally perceived to face more difficulty in shifting to new forms of work organisation compared to private sector organisations. Therefore, successful change in such an environment can send an important message to the wider corporate world that it is possible. Additionally, they might find it easier to resolve the regulatory uncertainty issues with other authorities than private companies might.

As part of the 'NOVO project' at FPS Belgium, several initiatives have been taken aimed at motivating the employees, improving the working environment and changing the traditional working culture towards a more cooperative and collaborative attitude. Two main innovations were introduced: teleworking and the possibility to measure work on the basis of performance instead of working hours. These two main initiatives have been accompanied by the creation of a new working space with dynamic offices and clean desks (no personalised desks - top management included). Before adopting the new office policy, the system was tested on a group of 40 employees. The results were positive, showing to the FPS staff the feasibility of the dynamic office system. For all the employees based in Brussels (around 1,000), FPS has now in total 668 desks, 154 spots for conversation and 25 meeting rooms. The institution is renting $70 \%$ of office space (six floors of the Financial Tower) instead of $100 \%$ where each employee had his/her own desk. The initial investment was $€ 10$ million, but, in the long term, the dynamic office approach saved $30 \%$ in office space and $€ 6$ million are saved each year. To make the dynamic offices and teleworking a reality, in 2009, new devices were given to the employees and internet connections installed in the employees' homes (personal laptops, USB key, LCD screen), the ICT infrastructure was renovated and new communications tools introduced: such as the soft phone (device to call from your computer) and office communicator (chat).

The FPS example also shows that since benefits of such a change can be tangible in financial terms, using public expenditure to support such projects can be more easily justified for public institutions and does not encounter state aid problems. Therefore, government initiatives to specifically encourage/foster change in the public sector or its specific subsectors - e.g. public administration or education - can be one of the ways forward if a TEKES-type approach is not feasible or desirable in a given country. 


\section{References}

\section{Academic literature}

Alasoini, T. (2004), “The New Finnish Workplace Development Program (TEKES-FWDP) as an Approach to Innovation", Concepts and Transformation 9(3), pp. 279-295.

(2006), "In search of generative results: a new generation of programmes to develop work organisation", Economic and Industrial Democracy, Vol. 27, No. 1, pp. 9-37.

(2009), "Strategies to Promote Workplace Innovation: A Comparative Analysis of Nine National and Regional Approaches", Economic and Industrial Democracy, 30(4), pp. 614-642.

(2011), “Workplace Development as Part of Broad-based Innovation Policy: Exploiting and Exploring Three Types of Knowledge", Nordic Journal of Working Life Studies 1(1), pp. 23-43, (http:/ / ej.lib.cbs.dk/index.php/nordicwl/article/view/3311).

Alasoini, T., A. Heikkila, E. Ramstad and P. Ylostalo (2008), "High-involvement work practices through development projects? Management and employee views in comparison", Tekes - Finnish Funding Agency for Technology and Innovation, Finland, Helsinki.

Alexander B., D. Ettema and M.Dijst (2010), "Fragmentation of work activity as a multidimensional construct and its association with ICT, employment and sociodemographic characteristics", Journal of Transport Geography, Urban and Regional Research Centre Utrecht (URU).

Ananian S. and P. Aubert, (2004), "New Technologies, Workplace Organisation and the Age Structure of the Workforce: Further Evidence Using the REPONSE Survey", Documents de Travail de la DESE - Working Papers of the DESE g2004-11, Institut National de la Statistique et des Etudes Economiques, DESE, Paris.

Antoni, C.H. (2005), "Effects of team task structure on team climate for innovation and team outcomes", Enterprise and Work Innovation Studies, No. 1, Inovacao Empresarial e do Trabalho, (IET), Monte de Caparica, Portugal.

Anxo, D., C. Fagan, I. Cebrian and G. Moreno, (2007), "Patterns of labour market integration in Europe-a life course perspective on time policies", Socio-Economic Review 5, pp. 233-260.

Appelbaum, E., T. Bailey, P. Berg and A. Kalleberg (2000), Manufacturing Advantage - Why High-Performance Work Systems Pay off, ILR Press, Ithaca, NY.

Arnkil, R., P. Rissanen, S. Pitkänen, T. Piirainen, P. Koski, P. Berg and M. Vartiainen (2003), "The Finnish Workplace. Development Programme - A Small Giant?", Evaluation Report, Ministry of Labour, Finland.

Arthur, J.B. (1994), "Effects of Human Resource Systems on Manufacturing Performance and Turnover", Academy of Management Journal, 3(37), pp. 670-687.

Arundel, A., E. Lorenz, B. Lundvall and A. Valeyre (2007), “The Organisation of Work and Innovative Performance: a comparison of the EU-15", paper prepared for Blue Sky II Indicators Conference, 25-27 September, Ottowa, Canada.

Atkinson, J. (1984), "Manpower strategies for flexible organisations", Personnel Management, August, pp. 28-31. 
Bauer, T.K. (2004), "High Performance Workplace Practices and Job Satisfaction: Evidence from Europe", DP No. 1265, (IZA) Institute for the Study of Labour, Bonn, August.

Bayrak, E., JP. Conley and S. Wilkie (2011), “The economics of cloud computing”, Working Paper No. 11-W18, September, Vanderbilt University, Nashville.

Bekker, S. and T. Wilthagen (2008), “Europe's Pathways to Flexicurity: Lessons Presented from and to the Netherlands", Intereconomics, March/April.

Black, S.E. and L.M. Lynch (2003), "What's driving the new economy? The benefits of workplace innovation", Working Papers in Applied Economic Theory 2003-23, Federal Reserve Bank of San Francisco, San Francisco, CA.

Bosch, N., A. Delen and R. Euwals (2009), “Is part-time employment here to stay? Working hours of Dutch women over successive generations", Labour 24(1), pp. 35-54.

Boxall, P. and K. Macky (2009), "Research and theory on high-performance work systems: progressing the high-involvement stream", Human Resource Management Journal 19, (1), pp.3-23.

Business Decisions Limited (2002), "New Forms of Work Organisation: The Obstacles to Wider Diffusion", Report for the European Commission, BDL: Brussels, October.

Coleman, D. (2009), Enterprise Social Collaboration Research, Study, June (http://bit.ly/JrewdK).

Cottini, E., T. Kato and N.W. Nielsen (2009), "Adverse Workplace Conditions, HighInvolvement Work Practices and Labor Turnover: Evidence from Danish Linked Employer-Employee Data", DP No. 4587, (IZA) Institute for the Study of Labour, Bonn.

Couclelis, H. (2003), Housing and the new geography of accessibility in the information age. Open House International, theme issue on "ICT, Housing \& the Built Environment", 28(4), pp. 7-13.

Cressey, P. and M. Kelleher (2003),"The Conundrum of the Learning Organisation Instrumental and Emancipatory Theories of Learning", in B. Nyhan, P. Cressey, M. Kelleher and R. Poell (eds), Learning Organisations: European perspectives, theories and practices, Luxemborg: CEDEFOP, pp. 93-107.

Cristini, A. and D. Pozzoli (2008), "Workplace Practices and Firm Performance in manufacturing: A Comparative Study of Italy and the UK", International Journal of Manpower, Vol. 31, No. 7, pp. 818-842.

Cristini, A., T. Eriksson and D. Pozzoli (2011), "High-Performance Management Practices and Employee Outcomes in Denmark", Working Papers 11-1, University of Aarhus, Aarhus School of Business, Department of Economics.

De Kok, J.M.P. and D.N. Den Hartog (2006), “High performance work systems, performance and innovativeness in small firms", EIM Scales Paper N.200520, EIM: Zoetermeer, The Netherlands.

Dhondt, S. (2004), "Workplace innovation as the driving force for innovation. New roles for social partners" (http://www.ser.nl/nl/publicaties/overige/20002008/2004/b23574.aspx).

Ebrahim, A.N., A. Shamsuddin and T. Zahari (2009), "Innovation and R\&D Activities in Virtual Team", European Journal of Scientific Research, Vol. 34 No. 3, pp. 297-307. 
Eeckelaert, L., S. Dhondt, P. Oeij, P.F. Pot, G.I Nicolescu, J. Webster and D. Elsler (Forthcoming), "Review of workplace innovation and its relation with occupational safety and health, European Agency for Safety and Health at Work, Bilbao.

Etro, F. (2009), "The Economic Impact of Cloud Computing on Business Creation, Employment and Output in Europe An application of the Endogenous Market Structures Approach to a GPT", Innovation Review of Business and Economics, Vol. 2, No.2, pp. 179-220.

--12010), "The economics of cloud computing" (http://www.voxeu.org/index.php?q=node/4671).

Eurofound (2005), "New forms of work organisation. Can Europe realise its potential? Results of a survey of direct participation in Europe", European Foundation for the Improvement of Living and Working Conditions, Dublin.

(2009), "Working Conditions in the European Union: Work Organisation" European Foundation for the Improvement of Living and Working Conditions, Dublin (http:// www.eurofound.europa.eu/publications/htmlfiles/ef0862.htm).

(2010a), "5th European Working Conditions Survey", European Foundation for the Improvement of Living and Working Conditions, Dublin.

(2010b), "European Company Survey 2009: Overview", European Foundation for the Improvement of Living and Working Conditions, Dublin.

- (2011) "Recent developments in work organisation in the EU27 Member States and Norway" European Foundation for the Improvement of Living and Working Conditions,

Dublin (http://www.eurofound.europa.eu/publications/htmlfiles/ef11461.htm).

Falk, A., I. Menrath, P.E. Verde and J. Siegrist (2011), “Cardiovascular Consequences of Unfair Pay", SOEP paper, Berlin.

Ferreira, P., I. Neira and E. Vieira (2010), "The influence of human capital of the workforce in the adoption of high-performance work systems: the case of Portugal and Spain", paper prepared for the XIX meeting of the Economics of Education Association, University of Zaragoza, Zaragoza.

Fershtman, C.N. Gandal (2012), "Migration to the cloud ecosystem: Ushering in a new generation of platform competition" (http:/ / www.voxeu.org/index.php?q=node/7867).

Fichman, R.G. (1992), "Information Technology Diffusion: A Review of Empirical Research", Proceedings of the Thirteenth International Conference on Information Systems (ICIS), December, Dallas, 195-206.

Gagliardi, D. (2011), “Next Generation Entrepreneur: How Web 2.0 Technologies Creep into SMEs", eChallenges e-2011 Conference Proceedings, Paul Cunningham and Miriam Cunningham (eds), IIMC International Information Management Corporation.

Gassmann, O. and M. von Zedtwitz (2003), "Trends and determinants of managing virtual R\&D teams", RED Management, Vol. 33, No. 3, pp. 243-262.

Geoghegan, W.H. (1994), “Whatever happened to instructional technology?”, Paper prepared for the 22nd Annual Conference of the International Business Schools Computing Association, Baltimore, Maryland, 17-20 July. 
Gillen, D. and J. Doug (2002), "Bus Rapid Transit and the use of AVL Technology: A Survey of Integrating Change", UC Berkeley.

Godard, J. (2004), "A Critical Assessment of the High-Performance Paradigm”, British Journal of Industrial Relations, No. 42, pp. 349-378.

Golden, T.D., J.F. Veiga and D. Richard (2008), "The Impact of Professional Isolation on Teleworker Job Performance and Turnover Intentions: Does Time Spent Teleworking, Interacting Face-to-Face, or Having Access to Communication-Enhancing Technology Matter?", Journal of Applied Psychology, Vol. 93(6), pp. 1412-1421, November.

Goudswaard, A., P. Oeij, T. Brugman and T. De Jong (2009), “Good practice guide to internal flexibility policies in companies", European Foundation for the Improvement of living and Working Conditions, Dublin.

Greenbaum, J. (2004), “Windows on the workplace, technology, jobs, and the organisation of office work", Monthly Review Press, New York, NY.

Gustavsen, B. (2007), "Work organisation and the Scandinavian model", Economic and industrial democracy, Vol. 28, no. 4, pp. 650-671, Sage, Department of Economic History, Uppsala University, Sweden.

Guthrie, J.P. (2001), “High-involvement work practices, turnover, and productivity: Evidence from New Zealand", Academy of Management Journal, 1(44) pp. 180-190.

Handel, M.J. and David I. Levine (2004), "The Effects of New Work Practices on Workers", Industrial Relations 43:1-43.

Heywooda, J., U. Jirjahn and X. Wei (2008), “Teamwork, monitoring and absence”, Journal of Economic Behavior \& Organisation, No. 68, pp. 676-690.

Huselid, M.A. (1995), "The Impact of Human Resource Management Practices on Turnover, Productivity, and Corporate Financial Performance", Academy of Management Journal, 3(38) pp. 635-672.

Jones, D.C., P. Kalmi, T. Kato and M. Mäkinen (2008), “The effects of human resource management practices on firm productivity - preliminary evidence from Finland", The Research Institute of the Finnish Economy, Discussion Paper No. 1121.

Kalmi, P. and A. Kauhanen (2008) "Workplace Innovations and Employee Outcomes: Evidence from Finland", Industrial Relations, Vol. 47(3) pp. 430-459.

Karasek, R.A. (1979), “Job demands, Job decision latitude and Mental Strain: Implications for Job Redesign", Administrative Science Quarterly, Vol. 24, pp. 285-308.

Kitou, E. and A. Horvath (2008), "External Air Pollution Costs of Telework", International Journal of Life Cycle Assessment, Vol. 13(2), pp. 155-165.

KPMG (2011), "Work fragmentation, how much is too much?" (www.kpmg.com.au).

Kristiansen, M. and J. Bloch-Poulsen (2011), "Participation as Enactment of Power in Dialogic Organisational Action Research. Reflections on Conflicting Interests and Actionability", International Journal of Action Research, No. 7, Issue 3, pp. 319-346.

Lawler, E. (1986), High-Involvement Management, Jossey-Bass, New Jersey, San Francisco.

MacDuffie, J.P. (1995), “Human Resource Bundles and Manufacturing Performance: Organisational Logic and Flexible Production Systems in the World Auto Industry", Industrial and Labor Relations Review, Vol. 2(48), pp. 197-221. 
Malone,T.W., R.J Laubacher and T. Johns ( 2011), “The age of specialization”, Harvard Business Review, July/August.

McKinsey Global Institute (2011), "An economy that works: Job creation and America's future", (http://www.mckinsey.com).

(2012),"Help wanted: The future of work in advanced economies", (http:/ / www.mckinsey.com).

OECD (2010), "The OECD innovation strategy: getting a head start on tomorrow", OECD Publishing, Paris (www.oecd.org/innovation/strategy).

Origo, F. and L. Pagani (2008), "Workplace flexibility and job satisfaction: some evidence from Europe", International Journal of Manpower, Emerald Group Publishing, Vol. 29(6), pp. 539-566, September.

Osimo, D., K. Szkuta, P. Foley and others (2010), “Enterprise 2.0 study: D4 Final report", Brussels, 7 December.

Petra, A. and D. Czarnitzki (2012), "Small firm innovation performance and employee involvement", ZEW Discussion Papers 12-013, ZEW - Zentrum für Europäische Wirtschaftsforschung / Center for European Economic Research, Mannheim, Germany.

Pfeffer, J. (1994), Competitive Advantage Through People, Boston: Harvard Business School Press.

Pot, F. and others (2011), "Social innovation of work and employment, Challenge Social Innovation", paper prepared for Proceedings workshop: Social innovation at work, Vienna, 19-21 September.

Powell, A., G. Piccoli and B. Ives (2004), “Virtual teams: a review of current literature and directions for future research", Data base for Advances in Information Systems, pp. 3536.

PWC (2011), "Een verkenning van macroeconomische effecten van het Nieuwe Werken" (http://www.hetnieuwewerkendoejezelf.nl/media/48867/rapport_economische_bate n_hnw.pdf).

Ramsay, H., D. Scholarios and B. Harley (2000), "Employees and High-Performance Work Systems: Testing Inside the Black Box", British Journal of Industrial Relations, No. 38:4, pp. 501-531.

Ramstad, E. (2005), "Simultaneous improvement in performance and the quality of working life through developing the work organization", in T. Alasoini, E. Ramstad and N. Rouhiainen, The Finnish Workplace Development Programme as an expanding activity Results, challenges, opportunities, TYKES report 47.

(2005) “Self-assessment results of the TYKE programme's development projects (1996-2003) in examination", in T. Alasoini, E. Ramstad and N. Rouhiainen, The Finnish Workplace Development Programme as an expanding activity Results, challenges, opportunities, TYKES report 47.

(2009) "International Journal of Productivity and Performance Management Emerald Article: Promoting performance and the quality of working life simultaneously", International Journal of Productivity and Performance Management, Vol. 58, No. 5, pp. 423-436. 
Rhoads, C. and S. Silver (2005, December 29), "Working at Home Gets Easier: Advances in Rogers, E.M. (1995), Diffusion of innovations (4th ed.), New York, NY: Free Press.

Ruth, S. and I. Choudhury (2008), "Telework: A Productivity Paradox?", IEEE Internet Computing, Vol.12, No. 6, pp. 80-83.

Schin, T. (2008), "Earnings inequality within organisations", Social Science Research, Department of Sociology, University of California, Berkeley, CA.

Schmidt, T. and C. Rammer (2007), “Non-technological and Technological Innovation: Strange Bedfellows?", Discussion Paper No. 07-052.

Straus, S. and F. Olivera (2000), "Knowledge acquisition in virtual teams", in Griffith (ed.), Research on Managing Groups and Teams, Vol. 3, JAI Press.

Swart, J., N. Kinnie and J. Purcell (2004), "Human Resource Advantage in the Networked Organisation, management revue", The International Review of Management Studies, 15, issue 3, pp. 288-305.

Tan, T.C.F. (2010), "A perception-based model for technological innovation in small and medium enterprises", 18th European Conference on Information Systems.

Tarde, G.D. and E.W.C. Parsons (1903), The laws of imitation, New York, NY: Holt and company Technology Make Telecommuting More Feasible", Wall Street Journal.

Thomas, P., L. Carswell, B. Price and M. Petre (2004), "Is there a wage payoff to innovative work practices?", Industrial Relations, 43 (1), pp. 67-97.

Tornatzky, L.G. and K.J. Klein (1982), "Innovation characteristics and innovation adoptionimplementation: A meta-analysis of findings", IEEE Transactions on Engineering Management, Vol. 29, No. 1, pp. 28-45.

Totterdill, P. (2009), “Workplace Innovation Policies in European Countries", report to (Kowin) The work Institute (www.ukwon.net).

Totterdill, P., S. Dhondt and S. Milsome(2002), "Partners at Work? A Report to Europe's Policy Makers and Social Partners", The Work Institute, Nottingham (www.ukwon.net).

Verhofstadt, E., H. De Witte and E. Omey (2007), "Are young workers compensated for a high strain job?", Working paper 2007/436, University of Gent, January.

Viebrock, E. and J. Clasen (2009), "Flexicurity and welfare reform: a review”, Socio-Economic Review No. 7, pp.305-331.

Visser, J. (2002), "The first part-time economy in the world: a model to be followed?", Journal of European Social Policy, Vol. 12(1), pp. 23-42.

Westfall, R.D. (2004), “Does Telecommuting Really Increase Productivity?”, Communications of the ACM, Vol. (47)8, pp. 93-96.

Wilthagen, T. (2007), “Flexicurity Practices. Rapporteur of the European Expert Group on Flexicurity"(http://www.lex.unict.it/eurolabor/documentazione/altridoc/ricerche_r apporti/EEGF_flexi_practices_may07en.pdf).

Zoghi, C., D. Mohr and P.B Meyer (2005), “Workplace Organisation and Innovation”, BLS Working Paper No. 405, US Department of Labor, Washington, D.C.

Zoll, R.(2004), “The Paradoxes of Subjectivization of Work" (107-120), in Globalisation, company strategies and quality of working life in Europe, F. Garibaldo and T. Volker (eds), Vol. 25, Peter Lang, Frankfurt am Main. 


\section{Official EU legislation and reports}

European Commission (1997), Green Paper on Partnership for a new organisation of work, Luxembourg.

European Commission (2007), Improving quality and productivity at work: Community strategy 2007-2012 on health and safety at work. Brussels, COM(2007) 62 final.

European Economic and Social Committee (2007), Promoting sustainable productivity in the European workplace. Brussels (SOC/266).

European Commission (2010a), Europe 2020. A European strategy for smart, sustainable and inclusive growth, Brussels: $\operatorname{COM}(2010) 2020$.

European Commission (2010), Agenda for new skills and jobs, Brussels, COM (2010) 682.

European Commission (2010d), Europe 2020 Flagship Initiative Innovation Union, Brussels, COM (2010)546 final.

European Commission (2010c), Accompanying document to the Europe 2020 Flagship Initiative Innovation Union, Brussels, Commission staff working document, COM(2010)546/ SEC(2010)1161 final.

European Parliament (2011), Resolution of 26 October 2011 on the Agenda for New Skills and New Jobs, Brussels, Brussels, (2011/2067(INI).

European Economic and Social Committee 'Innovative workplaces as a source of productivity and quality jobs' (own-initiative opinion), Brussels, 2011/C 132/05.

European Commission (2010a), Social innovation as part of the Europe 2020 strategy, Brussels: Bureau of European Policy Advisers 9.

European Commission (2010b), Proposal for a Council Decision on guidelines for the employment policies of the Member States. Part II of the Europe 2020 Integrated Guidelines, Brussels: COM92010) 193/3.

European Commission (2010c), Accompanying document to the Europe 2020 Flagship Initiative Innovation Union, Brussels: Commission staff working document, COM(2010)546/ SEC(2010)1161.

European Economic and Social Committee (2011), Innovative workplaces as a source of productivity and quality jobs, Brussels (SC/034). 


\section{Annex 1. Mini-case studies}

\section{SGI/GI}

The Slovak Governance Institute is a non-governmental organisation and think tank in Bratislava, Slovakia. It was created by two economists, Miroslav Beblavý and Andrej Salner, in 2001. It is a leading Slovak think tank in the areas of education and social policy, good governance and public administration. The two founders alternated as CEOs between 2001 and 2008, while Ctibor Košt'ál has been the CEO since late 2008. It is financed primarily by grants from institutions such as the Open Society Institute, the European Commission and others. The Governance Institute (GI) was created in 2007 as an affiliated for-profit consulting firm. In 2011, it was disaffiliated from SGI and changed its name. GI was created to administratively separate for-profit, mainly international consulting activities from mainly Slovakia-oriented public policy and advocacy activities at the SGI core. Therefore, it had no separate staff, but SGI personnel were utilized. Its work was funded based on public tenders won, with principal customers being the DFID, OECD, European Commission and OSI.

Joint annual turnover of the two organisations has oscillated between $€ 200,000$ and $€ 500,000$ annually since its inception.

SGI does not have stable employment patterns that would allow producing a simple headcount. It has:

- one CEO,

- seven partners (one of whom is the CEO), who collectively hold all decision-making powers,

- a changing number of other employees, frequently part-time/students (between 2 and 6 at a time), including a part-time accountant and project managers; and

- a changing number of interns, who are usually between 50 and $100 \%$ of full-time equivalent and who are usually unpaid (between 2 and 8 at a time).

It should also be noted that one of the authors of this study, Miroslav Beblavý, is a co-founder of SGI, which presents potential conflict-of-interest issues in the research and its presentation. However, an internal CEPS review concluded that since SGI has no vested interest in the outcomes of this study, is not involved in selling any of the products or benefitting from policy issues discussed here, the risk was outweighed by the ability to collect confidential data and present this very interesting case.

\section{Open University}

The OU is a distance learning and research university founded in 1969 by the Royal Charter in the United Kingdom. First students $(25,000)$ were enrolled in January 1971 with a choice of multidisciplinary foundation courses in the arts, social sciences, science or maths. Contrary to standard admission procedures, the OU did not insist on any prior educational qualifications - the university required students to take two foundational courses before moving on to higher level study and then to a BA degree.

In the late 1970s the total number of students reached 70,000 with approximately 6,000 people graduating each year. From then on, the institution would each year set new records in the number of people applying to study and achieving their degree. This increase came in the face of $7 \%$ cut in the university's grant when Margaret Thatcher, the new Education Secretary, was not impressed with the project.

New methods of learning were introduced after computers began to replace typewriters on desks and video recorders replaced the need to set the alarm to view the OU's early morning broadcasts. The university introduced its first taught higher degrees using the same multi-media mix of teaching and learning methods. 
The OU has always pioneered the use of new technologies for studying. Staff at the OU started to use CoSy, an asynchronous text based communication application, in 1986. By 1988, the University had a Personal Computing policy and had introduced three courses that required use of a computer.

Expansion continued to be the keyword for the university during the 1990s. New areas of study included English law (in association with the College of Law), modern languages and expanded programmes in most other faculties and schools.

Since 2000, the OU explored the opportunities of using the internet and made use of the internet a compulsory element in a course. This led to the openness of the university and to the OU making its materials readily and freely available to the global audience.

OU counts today more than 260,000 students and a total income for the year 2009-2010 of $£ 450.1$ million.

\section{Oticon}

The Danish hearing aid company, Oticon, was founded in 1904 as an importer of hearing aid devices from the United Kingdom. After the Second World War it began producing its own hearing aid devices and established itself as one of the world market leaders for hearing aids in the 1960s and 70s. Today it employs more than 3,500 people worldwide and is among the three largest producers of hearing aid devices with sales in over 100 countries around the world. At the beginning of the 1990s unique organisational changes which took place to respond to a crisis due to the difficulty to move from indiscrete behind-the-ear devices to discrete in-the-ear devices facilitated by technological innovation. The company was comparably smaller then and had around 1,000 employees and the organisational changes described herein concerned approximate 130 workers in the Copenhagen headquarters. Today, Oticon is part of the limited company William Demant Holding and is listed on the Copenhagen Stock Exchange.

\section{FPS Social Security}

FPS is mainly based in Brussels but it employs as well 300 people in its regional offices around Belgium. It counts in total 1302 employees, including 337 independent contractors and 965 statutory employees.

FPS social security represents an interesting case of public service that during the last years implemented several forms of workplace innovations. This process of transformation is part of a multilateral initiative, named NOVO, launched by the FPS Executive Committee in 2006 and oriented at the modernization of the whole institution. NOVO's goal is about a new office culture oriented at the teamwork and leadership development, digitising and modernising the IT infrastructure, about dynamic office and pubic cooperation.

Two main innovations have been introduced: teleworking and the possibility to measure work on the base of performance instead of working hours. These two main initiatives have been accompanied by the creation of a new working space with dynamic offices and clean desks (no personalized desks - top management included). The results were positives, showing to the FPS stuff the feasibility of the dynamic office system. The initial investment was $€ 10$ million, but in the long term, the dynamic office approach saved $30 \%$ in office space and $€ 6$ million are saved each year (http://www.socialsecurity.fgov.be/hraward/). To make the dynamic offices and teleworking a reality, in 2009, new devices were given to the employees and internet connections installed in the employees' homes (personal laptops, USB key, screen LCD), the ICT infrastructure was renovated and new communication tools introduced: such as the soft phone (device to call from your computer) and office communicator (chat). 


\section{Annex 2. Examples of recent information technology products to support WPI}

The table below is not exhaustive, but it gives a good idea of new software that can make a difference in work organisations, especially SMEs. The list also contains information about the cost and utility of each element considered.

Table A1. Examples of user-friendly technologies at the workplace

\begin{tabular}{|c|c|c|}
\hline $\begin{array}{l}\text { Technology/ } \\
\text { software/apps }\end{array}$ & Pricing & Description \\
\hline \multicolumn{3}{|c|}{ Project Management } \\
\hline $\begin{array}{l}\text { Google Apps } \\
\text { for Business }\end{array}$ & $\begin{array}{l}\text { Free for individuals } \\
\text { and small teams (up } \\
\text { to } 10 \text { users). For } \\
\text { small and medium } \\
\text { businesses } \\
\$ 5 / \text { user/month, with } \\
\text { advanced security } \\
\$ 10 / \text { user/month. } \\
\text { Free trial period. }\end{array}$ & $\begin{array}{l}\text { The business package includes: } \\
\text { Gmail - Authenticated encrypted connections to Google's servers, fully compatible } \\
\text { with other Google apps and tools, email with } 25 \mathrm{~GB} \text { of storage. Includes built-in chat. } \\
\text { Calendar - Event-scheduling app that can automatically send invitations and track } \\
\text { RSVPs sent through Gmail. Access from any device with a web browser. The Google } \\
\text { Calendar add-on for Chrome enables scheduling and responding to invites without } \\
\text { working internet connection. Possible delegating calendar management to other } \\
\text { person and automatically sends reminders about upcoming events. Enables creating } \\
\text { appointment slots for other co-workers to sign-up and time-zone conversion. } \\
\text { Docs - Online (real-time) editing and sharing tool for text documents, presentations, } \\
\text { spreadsheets, forms, drawings and tables. Optical character recognition enables } \\
\text { import of editable text from PDFs and images. Allows docs import (upload) and } \\
\text { export (download). Google Spreadsheets includes data analysis tools such as pivot } \\
\text { tables, filters, data validation and solver. Includes chat window. } \\
\text { Sites - cooperative creating of websites without coding. Different permission lists to } \\
\text { different people so that the control over the content is granted. } \\
\text { Vault - optional add for archiving, e-discovery and information governance } \\
\text { capabilities for additional } \$ 50 / \text { user/year or } \$ 5 / \text { user } / \text { month with built-in disaster } \\
\text { recovery } \\
\text { More - additional apps - e.g. Google Moderator - Manageable discussions for co- } \\
\text { workers. Allows people to submit questions, ideas, or suggestions for discussion. } \\
\text { All of the above covers mobile devices (compatible with Android, iOS, Blackberry } \\
\text { and Windows Phone). } \\
\text { Google also offers wide range of free collaborative tools: e.g. Google Reader (web- } \\
\text { based news aggregator, Google Sites (website creation tool), statistical tools - Google } \\
\text { Analytics, Google Fusion Tables (gathering and visualizing arbitrary data), Blogger } \\
\text { (weblog publishing tool) and many more. }\end{array}$ \\
\hline $\begin{array}{l}\text { Microsoft } \\
\text { SharePoint } \\
\text { Workspace }\end{array}$ & Licensing costs vary. & $\begin{array}{l}\text { Allows access to Microsoft SharePoint team sites. Synchronizes SharePoint Server } \\
2010 \text { document libraries and enables to access, view, and edit files anytime and } \\
\text { anywhere. }\end{array}$ \\
\hline $\begin{array}{l}\text { Microsoft } \\
\text { Exchange }\end{array}$ & $\begin{array}{l}\text { Exchange online } \\
\text { version costs } \$ 4 \text { to } \$ 8 \\
\text { / user/month. } \\
\text { Exchange Server } \\
2010 \text { Standard } \\
\text { Edition costs } \$ 699 . .\end{array}$ & $\begin{array}{l}\text { Microsoft Exchange provides businesses with email, calendar, and contacts on the } \\
\text { PC, phone and web. Employees can stay connected and in sync. Built-in integrated } \\
\text { email archiving, retention, and discovery capabilities, offers users a single inbox } \\
\text { access to voice mail and email, while allowing IT to manage both systems from a } \\
\text { single platform. Allows IT administrators to delegate permissions to users such as } \\
\text { managing distribution lists, editing personal information and performing multi- } \\
\text { mailbox searches. }\end{array}$ \\
\hline Basecamp & $\begin{array}{l}\$ 20 / \text { month to } \\
\$ 150 / \text { month. Free } \\
\text { trial period. }\end{array}$ & $\begin{array}{l}\text { Web-based project-management tool. Basecamp features web-based calendar, to-do } \\
\text { lists, wiki-style web-based text documents, milestone management, file sharing, time } \\
\text { tracking, messaging system and keeps track of task assigned and completed. It can } \\
\text { recover things deleted by accident and temporarily loop-in people who aren't part of } \\
\text { a project. Collaboration in real-time with co-workers and clients and keeps people } \\
\text { organizes into companies and groups/departments. Documents can be dragged and } \\
\text { dropped from computer into Basecamp. }\end{array}$ \\
\hline MindManager & $\begin{array}{l}\$ 79 \text { for Academic } \\
\text { and Non-profit to } \\
\$ 399 \text { for Business } \\
\text { Version. }\end{array}$ & $\begin{array}{l}\text { Mapping software for capturing information creates clarity, ensure participation, and } \\
\text { enhance innovative thinking. Shared context includes hyperlinks, attachments, notes, } \\
\text { images, and spreadsheets. Imports from Microsoft Word and Project and export to } \\
\text { Word, Project, PowerPoint, SWF, PDF, image or web pages. Integrates with Mindjet } \\
\text { Connect, Microsoft Outlook and SharePoint. } \\
\text { Task management tools track priorities, percentage of completion, resources, ensure } \\
\text { visibility, and keep projects on schedule. }\end{array}$ \\
\hline
\end{tabular}




\begin{tabular}{|c|c|c|}
\hline Aceproject & $\begin{array}{l}\text { Limited free access. } \\
\text { Standard version } \\
\text { starts at } \$ 24 / \text { month } \\
\text { for unlimited users, } \\
15 \text { projects, } 500 \text { tasks } \\
\text { and } 5 \text { Gb storage. } \\
\text { Gold version is } \\
\$ 99 / \text { month. } \\
\text { (intranet-version } \\
\text { used with customer's } \\
\text { own server starts at } \\
\$ 2495 \text { ) }\end{array}$ & $\begin{array}{l}\text { Free web-Based project management software, time tracking system and expense } \\
\text { tool. Includes Gantt charts, calendars, document management (upload, recovery, } \\
\text { restricted access) and document sharing. Time tracking features include time reports } \\
\text { and time approval. Internal mailbox, task reminders and discussion forum with HR } \\
\text { management. HR management ensures that users can be employees, subcontractors, } \\
\text { clients, telecommuters, or staff working at other branches. Differentiated access } \\
\text { permissions and mobile access are included. }\end{array}$ \\
\hline \multicolumn{3}{|c|}{ Joint Calendar Scheduling } \\
\hline Doodle & $\begin{array}{l}\text { Free. Ad-free } \\
\text { professional version } \\
\text { for companies and } \\
\text { organisations with } \\
\text { premium } \\
\text { functionality and } \\
\text { theming possibilities } \\
\text { comes with charge. }\end{array}$ & $\begin{array}{l}\text { Connects different calendars with Doodle. Answering meeting requests directly in } \\
\text { the calendar interface. Sharing of free/busy data with selected contacts on Doodle. } \\
\text { Coordinates meetings and available slots for partners, colleagues, and friends by } \\
\text { showing them when availability and how to be contacted. } \\
\text { Ad-free professional version of Doodle for individuals (Solo) or companies and } \\
\text { organisations (Business or Enterprise). A premium subscription offers premium } \\
\text { functionality and theming possibilities. }\end{array}$ \\
\hline $\begin{array}{l}\text { Mozilla } \\
\text { Sunbird }\end{array}$ & Free & $\begin{array}{l}\text { Cross-platform calendar application from the Mozilla foundation. It is a standalone } \\
\text { calendar provides an overview of the day, week, several weeks or month, whilst } \\
\text { several sub frames provide information about events scheduled and tasks still to be } \\
\text { completed. Users are able to host their calendars with access from anywhere that is } \\
\text { connected to the Internet. Operable with iCal. }\end{array}$ \\
\hline \multicolumn{3}{|c|}{ Joint Document Production (see also Project Management Tools) } \\
\hline Etherpad & Free & $\begin{array}{l}\text { Real-time document collaboration tool for groups of users. Simple online word- } \\
\text { processor with formatting options, color-coded edits, history playback. Enables } \\
\text { HTML, Word and rtf imports, exports as HTML, Word, and PDF. }\end{array}$ \\
\hline \multicolumn{3}{|c|}{ Online Syncing Service } \\
\hline Dropbox & $\begin{array}{l}\text { Basic account with } \\
\text { limited storage is } \\
\text { free, plans for teams } \\
\text { of } 5 \text { users start at } \\
\$ 795 \text {. }\end{array}$ & $\begin{array}{l}\text { Docs, slides, and large files shared with colleagues instantly. Dropbox works with } \\
\text { Windows, Mac, Linux, iPad, iPhone, Android, and BlackBerry, both online and } \\
\text { offline. }\end{array}$ \\
\hline Wuala & $\begin{array}{l}\text { Starter pack for } 5 \\
\text { users and } 100 \mathrm{~GB} \\
\text { storage starts at } 299 \\
\text { EUR. (free trial } \\
\text { period) }\end{array}$ & $\begin{array}{l}\text { Data sync tool secures and centralizes workspace, allowing users to access it from } \\
\text { anywhere. Data is encrypted and users can edit and comment on files directly. By } \\
\text { synchronizing specific folders across multiple computers, files are always up-to-date } \\
\text { and available on multiple computers. }\end{array}$ \\
\hline \multicolumn{3}{|c|}{ Social Networks } \\
\hline Facebook & Free & $\begin{array}{l}\text { Social networking service and website. Business accounts are designed for } \\
\text { individuals who want to use the site to administer pages and their ad campaigns. } \\
\text { Enables individual users to create limited profiles and friends lists (Work, Family) } \\
\text { and thus enables selective content. Self-promotion, PR, establishing credibility, } \\
\text { research prospects before meeting, useful HR tool, FB ads to attract well-targeted } \\
\text { audience. } \\
\text { Enables interactive scheduling of events, building networks of alumni, co-workers, } \\
\text { etc. }\end{array}$ \\
\hline Twitter & Free & $\begin{array}{l}\text { Social networking and micro blogging tool helps making professional relationships } \\
\text { stronger and gives it a human touch. Enables free promotion of professional outputs } \\
\text { and PR (blogs promotion, media outputs, personalised advertising), getting real-time } \\
\text { feedback, creates sense of professional community. }\end{array}$ \\
\hline Academia.edu & Free & $\begin{array}{l}\text { Platform for academics to share research papers. Enables seeing analytics on } \\
\text { customer's profile and papers and follow other people in the field of study. }\end{array}$ \\
\hline LinkedIn & $\begin{array}{l}\text { Free basic version, } \\
\text { business upgrades } \\
\text { vary between } 14,95 \\
\text { EUR/month to } 71,95 \\
\text { EUR/month }\end{array}$ & $\begin{array}{l}\text { Professional social network. Supports formation of interest groups, helps recruitment } \\
\text { and job searching. Premium version includes advanced talent filters and trusted } \\
\text { messages to anyone on LinkedIn. }\end{array}$ \\
\hline
\end{tabular}




\begin{tabular}{|c|c|c|}
\hline Yammer & \begin{tabular}{|l|} 
Free basic version, \\
business upgrades \\
vary between $5 \$$ per \\
months per person or \\
$79 \$$ group/month \\
\end{tabular} & $\begin{array}{l}\text { Yammer is a social network designed for companies. It is as easy to use as great } \\
\text { consumer software like Facebook and Twitter, but meant for business collaboration. }\end{array}$ \\
\hline \multicolumn{3}{|c|}{ Polling/Surveys } \\
\hline $\begin{array}{l}\text { Survey } \\
\text { Monkey }\end{array}$ & $\begin{array}{l}\text { Free basic plan, } \\
\text { varying professional } \\
\text { versions from } 25 \text { to } \\
800 \mathrm{EUR} / \text { month }\end{array}$ & $\begin{array}{l}\text { Web-based survey tool with templates and customized themes, advanced } \\
\text { questioning (randomization, answer piping), survey completion progress bar, } \\
\text { sharing and embedding options. Survey Monkey offers analytical features: filtering, } \\
\text { cross-tabulating responses, custom charts. }\end{array}$ \\
\hline Lime Survey & Free & $\begin{array}{l}\text { Open source, downloadable survey application supports integration of pictures and } \\
\text { movies into a survey, conditions for questions depending on earlier answers, re- } \\
\text { usable editable answer sets and ready-made importable questions, sending of } \\
\text { invitations, reminders and tokens by email and statistical and graphical analysis with } \\
\text { export facility. }\end{array}$ \\
\hline $\begin{array}{l}\text { Rational } \\
\text { Survey }\end{array}$ & $\begin{array}{l}\text { Free basic version, } \\
\$ 30 / \text { months }\end{array}$ & $\begin{array}{l}\text { Survey tool for creating questionnaire based surveys and polls online. Supports } \\
\text { distributing via twitter and Facebook, supports real time analysis of responses and } \\
\text { export through CSV, Excel, PDF and generates custom graphs. }\end{array}$ \\
\hline \multicolumn{3}{|c|}{ Chat and Videoconference } \\
\hline $\begin{array}{l}\text { Skype } \\
\text { (Manager) }\end{array}$ & $\begin{array}{l}\text { Free (Skype-to- } \\
\text { Skype), different } \\
\text { business offers }\end{array}$ & $\begin{array}{l}\text { Skype enables calling Skype-to-Skype, to landlines and mobiles, conference calls, } \\
\text { group video calling, instant messaging and files/text message sending. } \\
\text { Skype Manager is a web-based management tool that centrally manages Skype for } \\
\text { businesses. Business accounts keep track of spending, allocate features and monitor } \\
\text { usage in real time. Enables group video calling. }\end{array}$ \\
\hline $\begin{array}{l}\text { Windows Live } \\
\text { Messenger }\end{array}$ & Free & $\begin{array}{l}\text { Instant messaging client. Allows video calls, integration with social networks and } \\
\text { mobile version. }\end{array}$ \\
\hline Pidgin & Free & $\begin{array}{l}\text { Pidgin is a chat program with simultaneous sign-in to multiple chat networks. } \\
\text { Integrates MSN, Google Talk, and Yahoo chat room at the same time in one } \\
\text { programme. Enables file transfers, away messages, icons, and typing notifications. }\end{array}$ \\
\hline Google Talk & Free & $\begin{array}{l}\text { Either as a widget to use from a Google site or software download. Google Talk } \\
\text { automatically loads contacts from a Gmail account. Enables instant messaging, file } \\
\text { transfer, PC-to-PC calls, also multiple audio conferencing. }\end{array}$ \\
\hline Meebo & Free & $\begin{array}{l}\text { Web-based chat application boasts support for all popular chat networks, video and } \\
\text { voice chat, with an iPhone interface. }\end{array}$ \\
\hline Microsoft Lync & Pricing varies & $\begin{array}{l}\text { Unified communications platform. Users can keep track of contacts' availability, } \\
\text { enables instant messaging, start or join an audio, video, or web conference or make a } \\
\text { phone call. Lync is built to fully integrate with Microsoft Office. }\end{array}$ \\
\hline
\end{tabular}

Source: Authors' own elaboration. 


\section{Annex 3. Glossary}

EWCS - European working conditions survey

HPWS - High-performance work system

WPI - Workplace innovation

HCEP - High-commitment employment practices

HIWP - High involvement workplace practices

AWP - Alternative workplace practices

AMO - Ability, motivation and opportunity

TFP - Total factor productivity

QWL - Quality of working life

DCM - Demand-Control Model 


\section{ABOUT CEPS}

Founded in Brussels in 1983, the Centre for European Policy Studies (CEPS) is widely recognised as the most experienced and authoritative think tank operating in the European Union today. CEPS acts as a leading forum for debate on EU affairs, distinguished by its strong in-house research capacity, complemented by an extensive network of partner institutes throughout the world.

\section{Goals}

- Carry out state-of-the-art policy research leading to innovative solutions to the challenges facing Europe today,

- Maintain the highest standards of academic excellence and unqualified independence

- Act as a forum for discussion among all stakeholders in the European policy process, and

- Providea regular flow of authoritative publications offering policy analysis and recommendations,

\section{Assets}

- Multidisciplinary, multinational \& multicultural research team of knowledgeable analysts,

- Participation in several research networks, comprising other highly reputable research institutes from throughout Europe, to complement and consolidate CEPS' research expertise and to extend its outreach,

- An extensive membership base of some 132 Corporate M embers and 118 Institutional Members, which provide expertise and practical experience and act as a sounding board for the feasi bility of CEPS policy proposals.

\section{Programme Structure}

\section{In-house Research Programmes}

\section{Economic and Social Welfare Policies}

Financial Institutions and Markets

Energy and Climate Change

EU Foreign, Security and Neighbourhood Policy

Justice and Home Affairs

Politics and Institutions

Regulatory Affairs

Agricultural and Rural Policy

\section{Independent Research Institutes managed by CEPS}

European Capital Markets Institute (ECMI)

European Credit Research Institute (ECRI)

\section{Research N etworks organised by CEPS}

European Climate Platform (ECP)

European N etwork for Better Regulation (ENBR)

European N etwork of Economic Policy

Research Institutes (ENEPRI)

European Policy Institutes N etwork (EPIN) 